Does Professional Development for Teachers Impact Student Behavior Utilizing ClassWide Function-Related Intervention Teams?

A Dissertation
presented to
the Faculty of the Graduate School
at the University of Missouri-Columbia
In Partial Fulfillment
of the Requirements for the Degree
Doctor of Education
br. James Sottile, Dissertation Supervisor
April Phillips

May 2021 
The undersigned, appointed by the dean of the Graduate School, have examined the dissertation entitled

Does Professional Development for Teachers Impact Student Behavior Utilizing ClassWide Function-Related Intervention Teams?

presented by April Phillips, a candidate for the degree of Doctor of Education, and hereby certify that, in their opinion, it is worthy of acceptance.

Professor James Sottile

Professor Reesha Adamson

Professor Jon Turner

Professor Ximena Uribe-Zarain 


\section{DEDICATION}

I dedicate this to my husband. Without his support and encouragement, it may have not come to fruition. He spent time listening and reading my work. He set up a work space and acknowledged the time I needed to work.

I also dedicate this body of work to my children. I needed your help along the way and your encouragement pushed me on. I hope that I have inspired you to work hard towards your goals. I love you to infinity and beyond.

My parents and my sister have always been there for me and believed in me. I am forever in your debt. I hope my parents are smiling from heaven, you are missed.

I dedicate this study to my fellow educators. I know you have a tough job at times but you are needed and appreciated. I hope that this information helps you and your students. You have been my focus since the beginning of this journey. I especially want to thank Mrs. W., Mrs. E., Mrs. K., Mrs. D., Mrs. L., Ms. L., Mrs. G., Ms. R., Mrs. T., Mrs. C., Mrs. P., Mrs. S, Dr. F., Dr. D., and Mrs. R. Without you, this study would not have happened. 


\section{ACKNOWLEDGEMENTS}

First, I would like to acknowledge Dr. Sottile, my dissertation chair, who has provided a wealth of knowledge, support, encouragement and the confidence to keep moving forward. I want to thank my dissertation committee, Dr. Reesha Adamson, Dr. Jon Turner, and Dr. Ximena Uribe-Zarain for providing invaluable advice and assistance, both of which required their time. I want to thank the ELPA faculty for their instruction, feedback, and passion. You made the content desirable and leaving me wanting to learn more. I also want to thank my cohorts in Springfield and in the state. I learned so much for each and every one of you.

I am also very grateful for the support and encouragement I received from Ozark R-VI Public School, my supervisors, and my fellow educators.

Thank you, Peter at the Robinhood Resort, for supplying paper while I worked on my data analysis while on vacation in Big Bear Lake, California. 


\section{TABLE OF CONTENTS}

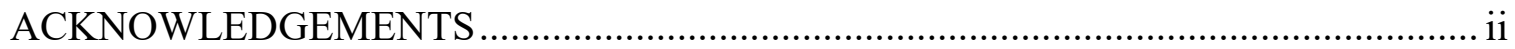

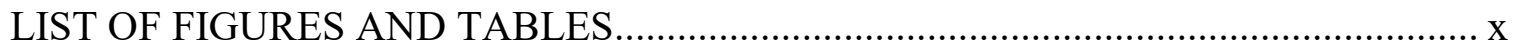

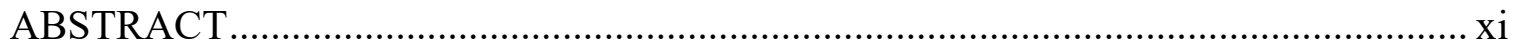

SECTION ONE: INTRODUCTION TO DISSERTATION .................................... 1

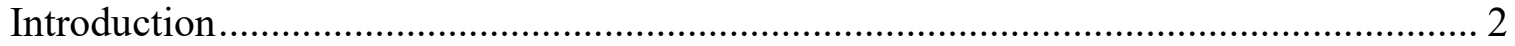

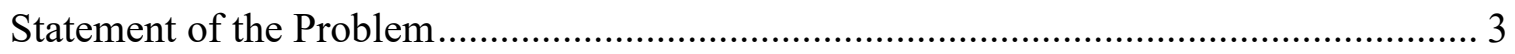

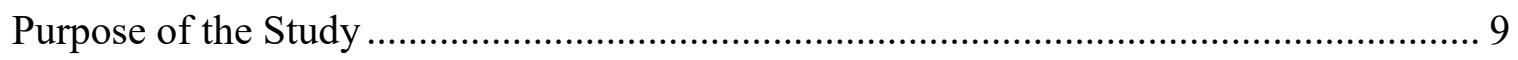

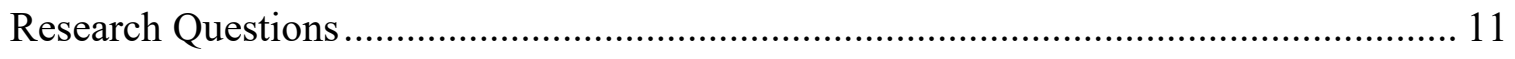

Theoretical Framework ...................................................................................... 12

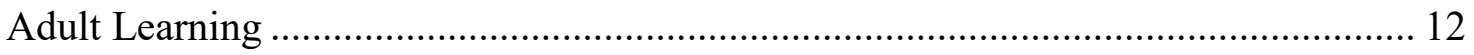

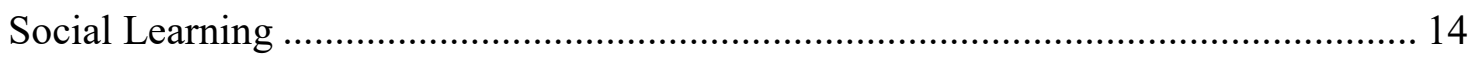

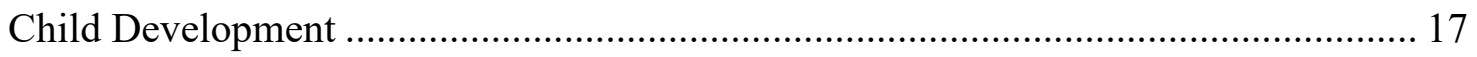

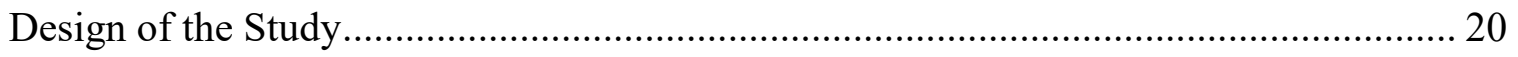

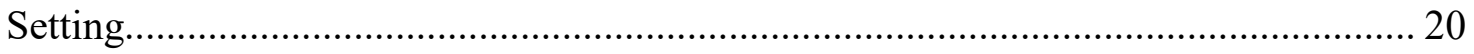

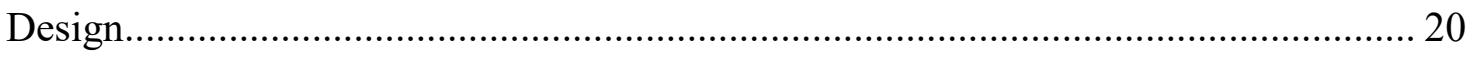

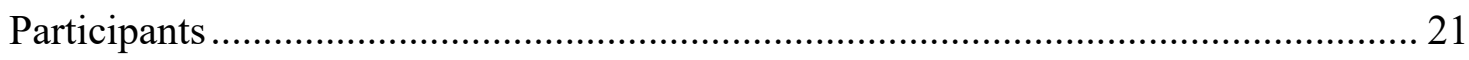

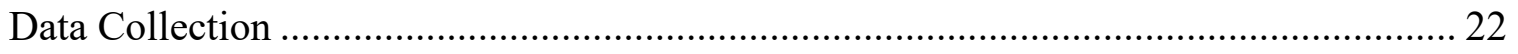

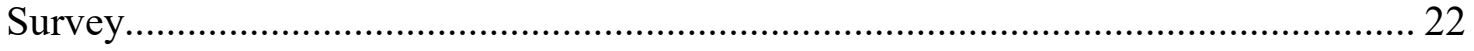

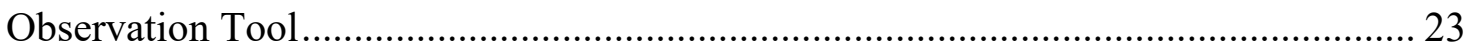




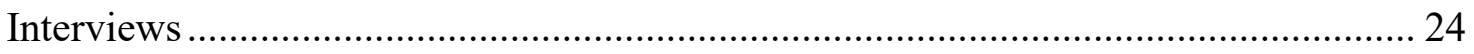

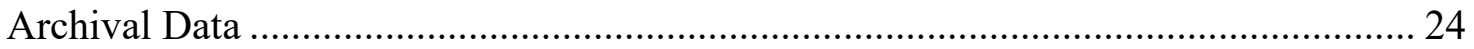

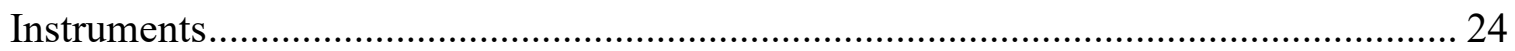

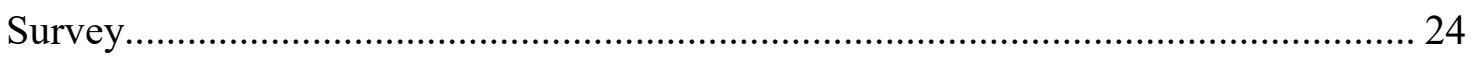

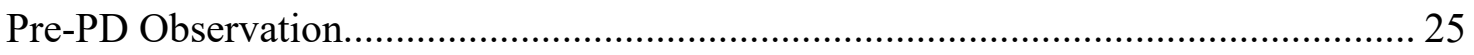

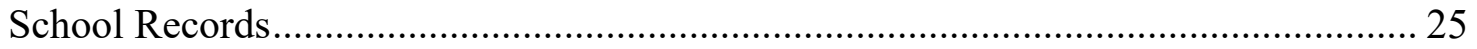

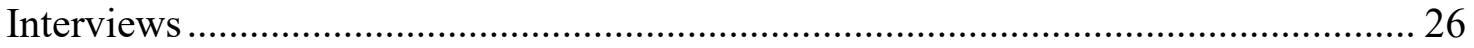

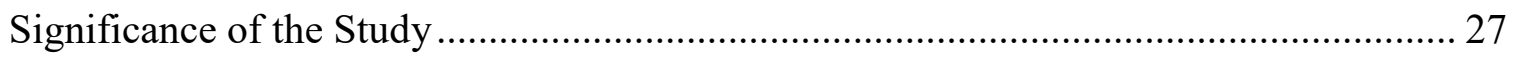

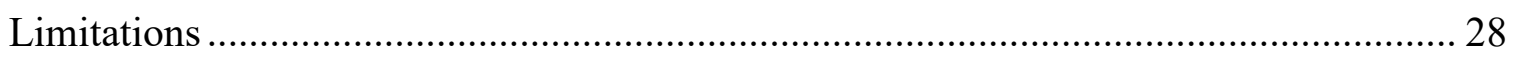

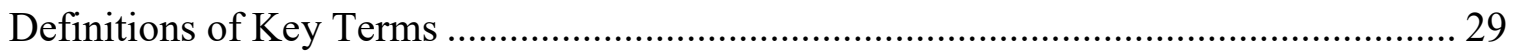

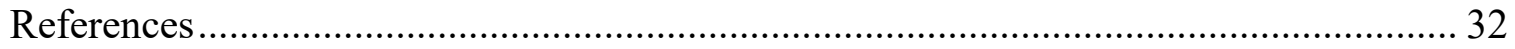

SECTION TWO: PRACTITIONER SETTING .................................................... 41

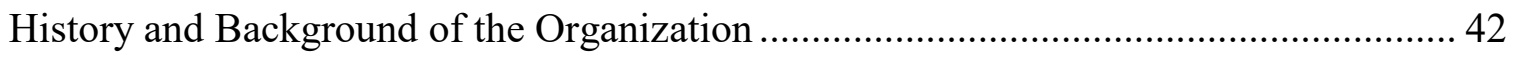

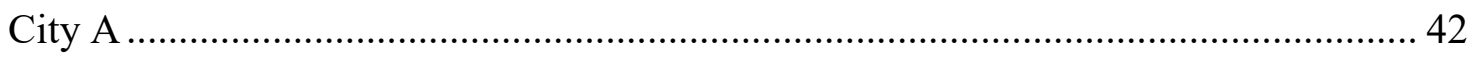

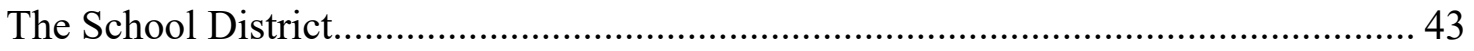

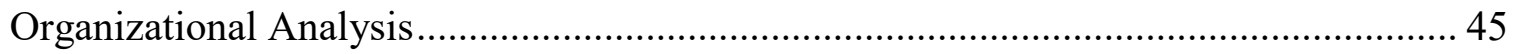

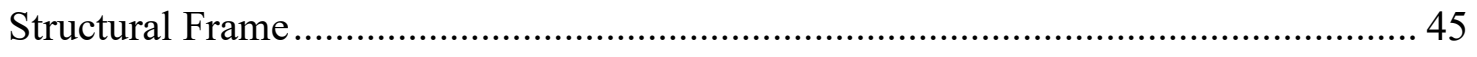

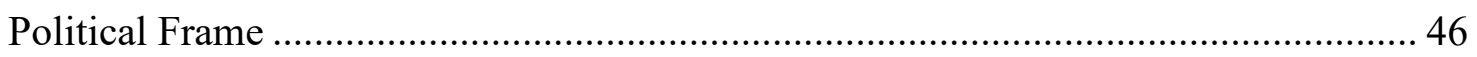

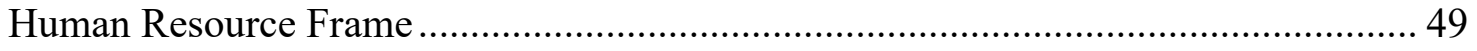

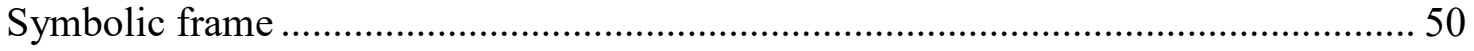




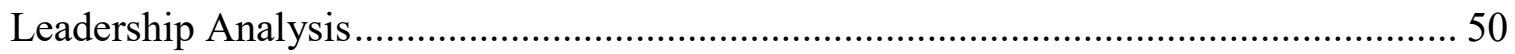

Implications for Research in the Practitioner Setting.................................................. 53

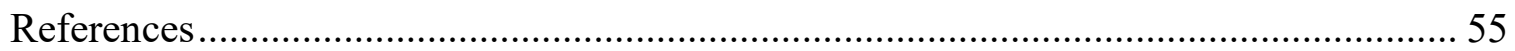

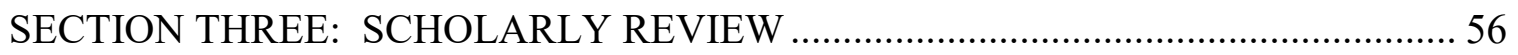

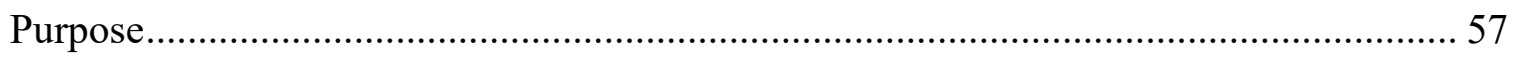

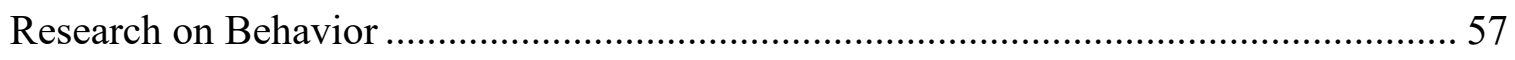

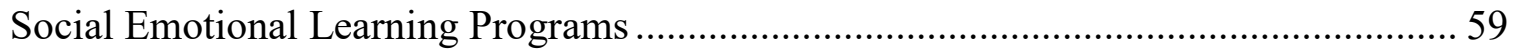

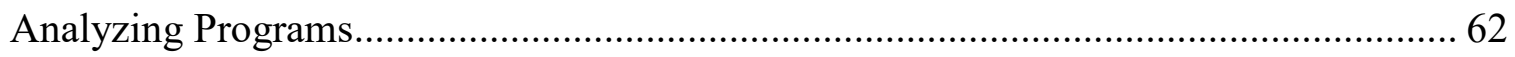

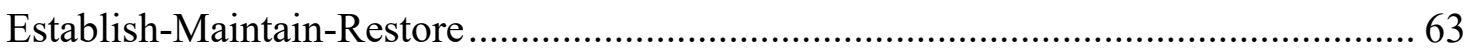

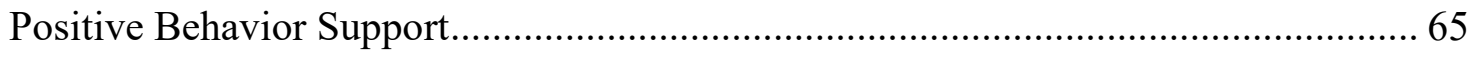

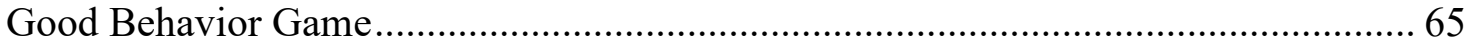

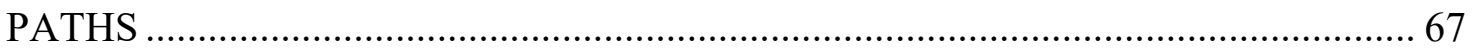

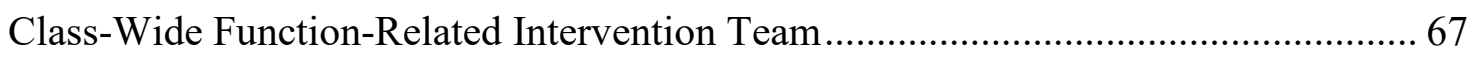

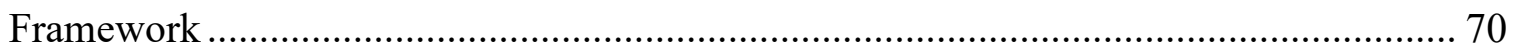

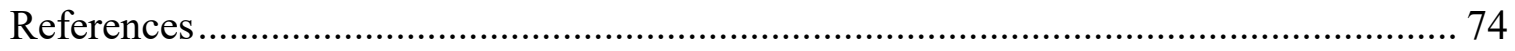

SECTION FOUR: CONTRIBUTION TO PRACTICE ………………....................... 80

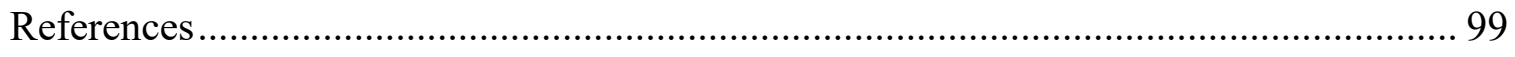

SECTION FIVE: CONTRIBUTION TO SCHOLARSHIP .......................................... 100

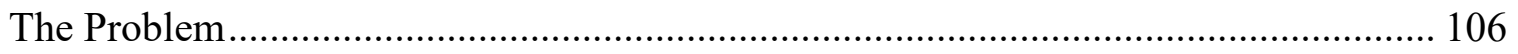

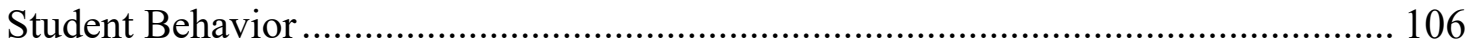




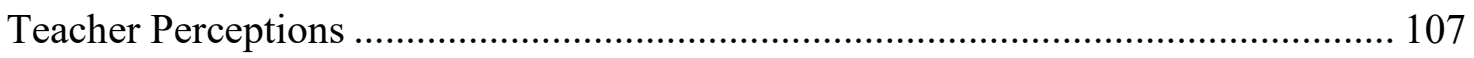

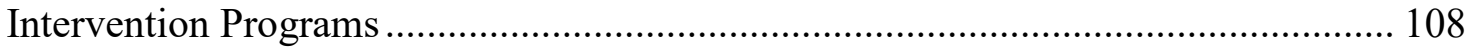

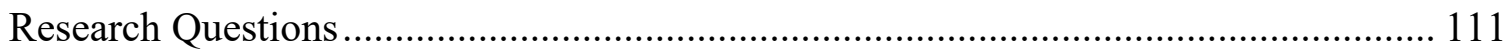

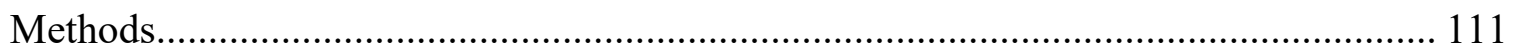

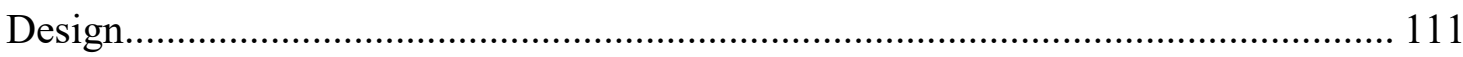

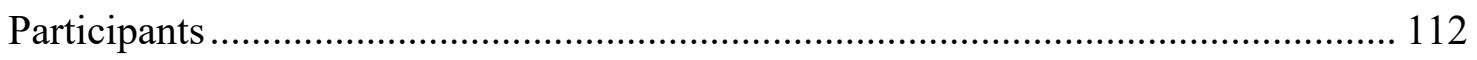

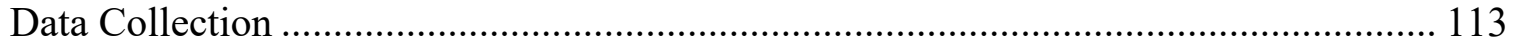

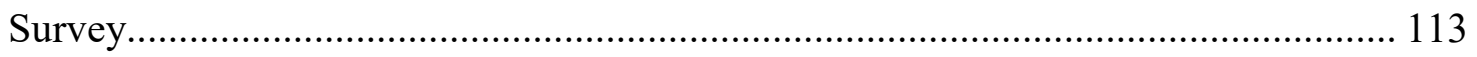

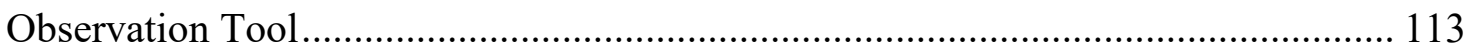

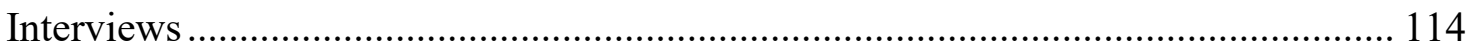

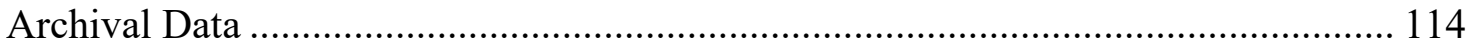

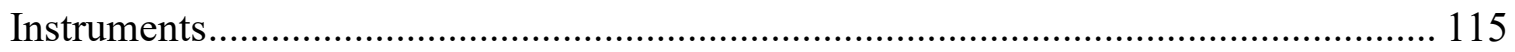

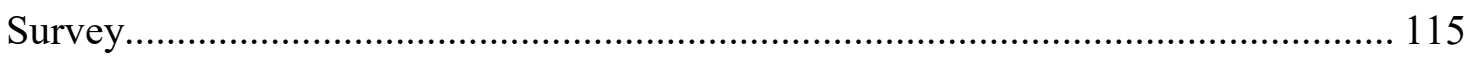

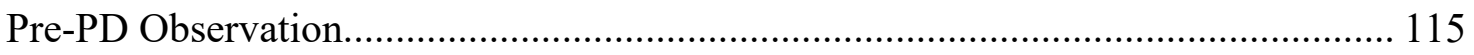

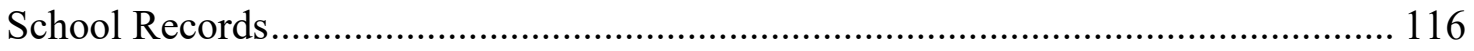

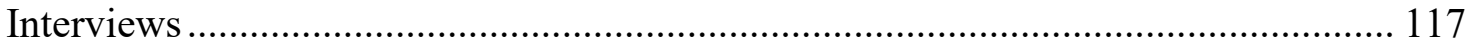

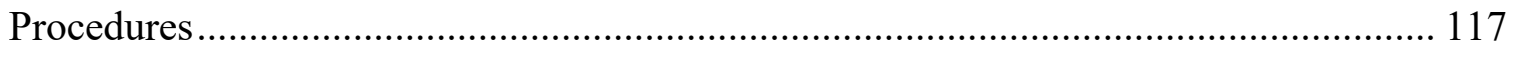

PD

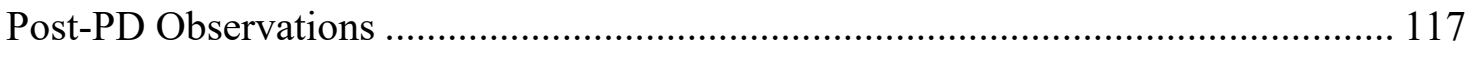

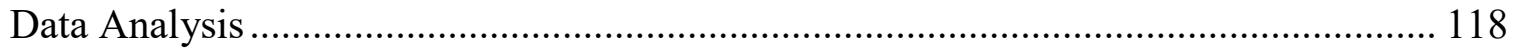




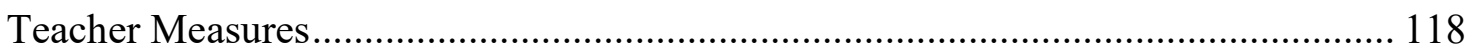

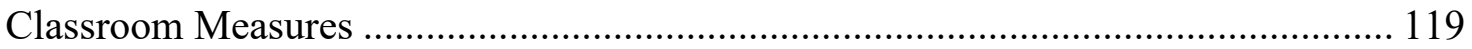

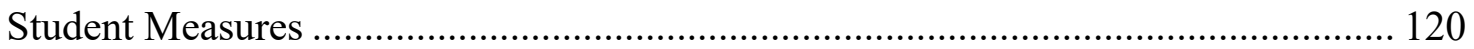

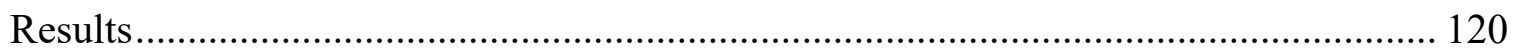

RQ1: Does the teacher professional development for Class-Wide Function-related Intervention Teams (CW-FIT) impact student behavior in elementary classroom? ... 120

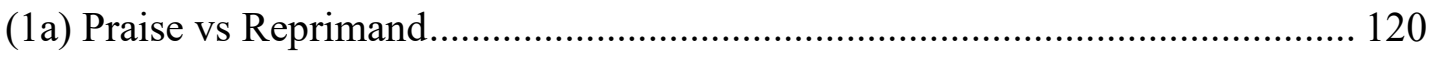

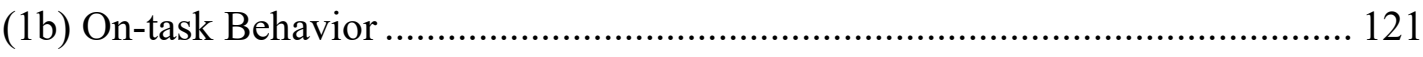

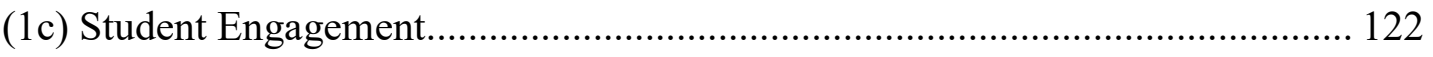

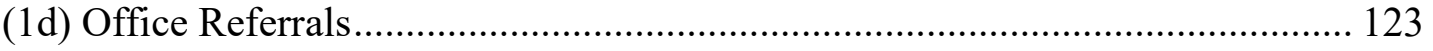

RQ2: What is the relationship between CW-FIT and student achievement?............. 123

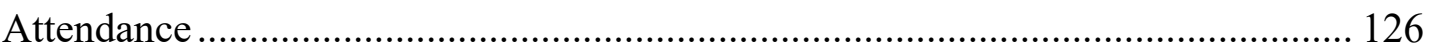

RQ3. Does the teacher professional development for Class-Wide Function-related

Intervention Teams (CW-FIT) influence teacher retention?.................................... 126

RQ4: What are the teacher perceptions of the professional development for Class-Wide

Function-related Intervention Teams (CW-FIT)? ............................................ 128

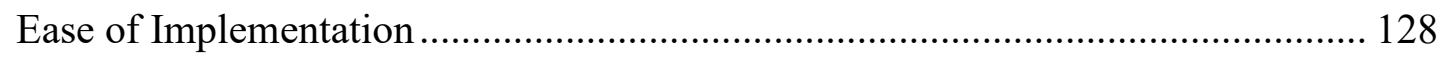

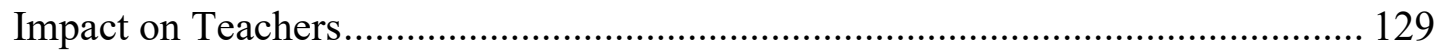

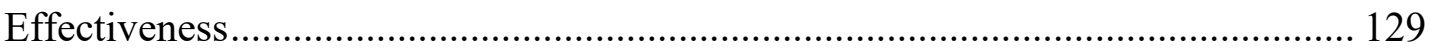

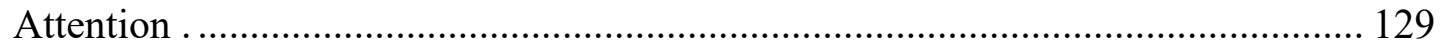




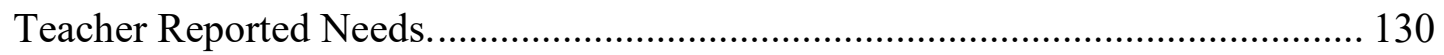

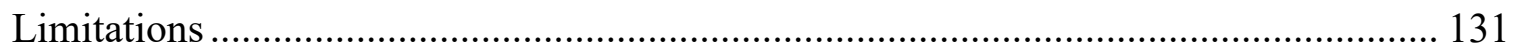

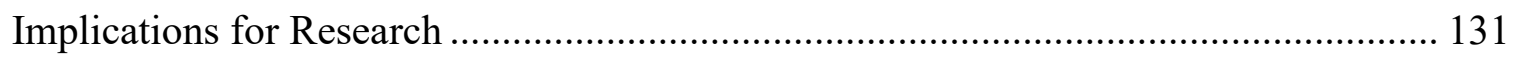

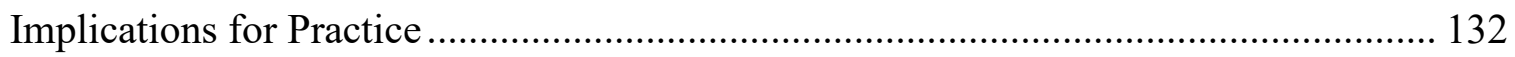

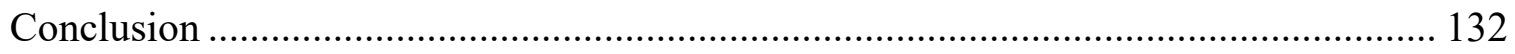

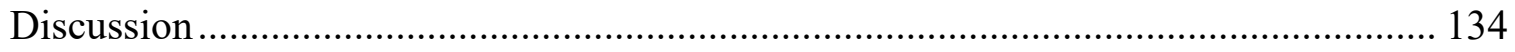

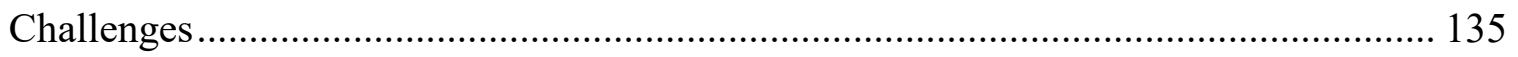

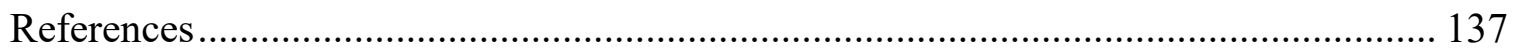

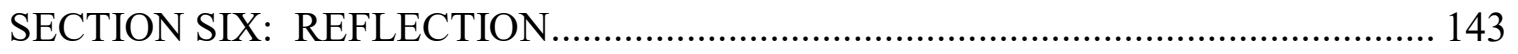

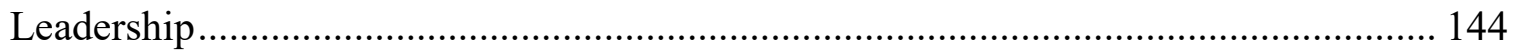

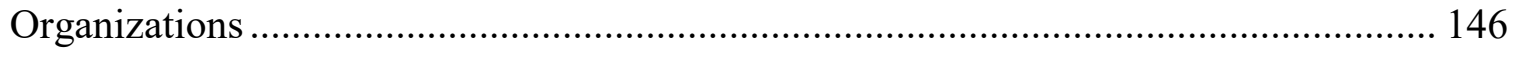

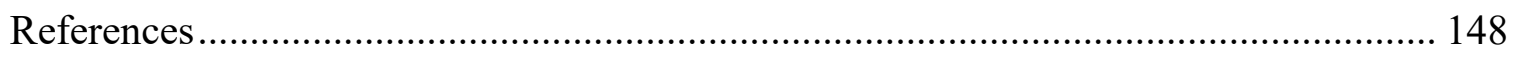

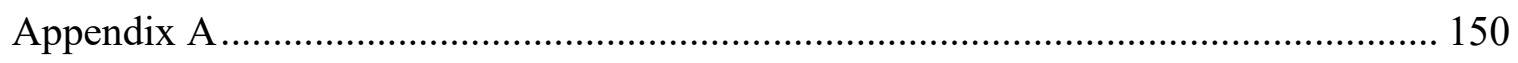

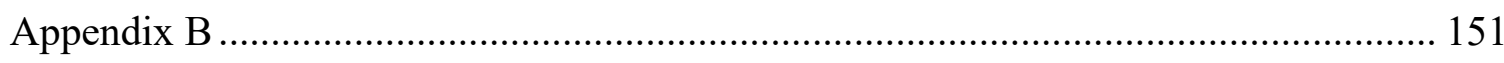

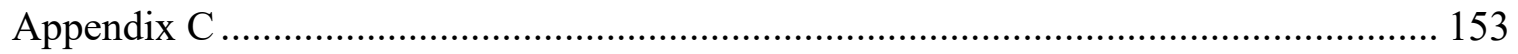

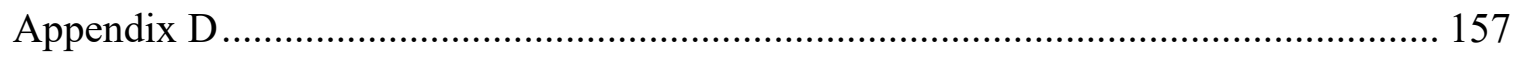

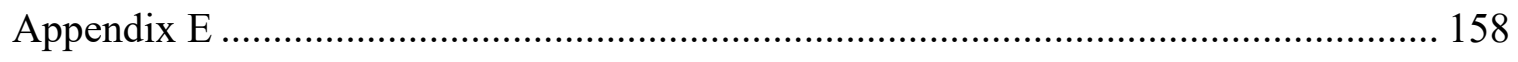

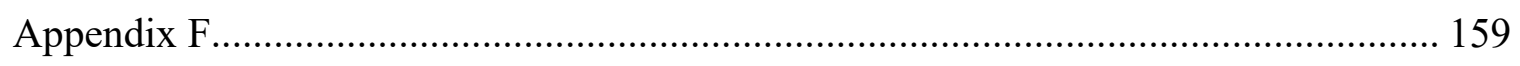

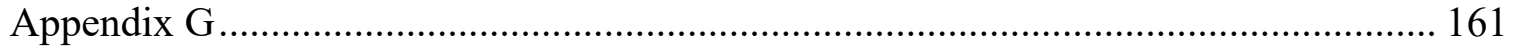




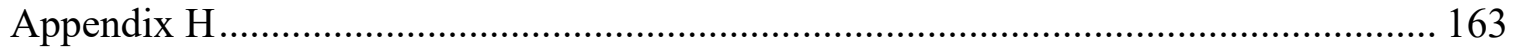

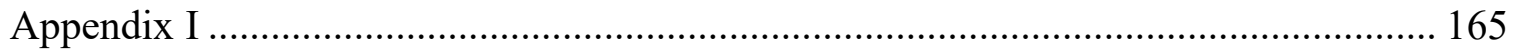

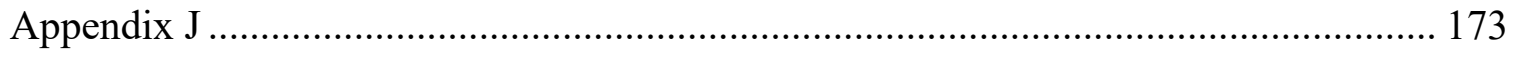

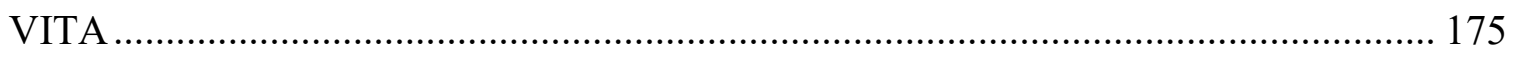




\section{LIST OF FIGURES AND TABLES}

Figure 1. Teacher Education and Student Behavior Visual Map.............. 11

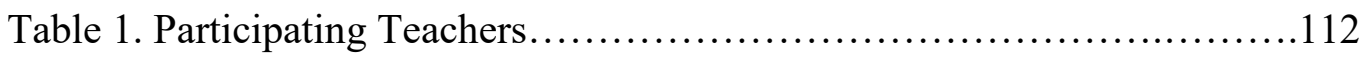

Table 2. Praise to Reprimand Ratios................................... 121

Table 3. Percentage of on-task behavior.............................. 122

Table 4. Student Engagement..........................................123

Table 5. Descriptive statistics for the ELA Evaluate scores.................... 124

Table 6. Descriptive statistics for the Math Evaluate scores...................125

Table 7. Two-way ANOVA table for ELA Evaluate scores................... 126

Table 8. Two-way ANOVA table for Math Evaluate scores...................126 


\title{
DOES PROFESSIONAL DEVELOPMENT FOR TEACHERS IMPACT STUDENT BEHAVIOR UTILIZING CLASS-WIDE FUNCTION-RELATED INTERVENTION TEAMS?
}

\author{
April Phillips \\ Dr. James Sottile, Dissertation Supervisor
}

\begin{abstract}
Students who disrupt the classroom due to externalizing behaviors can impact all of these, but more importantly, these behaviors interrupt student learning. Due to these stressors, the purpose of this study was to explore how a behavior intervention program, Class-Wide Function-related Intervention Teams (CW-FIT), within the scope of teacher professional development, can impact students' behaviors, improve teacher retention, and ultimately improve academic experiences in a suburban elementary school in Southwest Missouri. The mixed-methods study used a convergent mixed method design to explore how the CW-FIT impacted behaviors of elementary students. It also examined the correlation, if any, between teacher professional development of the CW-FIT and office referrals, teacher retention, and student achievement. Participants in this research study started with 12 elementary teachers and 10 classrooms. After the Pandemic began, the study continued in the fall of 2020 and included 11 teachers and nine classrooms (from third to fifth grade). Analysis of observation results, documents, and interviews, found that CW-FIT positively impacted student behavior in the participating elementary classrooms. Evidence showed the need for PD, how the CW-FIT increased student achievement through student engagement and teacher praise, and on-task behavior.
\end{abstract}


SECTION ONE: INTRODUCTION TO DISSERTATION 


\section{Introduction}

Elementary teachers have many responsibilities, including planning instruction, grading, analyzing student achievement data, and improving student achievement on state assessments. Students who disrupt the classroom due to externalizing behaviors can impact all of these, but more importantly, these behaviors interrupt student learning. This is a dichotomous dilemma in which the student hurts themselves, others, as well as the teacher (Pas, Bradshaw, Hershfeldt, \& Leaf, 2010). A former elementary teacher in Southwest Missouri stated,

See, I had this student who would crawl under the table and scream, throw fits, and pretty much disrupt the learning of everyone else. I loved him, because we do. That's what teachers do, we fight for everyone to be successful. We know that there is an underlying cause and that students are not doing this to make our lives harder but are dealing with something much more difficult. But in all honesty, it drains you. It can often suck the life out of you and make you wonder if you are making a difference (S. J., personal communication, February 10, 2019).

The consequences of inadequate professional development and preparedness impact classrooms and ill-prepared teachers impact teachers and students. The cost of students disrupting instruction or losing instruction due to discipline could be argued to be more invaluable than the monetary costs of professional development. Research has shown that when teachers implement strategies or programs with fidelity, office referrals decrease (Hawken, MacLeod, Rawlings, 2007; Kaufman et al., 2009; Luiselli, Putnam, Handler et al., 2005). This study hypothesized if teachers had explicit professional 
development on preventing or de-escalating externalizing behaviors, there would be a decrease of externalizing behaviors which would reduce the number of office referrals, increase teacher retention, and improve student achievement.

\section{Statement of the Problem}

According to Cree et al., (2018), one in six U.S. children aged two-eight years (17.4\%) had a medically diagnosed mental, behavioral, or developmental disorder. These children, and those without a medical diagnosis, but with externalizing behaviors, are in classrooms, and all deserve a free and appropriate public education (FAPE) along with their peers that do not demonstrate externalizing behaviors. Externalizing behaviors often involve one or more of the following: destructive and aggressive behavior, defiance, temper tantrums, impulsive and hyperactive actions, making inappropriate noises in the classroom, blurting out, not following directions, being off task, yelling, inappropriate language, or lying (Henricsson \& Rydell, 2004; Pelco \& Reed-Victor, 2007). These behaviors can have a duration from a few minutes to hours, and their frequency can range from once a month to many episodes per day (Green, Whitney, \& Potegal, 2011; National Collaborating Centre for Mental Health, 2013). The length of duration, level of intensity, and frequency all contribute to the disruption of the classroom, learning, and stress of the teacher and students (National Collaborating Centre for Mental Health).

Externalizing behaviors can be related to medical diagnoses such as Oppositional Defiant Disorder (ODD), Bipolar, ADHD (combined type), or Disruptive Mood Dysregulation Disorder (DMDD) (American Psychiatric Association, 2013). According to Farley, Adam, Lutton, and Scoville (2005), "Oppositional and defiant behaviors include noncompliance, temper tantrums, arguing, and mild aggression" (p. 1). Deficits in 
executive functioning have been hypothesized to increase youths' risk for social problemsolving difficulties, which may, in part, explain the link between executive functions and aggressive behavior (Ellis, Weiss, \& Lochman, 2009). Although teacher professional development for behavior interventions has been explored in the area of student behavior (Cook et al., 2018; Moore et al., 2017; Pas et al., 2010; Shook, 2012), few studies have explicitly looked at the correlation between externalizing behaviors and the professional development teachers receive for these behaviors.

Teachers are sometimes on their own to handle the students that demonstrate externalizing behaviors. Zee, de Jong, and Koomen (2016) looked at teacher selfefficiency and dealing with externalizing behaviors. They found that students with externalizing behavior (i.e., aggression, hyperactivity, antisocial) are the core of the daily challenges teachers face (Zee et al., 2016). Other challenges teachers experience include teacher burnout (Pas et al., 2010), loss of teaching efficacy (Klassen \& Chiu, 2010), and, most significantly, an exit from the teaching profession (Algozzine et al., 2008).

To date, research has been conducted on Social-Cognitive Theory (Martin, Burns, \& Collie, 2017), executive functioning and aggressive behavior (Ellis, Weiss, \& Lochman, 2009), teacher perceptions of challenging behavior (Butler \& Monda-Amaya, 2016), teacher knowledge/perception of classroom/behavior management (Moore et al., 2017), student self-efficacy and teacher self-efficacy (Klassen \& Chiu, 2010), and how programs impacted student learning outcomes and behavior. For example, the following programs have been researched: PATHS (Bierman et al., 2013), the Good Behavior Game (GBG) (Elswick \& Casey, 2012; Jones et al., 2017), Establish-Maintain-Restore (EMR) (Cook et al., 2018), Class-Wide Function-related Intervention Teams (CW-FIT) 
(Caldarella et al., 2018; Nelson et al., 2018; and Wills, Wehby, Caldarella, Kamps \& Swinburne Romine, 2018), and positive behavior supports (Luiselli et al., 2005). In these studies, student populations varied from majority-minority to average/high socioeconomic status, balanced amounts of gender differences, and between kindergarten and sixth grades.

Cook et al. (2018) conducted a study in which they evaluated the EstablishMaintain-Restore (EMR) program through a brief professional development for upper elementary teachers and follow-up support. They considered if EMR produced a positive change with student-teacher relationships, with behavior (as measured by academic engagement and disruptive behavior), and with student demographic variables (Cook et al., 2018). Cook et al. (2018) completed pre-treatment observations in all ten classrooms then immediately provided professional development with an active participation approach (Birman et al., 2000). Support also included scripts and a PowerPoint presentation for reference with the five classrooms (Cook et al., 2018). Cook et al. defined academic engagement to include writing, reading audibly, raising a hand and patiently waiting, speaking to the teacher or other students about assignments or content, and investigating content related to an assignment. They defined disruptive behavior to include: "call outs, talking to peers when not permitted, getting out of seat, getting peers off-task, making noise with an object" (Cook et al., 2018, p. 232).

After a week of implementation, the researchers collaborated with the five teachers for further content review, questions, planning, and gave them a quiz to check for understanding (Cook et al., 2018). After two months, the researchers observed all ten classrooms again (Cook et al., 2018). Cook et al. (2018) found that EMR produced 
positive teacher-student relationships, impacted student learning outcomes through increased engagement, and decreased disruptive behavior. Although this study found a correlation between a program, EMR, professional development, and disruptive behavior, learning outcomes were not investigated thoroughly. Cook et al. (2018) only used observational data to determine whether students were actively engaged and did not measure academic learning outcomes. This study also did not analyze any change to office discipline referrals (ODRs), nor the effect on externalizing behaviors such as destructive and aggressive behavior, defiance, temper tantrums, impulsive and hyperactive actions, making inappropriate noises in the classroom, not following directions, yelling, inappropriate language, or lying (Henricsson \& Rydell, 2004; Pelco \& Reed-Victor, 2007). Finally, little is known about the effect of behavior professional development for teachers and the impact on teacher retention.

Elswick and Casey (2012) researched the Good Behavior Game (GBG) and found that it was easy to implement as a class-wide intervention. The first-grade classroom met the conditions required for selection: "(a) multiple referrals to the school social worker to assist in creating Behavior Intervention Plans (BIPs) for at least one identified student" (Elswick \& Casey, 2012, p. 38), and (b) student office referrals for exhibiting behavioral disruptions that interrupted the student and other's learning experiences. The teacher was given training for one week and until the teacher had 100\% integrity (Elswick \& Casey, 2012). The professional development comprised of information on the GBG's background, "purpose, previous research, and a discussion about the GBG implementation and protocol. The discussion of the implementation of the GBG consisted of didactic training covering all of the steps necessary for a high level of procedural 
integrity" (Elswick \& Casey, 2012, p. 40). The teacher also received a manual and all materials necessary for implementation. Before and after implementation observational data was recorded over five weeks for talking out, out of seat behavior, and being disrespectful. Disrespectful behaviors included "peer-to-peer frustration or aggression (verbal or physical)" (Elswick \& Casey, 2012, p. 38). Baseline and after implementation data was recorded over five weeks for talking out, out of seat behavior, and being disrespectful. The average talking out behaviors decreased from 21.5 to 6.28 per collection period, out of seat behavior decreased from 14.6 to 1 , and disrespectful behavior decreased from 3.7 to 0.14 (Elswick \& Casey, 2012). The research on the GBG demonstrated a correlation to the professional development of a behavior program and student behavior but not to academic achievement, office referrals, nor teacher retention.

Class-Wide Function-related Intervention Teams (CW-FIT) was developed in 2005 by Howard Wills and Debra Kamps and the Juniper Gardens Children's Project in association with the University of Kansas (2019). This behavior intervention program was "designed to explicitly teach and reinforce appropriate social behaviors through" (University of Missouri, 2019, p. 1) games in the general education setting. CW-FIT incorporates many research-based behavioral strategies such as: direct instruction of skills, self and peer management, extinction by removing reinforcement, differential reinforcement of alternative behaviors through dependent group contingencies, token economy, and teacher praise (University of Missouri, 2019). CW-FIT has been researched over 20 times (H.W., personal communication, November 8, 2019). Recent studies investigated the use of the program in differing elementary schools (Caldarella et al., 2018; Nelson et al., 2018; and Wills et al., 2018) and how the program affected 
student engagement, disruptive behaviors, and teacher praise. The studies did not investigate relationships between CW-FIT and academic performance or office referrals.

Wills, Wehby, Caldarella et al. (2018) wanted to replicate the first CWFIT randomized controlled trials but this study went across three states-Missouri, Utah, and Tennessee with 21 elementary schools, 155 general education teachers, and 324 students. Kindergarten through sixth-grade classrooms, including special education classrooms, were a part of the six-month study. Teachers were provided two hours of training, opportunities to observe modeling up to two sessions, and weekly to biweekly feedback sessions with the project staff to ensure fidelity of implementation. Tier 2 interventions were designed for students that demonstrated "more than 10 disruptive behaviors in three of five observations, did not improve engagement to $75 \% \ldots$ or received teacher input of a poor response to intervention" (Wills et al., 2018, p. 443). Data was collected through direct observations. Engagement of students in the CW-FIT group was significant; disruptive behaviors decreased significantly within the CW-FIT group, praise increased for all students, but more so for those targeted in the Tier 2 intervention, and the number of reprimands reduced, but a more significant decrease was found for students receiving Tier 2 interventions (Wills et al., 2018).

Nelson et al. (2018) researched how CW-FIT affected elementary students' ontask behavior in art classrooms. The participants were two third-grade classes and one fifth-grade class, all taught by the same instructor. The teachers were trained in two hours to implement CW-FIT with fidelity. The research team used seven to 10 direct observations to gather baseline and intervention data points for the classrooms. "On-task 
behavior immediately improved during implementation of CW-FIT" (Nelson et al., 2018, p. 233) and overall improvement by the end of the study. Nelson et al. (2018) found that the praise to reprimand ratio increased from 0.91:1 to 4.35:1. Classroom 1 (third grade) and Classroom 2 (fifth grade) had a significant decrease in reprimands, and praise increased in Classroom 2.

Caldarella et al. (2018) conducted a randomized control trial with 149 general education teachers and 11 special education elementary school teachers in 19 schools across three states. Teachers identified 350 students at risk for emotional and behavioral disorders (Caldarella et al., 2018). CW-FIT was implemented for about four months (Caldarella et al., 2018). Students were directly observed by trained staff (Caldarella et al., 2018). Two-hour training was presented to the teachers after baseline observations were completed (Caldarella et al., 2018). Coaches were available to give feedback for up to two weeks after training (Caldarella et al., 2018). Results presented significant improvements in social skills for the students in the treatment classrooms in comparison to those in the control classrooms (Caldarella et al., 2018). There were no significant differences in ratings of problem behaviors; however, the behaviors measured were of blaming others, taking things that belonged to others, and being overly demanding of the teacher's attention, which was different than previous studies (Caldarella et al., 2018).

\section{Purpose of the Study}

Teachers experience various externalizing student behaviors often, and in a high stakes race for student achievement, they are struggling with educating all students when others are acting out, disrupting class, or lose instructional time due to discipline (disruptive students and classmates lose instructional time due to the disruption). 
Teachers report they are frustrated, do not know what to do with students who externalize behavior, and feel unsupported (Butler \& Monda-Amaya, 2016). According to Greenberg, Domitrovich, Weissberg et al. (2017), "evidence-based SEL [Social Emotional Learning] interventions in all schools - that is, universal interventions - could substantially affect public health" (p.1). These interventions can improve student's confidence in themselves; increase engagement in school, along with improving their test scores and grades; and reduce conduct problems while promoting desirable behaviors (Greenberg et al., 2017). "In the long term, children with greater social-emotional competence are more likely to be ready for college, succeed in their careers, have positive relationships and better mental health, and become engaged citizens" (Greenberg et al., 2017, p. 1).

Due to the stressors teachers have (Butler \& Monda-Amaya, 2016), the purpose of this study was to explore how a behavior intervention program, the classwide functionrelated intervention teams (CW-FIT), within the scope of teacher professional development, can impact students' behaviors, improve teacher retention, and ultimately improve academic experiences in a suburban elementary school in Southwest Missouri. The mixed-methods study used a convergent mixed method design (Creswell, 2014) to explore how the CW-FIT impacted behaviors of elementary students. It also examined the correlation, if any, between teacher professional development of the CW-FIT and office referrals, teacher retention, and student achievement (Figure 1). 
Figure 1.

Teacher Education and Student Behavior Visual Map.

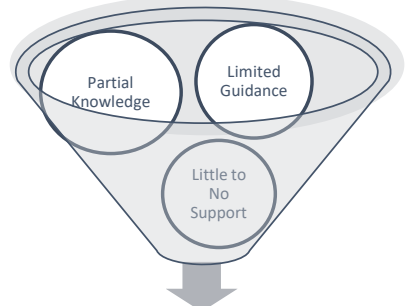

-Increases negative behaviors

- Decreases student achievement

-Decreases teacher self-efficacy

-Decreases teacher retention

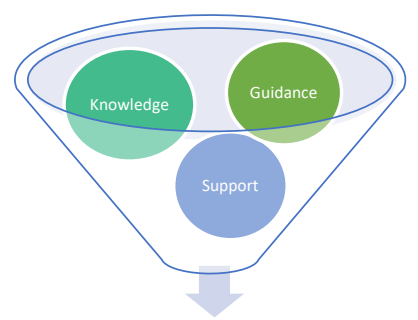

- Decreases negative behaviors

-Increases student achievement

-Increases teacher self-efficacy

-Increases teacher retention

Note: This figure demonstrates the hypothesized relationships between teacher professional development and behavior, student achievement, and teacher retention.

\section{Research Questions}

The research questions guiding this study were:

1. Does the teacher professional development for Class-Wide Function-related Intervention Teams (CW-FIT) impact student behavior in an elementary classroom?

a) in terms of praise versus reprimand ratios

b) in terms of student on-task behavior

c) in terms of student engagement

d) in terms of office discipline referrals (ODR)

2. What is the relationship between CW-FIT and student achievement?

3. Does the teacher professional development for Class-Wide Function-related Intervention Teams (CW-FIT) influence teacher retention? 
4. What are the teacher perceptions of the professional development for ClassWide Function-related Intervention Teams (CW-FIT)?

\section{Theoretical Framework}

\section{Adult Learning}

Adult learning is fundamental to this study. For change to occur in student behavior, we must first start with the knowledge the teachers have and use a variety of teaching approaches to prevent or address students' externalizing behavior. Knowles (1980) stated that andragogy accepts that a teacher cannot make a person learn, but they can support a person with learning. By understanding how adults learn, facilitating the transfer of knowledge should have a more significant impact on educators and the students they teach.

According to Knowles (1980), adult learning or andragogy is based on "four crucial assumptions about the characteristics of learners" (p. 44) that is different than pedagogy. These assumptions include adults' transition from being dependent to being self-directed, life experiences are resources, readiness to learn is associated with social roles, and adults' perspectives change from postponing knowledge to immediacy of application. Adults learn "by observing and modeling others" (Merriam \& Bierema, 2014, p. 35). Adults have a profound inner need to be self-directing but may be dependent in momentary circumstances (Knowles, 1980). Educators want to improve and help students, but at times, they may not know what to do and need help from others.

Adults accumulate knowledge from experiences that can be used as resources for learning for themselves and others (Knowles, 1980). Personal experiences help others learn as well as allow for reflection from the storyteller. "Through listening to 
participants shar[ing] their story, the power dynamic begins to shift from teacher-centered to learner-centered" (Cueva, 2010, p. 84). According to Merriam and Bierema (2014), life experiences are a resource, and they stimulate the need for learning; however, they can also hinder learning based on habits, biases, and presumptions.

Adults are ready to learn when there is a need to learn and to assist in coping with real-life problems. New information must be meaningful and useful as to not waste time on something that will not help the learner. Adults wish to apply gained knowledge and or skills today to be more productive tomorrow (Knowles, 1980). Knowles (1980) stated that "learning is an internal process ... those methods and techniques which involve the individual most deeply in self-directed inquiry will produce the greatest learning" (p. 56). Self-directed adults can grow when they have opportunities to choose topics and to reflect on their learning (Chen, 2014)

Professional development can embody varying modes of delivery to have a more significant impact and pull from the participants' prior experiences. Merriam and Bierema (2014) noted that using several methods of "active learning strategies ... create more powerful, effective learning experiences for adults" (p. 125). Knowles (1980) and Merriam and Bierema (2014) suggested strategies such as lecture, group discussion, simulations, role-playing, practicing skills, and demonstrations. These draw on life experiences as well as increase intrinsic motivation when participants practice or achieve mastery (Merriam \& Bierema, 2014). "Learning occurs when appropriate stimuli are presented and the learner is subsequently rewarded for exhibiting the desired behavior" (Merriam \& Bierema, 2014, p. 150). 


\section{Social Learning}

Several theories contribute to this framework: social science theory (Creswell, 2014), social learning theory (SLT) (Bandura, 1977), social cognitive theory (SCT) (Martin, Burns, \& Collie, 2017), social development model (SDM) (Fleming, Catalano, Oxford et al., 2002), and social competence (Dodge, Pettit, McClaskey et al., 1986). These theories examine the development of social skills, cognitive capacity of emotional control, and behavioral change (Creswell, 2014; Walters, 2019). Harrington (2005) stated that "social theory can be defined as the study of scientific ways of thinking about social life...about methods of explaining social behavior... and numerous other concepts and problems in social life" (p. 1). Bandura (1977) proposed that social science theory is the personality as an interaction between the person and the environment.

Bandura (1977) stated that social learning theory (SLT) stresses the significance of observing and modeling behaviors, attitudes, and emotional reactions of others. SLT can explain behavior between cognitive, behavioral, and environmental influences (Bandura, 1977). This theory has been applied widely to the understanding of aggression and psychological conditions (Bandura, 1973). As Bandura (1979) explained, aggression is learned behavior and influenced by a person's environment and biological traits; however, even learned behavior is not always reenacted. SLT "distinguishes between acquisition of behaviors that have destructive and injurious potential and factors that determine whether individuals will perform what they have learned" (Bandura, 1979, p. $6)$.

Social cognitive theory (SCT) describes the influence of individual experiences, the actions of others, and environmental factors on health behaviors (Bandura, 1986). 
SCT (Bandura, 1986) recognized some aspects and methods are essential for students' academic functioning (Martin et al., 2016). These factors include self-efficacy and perceived control (personal agency) and relational support (interpersonal agency) (Martin et al., 2017). The SCT provides opportunities for social assistance through introducing expectations, self-efficacy, and observational learning, and other rewards to attain behavior change (Bandura, 1977). This theory also plays a role in organizations within decision making, goal-setting, and analytical thinking (Wood \& Bandura, 1989).

Fleming, Catalano, Oxford et al. (2002) stated that the SDM endeavors to explain the disparity in challenging behavior among youth. According to Fleming et al. (2002), the SDM "hypothesizes that during the elementary school developmental period children learn patterns of behavior, whether prosocial or antisocial, primarily from socializing units of family and school, with peers and neighborhood influences playing an increasing role as children" (p. 424) complete elementary grades. While SDM includes the developmental period during the elementary years, social competence encompasses the relationship between behavior and information processed, which could shed light on what a program impacts behavior and for other age levels of students. Finally, social competence is the cyclical relationship "between social behavior and social information processing" (Dodge et al., 1986, p. 2).

The theoretical framework selected for this study is social competence (Dodge et al., 1986). According to Perzigian (2018), the definition of social competence is "the myriad of skills with which individuals navigate and fulfill culturally normative social expectations in their interactions with others, such as in schools and communities" (p. 1) or simply put, "as effectiveness in social interaction" (Rose-Krasnor, 1997, p. 1). 
"Students who demonstrate school-valued prosocial behaviors (e.g., attentive listening or cooperating) are typically regarded as socially competent and are thus more likely to gain peer and teacher approval" (Perzigian, 2018, p. 2). Cyclical components of social competence include self-awareness, self-management, social awareness, relationship skills, and responsible decision-making (Greenberg et al., 2017) as well as "judgments by peers about the child's behavior and peers' behavior toward the child" (Dodge et al., 1986, p.3).

The study conducted by Dodge et al. (1986) examined students in second, third, and fourth grades within ten schools. Two percent of that population was deemed aggressive by their teachers and selected for the study, and a group of a similar number of non-aggressive students was chosen as a comparison population (Dodge et al., 1986). To determine social competence and social information processing, students rated how much they liked to play with each peer, shown video interactions, and asked questions regarding how the victim felt, how they knew, and how he or she would have responded (Dodge et al., 1986). Dodge et al. (1986) found that socially "incompetent children were those who displayed incoherent, awkward, and inept behavior" (p. 47).

Perzigian (2018) interviewed teachers in an urban alternative high school that had students placed there due to their behaviors. In this study, the teachers defined social competence as an understanding of how to react in all situations, even non-preferred activities, "to put on a happy face" (p. 5), and to be a self-advocate. Rose-Krasnor (1997) also stated that social competence is the "effectiveness in interaction, considered from both self and other perspectives" (p. 123). Rose-Krasnor made an important point to always consider a person's cultural background in regards to social competence. Other 
cultures regard being quiet and non-interactive as a positive attribute as compared to the general perception in the United States, where that mannerism is considered dismissal. The rationale for this framework, social competence, is embedded in SEL. The thought is if children have appropriate social and emotional skills, the short-range outcomes include: positive attitudes, positive relationships, less conduct problems, reduced distress, and increased academic performance but in the long-term would be to graduate from high school, be ready for college or a career, have healthy relationships, minimalize criminal tendencies, and be an involved citizen (Greenberg et al., 2017). The theory of social competence includes self-awareness, self-management, social awareness, relationship skills, and responsible decision-making which are included in the characteristics of SEL according to CASEL (2019): self-awareness, self-management, responsible decisionmaking, relationship skills, and social awareness (CASEL, 2019, Core-Competencies section; Greenberg et al., 2017).

\section{Child Development}

The components of the social competence theory (Dodge et al., 1986) aligns with the development of children during their elementary school years. Understanding what children are experiencing and learning during these years is critical to knowing what they are capable of learning and in what capacity. Children during early stages of development only think of themselves and cannot look beyond what is important to themselves (Erikson, 1950). Building relationships, learning self-control, becoming socially aware of themselves in situations, and managing their reactions to social situations are beginning to emerge and develop during the second through fifth grades of elementary school (Erikson, 1950). 
Inhelder and Piaget (1958) studied children and their development during the early twentieth century, and during this quest for knowledge, he traced four stages of development. Development through the stages depends upon three principles "maturation of the nervous system, experience" (Inhelder \& Piaget, 1958, p. 243) in the environment and influences of social setting. Inhelder and Piaget (1958) stated that equilibrium, or how the child adapts to conditions, occurs concurrently to these experiences. Equilibrium is a function of the child's behavior and expresses the probability of functions dependent upon "neuro-physiological conditions, physical environment, and social milieu" (Inhelder and Piaget, 1958, p. 243). For this study, the third stage, concrete operations, was used due to the age of the student population being researched. Concrete operations occur during the ages of seven to 12 years of age and during this stage, children attain a "concept of 'what is possible"' (Inhelder \& Piaget, 1958, p. 251). They act and do not imagine real situations (Inhelder \& Piaget, 1958). According to Inhelder and Piaget (1958), in the elementary years, children need both "inversion and reciprocity" (p. 273) as they are necessary for equilibrium in behavior. Inversion is ability to reverse an operation or cancel it and reversibility is permanently returning to the starting point of an operation (Inhelder \& Piaget, 1958).

Erikson (1950) developed eight stages of human development. The fourth stage and the fifth stage were used to analyze child development within the context of this study. In the fourth stage, industry versus inferiority occurs between the ages of five and 12 years. During this time, a child has learned that there is pleasure with work completion that involved attention and persistence. Increased learning and mastery of skills needed later in life are obtained during this stage. "In all cultures, at this stage, children receive 
some systematic instruction" (Erikson, 1950, p. 259). The primary asset of this stage is competence and there is danger if the child doesn't think of himself as adequate or able to do tasks (Erikson, 1950).

The fifth stage, identity versus identity diffusion (role confusion), occurs between the ages of 12 and 19 (Erikson, 1950). In this stage, a child's body matures, and he or she begins to separate from the parent to assume their own identity (Erikson, 1950). Roles change, and observations are made from role models such as parents, coaches, teachers, entertainment people, and possibly criminals (Erikson, 1950). At times, children in this stage still need rules and limits imposed for their safety, and the primary tasks are to learn truthfulness, consistency to self, and to have faith in self (Erikson, 1950). Since the students in this study could be approaching this age, it was necessary to note the transition of their development. During this stage, children start to care about how they look to others and are trying to connect for a "sense of continuity and sameness" (Erikson, 1950, p. 261).

Understanding adult learning, social learning theories, and child development are necessary to understand the purpose of this study; to better explore professional development of teachers and the change agents of children. These all connect by interdependency, and the smallest change to interactions between the teachers and students can create a profound difference in others' lives. The chosen design of this study was due to an identified problem of practice for elementary teachers. Teachers, the researcher knew, noted that they did not enough training to manage students that exhibit disruptive behavior, and these behaviors resulted in office referrals, decreased academic performance, and impacted the teachers' retention rate. 


\section{Design of the Study}

\section{Setting}

The research study setting was in a southwest Missouri suburban school district located in City A, south of a metropolitan city. The school district has a preschool/childcare facility, four elementary buildings, a middle school, a junior high, a high school, and an alternative high school. There are approximately 6,000 students within the district. The school district employs around 900 people, which includes about 99 teachers (Missouri Department of Elementary and Secondary Education, DESE, 2019). For this study, one elementary school was selected through convenience sampling due to the researcher's access to the building (Fink, 2017). This elementary has approximately 41 teachers and 650 students from kindergarten to fifth grade. In each grade level, there are between four and six classrooms. There are also five special education classrooms and five related arts classrooms (e.g., science, art, music, PE, computers).

\section{Design}

This research study was a convergent mixed method design that occurs when "qualitative and quantitative data are collected in parallel, analyzed separately, and then merged" (Creswell, 2014, p. 133). The reason for collecting both quantitative and qualitative data was to investigate the relationship, if any, between teacher professional development of the CW-FIT and office referrals, teacher retention, and student achievement. For this study, the researcher first collected survey data, observed participating classrooms prior to providing PD on CW-FIT, provided PD on CW-FIT only to participants, observed each classroom for fidelity in using the program, observed 
each classroom an additional six times, collected school and student records, and then interviewed each participant to help explain findings from survey responses.

\section{Participants}

Participants in this research study started with 12 elementary teachers and 10 classrooms. Before the Pandemic the study focused on two grade levels for a more manageable amount of data and participants (see Table 1). One of the fourth-grade classrooms was a co-taught setting, which included one general education teacher and one special education teacher. Two of the fifth-grade classes also included a special education teacher to provide co-teaching. Teachers were asked to participate by email (see Appendix A) which included informed consent (see Appendix B).

After the surveys (see Appendix C) and pre-intervention observations were completed, the participating teachers were provided professional development for ClassWide Function-related Intervention Teams (CW-FIT) behavior intervention. Howard Wills, the creator of CW-FIT, trained the researcher. The professional development was recorded and checked for fidelity by an outside source. After the professional development was completed, the researcher went into the classrooms for random fidelity checks of the intervention program (see Appendix D). Two more observations, approximately four weeks apart, were completed in each classroom. Finally, the postintervention observations were completed during the fourth quarter and interviews (see Appendix E) were completed by mid-June. After the researcher was granted permission to documents (discipline records, student demographic information, academic performance, and attendance), information was gathered at the end of the school year (Appendix F). 
All of the teachers were white females between the ages of late-twenties to midfifties. During the 2018-19 school year, the teachers in the elementary building had an average length of experience of 13.4 years, and $52.3 \%$ have a Master's degree or higher (DESE, Missouri Comprehensive Data System, 2019).

After the pandemic began, the study continued in the fall of 2020 and included 11 teachers and nine classrooms. The third-grade teacher taught a fourth-grade class when the study began, and due to the positive results witnessed, the participant asked to continue in the study. One of the previous fifth-grade teachers went on maternity leave. This group was identified through convenience sampling (Fink, 2017) as the researcher was employed in the same building. During the 2018-19 school year, the population of the elementary school was $88 \%$ White, $6 \%$ Hispanic, and $42 \%$ receive the Free/Reduced Lunch program (DESE, Missouri Comprehensive Data System).

\section{Data Collection}

Before collecting any data, permission to conduct the study was approved through the International Review Board (IRB) at the school district and researcher's University. This study was conducted over four school quarters in a single calendar year.

\section{Survey}

A survey was completed during the third quarter. The survey was distributed through email and an online survey format using Qualtrics. The email sent to participants included information stating responses were anonymous, an option to opt-out, and a request to have the survey completed within one week. 


\section{Observation Tool}

The researcher created the observation tool (see Appendix G) by using portions of the Classroom Practices Observation Tool (Midwest PBIS Network and Mid-Atlantic PBIS Network, 2019) and was trained on how to use it for the study. The first portion of the tool collected data on specific behavior and praise how the teacher responded to inappropriate Behaviors. This section was used to collect praise versus reprimand ratios for each collection period. The next section collected the amount of times students were on or off task as well as teacher-given opportunities to respond. Finally, the student engagement rubric was created in combination of the "Classroom Practices Observation Tool” (Midwest PBIS Network and Mid-Atlantic PBIS Network, 2019) and the "Quality Rating Definitions for CW-FIT Procedural Fidelity Checklist” (University of Kansas, Elementary School Materials, 2019).

To provide a more rigorous measure of rater agreement, an Interobserver agreement (IOA) was made. This person also worked in the same elementary as the participants and had extensive training on classroom management. The agreement was made to observe the classrooms at the same time. The first observation was used as a practice and not counted in the data. The observation data was scored if a matching number was found with each opportunity (Wills et al., 2018) data collection in the same timeframe using the exact agreement method (Vollmer, Sloman, \& St Peter Pipkin, 2008). Clearly defined examples were included as quality control measures (Berman \& Vasquez, 2015). The researcher then observed each participating classroom for baseline data. 


\section{Interviews}

Interviews were conducted after all observations were completed. The approximately hour-long interviews occurred after all classroom observations were complete towards the end of the first semester of the 2020-21 school year. After the researcher was granted permission to documents (discipline records, student demographic information, academic performance, and attendance), information was gathered and analyzed for patterns and trends.

\section{Archival Data}

Data were collected for all of the third through fifth grade classrooms to document the effect of CW-FIT and a control comparison. Data collected included office referrals for the first semester of the 2020-21 school year, discipline record details, academic performance on the Evaluate assessment for both English Language Arts (ELA) and Math, and student demographic information to analyze and triangulate the data (Nightingale \& Rossman, 2015).

\section{Instruments}

\section{Survey}

The survey (Appendix C) was designed to be a single point in time (Fink, 2017) through a cross-sectional design. The survey questions were created by the researcher based upon previously used surveys from the U.S. Department of Education \& National Center for Education Statistics (2016). It was designed for the current study and for future use in later studies. Eight quantitative survey items were closed-ended questions about behavior preventive or reduction programs, witnessed behaviors, teachers' feelings about aggressive students, training offered, consideration of leaving the education field, 
the average number of students in the participant's classroom, and years of experience. For example, one question asked participants "How often do you witness students exhibiting the following behaviors?" with 10 behaviors listed. Four qualitative survey items were open-ended questions about strategies used for students' externalizing behavior and why they thought about leaving the field of education or not.

\section{Pre-PD Observation}

The observation tool (Appendix G) was used to collect data simultaneously during 10-minute periods. Data collected included: teacher reactions to behavior (praise or reprimands), engagement and multiple opportunities to respond, on-task behavior, and a total student engagement rubric. The student engagement rubric had four opportunities to score zero, one or two points. One point could be awarded for each of the following: some disruptions but peers were not impacted, the teacher sometimes reminded students

of reinforcement, some inappropriate behavior was not addressed appropriately, or praise to reprimand ratio was $3: 1$. Two points were available for: no disruptions during the observation, the teacher always reminded students of reinforcement, inappropriate behavior was addressed appropriately, and the praise to reprimand ratio was $4: 1$ or greater.

\section{School Records}

Archival data access protocols were created to document student performance which could be used in the future for replication. These protocols were used to access classroom demographic summaries, office discipline referrals (ODR), and academic performance on Evaluate. Only ODRs for events that occurred in the classroom were counted. ODRs included the following types of infractions: Disrespectful/Disruptive, 
Fighting, Assault (3rd-4th degree), Threat/Verbal Assault, Weapon, or Vandalism. Evaluate is a web-based formative reading and math assessment based on "national and state standards-aligned formative assessments that simulate each state's end-of-year proficiency exams" (Catapult Learning, 2021, p. 3) for ELA and Math. "Evaluate assessments employ graphic-rich technology-enhanced question types (TEQs) that challenge students to go beyond typical multiple-choice test items and interact with the question in a variety of engaging ways (Catapult Learning, 2021, p. 4). Respect for the privacy of students and participants was maintained by disassociating names when collecting data from school records, and pseudonyms were used in reporting of the data (Creswell, 2014).

\section{Interviews}

The semi-structured interview protocol was designed to capture qualitative answers for the research questions: (3) "Does the teacher professional development for Class-Wide Function-related Intervention Teams (CW-FIT) influence teacher retention?" and (4) "What are the teacher perceptions of the professional development for ClassWide Function-related Intervention Teams (CW-FIT)?” The interview had seven questions. Topics explored included: teaching experiences; strategies used when students exhibited externalizing behavior; how teacher's felt in those situations; how behaviors impacted instruction, student achievement, class climate; perceptions regarding the PD on CW-FIT; how CW-FIT impacted their classroom, student attention, behavior, outlook on teaching career; and what support the teachers perceived they needed to continue using CW-FIT. The approximately hour-long interviews occurred after all classroom 
observations were complete towards the end of the first semester of the 2020-21 school year.

\section{Significance of the Study}

Breslau et al. (2009) reported, "in a recent nationally representative survey, 14 of 17 early onset psychiatric disorders examined were associated with lower probability of completing primary and secondary school, entering college, or completing a 4-year college degree" (p. 1). According to Kremer, Huang, Vaughn et al. (2016), externalizing "behavior problems had a negative relationship with academic performance, and some of these associations endured over time" (p. 1). This study will add to the existing literature by providing data on the results of professional development for CW-FIT and its correlation to office referrals, teacher retention, and student achievement.

The first group of people to benefit from this study would be the teachers and students that participated. If the professional development on the CW-FIT gives the teachers the knowledge on how to impact student behavior, then the classroom climate should improve as well as teacher self-efficacy. Students would benefit from an increase in instructional time, improved relationships between the teacher and peers, and improved academic achievement. The researcher hopes that this study would also increase the likelihood of teachers staying in the field of education. It is the hope that with the new training, they would feel supported and empowered.

This study will assist the institution by providing valuable information on the teachers' perceptions of professional development on student externalizing behavior and support they perceive to have. Also, the results of this study will demonstrate any correlation between student behaviors and office referrals, student achievement, and 
teacher retention. If the results of the study prove positive correlations between the variables, then the professional development could be replicated across the remaining buildings in the district.

\section{Summary}

In summary, this study aims to contribute valuable information on the teachers' professional development on student behavior and to impact behaviors committed by students. By recognizing the need for professional development in this area, the study will help educators and leaders learn if the CW-FIT works to impact behavior, decrease office referrals, increase student achievement, and increase teacher retention. Further understanding of professional development will assist all students, teachers, classrooms, schools, and districts. If proven beneficial, this study could help educators nationwide as this problem is not isolated in the area.

\section{Limitations}

Limitations of this study are the small sample size of only nine classrooms; selfreporting teachers through a survey and interviews; the classrooms and school were not randomly selected; and a lack of diversity. In addition, the COVID-19 pandemic disrupted the study during the spring of 2020. The school district was mandated by the Governor to be closed from mid-March to the end of the academic term. This caused the study to be restarted in the fall of 2020. Students were not allowed to be in close contact, wore masks, had dividers in-between them, could not participate in group work, or play with anyone outside their cohort. 


\section{Definitions of Key Terms}

Professional development is education and training opportunities to improve and support staff. According to the Missouri School Boards' Association (2019), professional development is sustained over time; focused on specific content areas or instructional practices; supports the collective learning of teachers; aligns with district, school and teacher goals; and is infused with active learning and provide teachers the opportunity to practice and apply new knowledge.

Student behavior refers to how a student acts in the classroom. According to the Good Behavior Game manual (NO AUTHOR), "classroom behaviors that might be considered good in one culture, community, or even school can be labeled in a different setting. The teacher must define explicitly for the students the desired, or target behaviors. The teacher cannot take for granted that the student knows exactly what proper behavior is for each situation" (p.2). This would include listening to the teacher, following school and social rules, and acting in a safe, respectful, responsible manner. In a negative outlook, it could include speaking disrespectfully, disruptive, making inappropriate noises, blurting out, not following directions, off task, lying, being irresponsible, not being safe towards others or materials.

Externalizing behaviors, according to Hymel, Rubin, Rowden et al. (1990) can be defined as hostility and aggression, and Henricsson and Rydell (2004) defined it as "destructive and aggressive behavior, defiance, temper tantrums, impulsive and hyperactive behavior" (p. 112). It can also include inappropriate language, yelling, and destructive towards materials. According to the World Health Organization (WHO) (1992), "conduct disorders are characterized by a repetitive and persistent pattern of 
dissocial, aggressive, or defiant conduct" (p. 266). This behavior could include:

"excessive levels of fighting or bullying; cruelty to animals or other people; severe destructiveness to property; fire setting; stealing; repeated lying; truancy from school and running away from home; unusually frequent and severe temper tantrums; defiant provocative behaviour; and persistent severe disobedience" (WHO, 1992, p. 267). The WHO (1992) described conduct behavior as when it is severe, it breaks social expectations. Iannotti (2012) reported that the costs of adolescent bullying, fighting, and violence in schools are a significant public health problem. "Physical aggression has been associated with an increase in injuries, violent crime, school adjustment problems, substance use, and mental health problems" (Iannotti, 2012, p. 16). These behaviors can last minutes or hours, and the frequency can range from once a month to many episodes per day (Green, Whitney, \& Potegal, 2011).

Mental health diagnoses or medical diagnoses could include: Oppositional Defiant Disorder (ODD), Bipolar, Attention Deficit Hyperactivity Disorder (ADHD) (combined type), or Disruptive Mood Dysregulation Disorder (DMDD) (American Psychiatric Association, 2013). This information may or may not be known to the researcher. According to Farley, Adam, Lutton et al. (2005), "oppositional and defiant behaviors include noncompliance, temper tantrums, arguing, and mild aggression" (p. 1).

Behavior interventions are strategies specifically chosen and implemented according to a specific child's need. Interventions could include extra time to complete tasks, specific seating (location, type of seat, near specific peer), breaking assignment up into smaller pieces, visual schedule, behavior contracts, visits to the counselor, rewards 
for good behavior, phone calls home, physical movement or breaks. The interventions are put into place on a specific schedule and applied by the teacher.

Positive behavior interventions and supports (PBIS) "is a framework for preventing problem behavior and supporting a person's social, emotional, and behavioral needs" (Crisis Prevention Institute, 2017, p.2). 


\section{References}

Algozzine, K., Christian, C., Marr, M. B., McClanahan, T., \& White, R. (2008). Demography of problem behavior in elementary schools. Exceptionality, 16(2), 93-104. doi:10.1080/09362830801981369

American Psychiatric Association. (2013). Diagnostic and Statistical Manual of Mental Disorders (5th ed.). Arlington, VA. Author.

Bandura, A. (1973). Aggression: A social learning analysis. Oxford, England: PrenticeHall.

Bandura, Albert. Social Learning Theory. Englewood Cliffs: Prentice. (1977). Print. Bandura, A. (1979). Psychological mechanisms of aggression. In M.VonCranach, K. Foppa, W. LePenies, \& D. Ploog (Eds.), Human ethology: Claims and limits of a new discipline. Cambridge: Cambridge University Press.

Bandura, A. (1986). Social foundations of thought and action: A social cognitive theory. Englewood Cliffs, N.J.: Prentice-Hall.

Berman, B. J. C., \& Vasquez, V. (2015). Using ratings by trained observers. In K. E. Newcomer, H. P. Hatry, \& J. S. Wholey (Eds.). (2015). Handbook of practical program evaluation, 412-444. Hoboken, NJ: John Wiley \& Sons.

Bierman, K. L., Coie, J., Dodge, K., Greenberg, M., Lochman, J., McMohan, R., \& Pinderhughes, E. (2013). School outcomes of aggressive-disruptive children: Prediction from kindergarten risk factors and impact of the fast track prevention program. Aggressive Behavior, 39(2), 114-130. doi:10.1002/ab.21467

Birman, B. F., Desimone, L., Porter, A. C., \& Garet, M. S. (2000). Designing professional development that works. Educational Leadership, 57(8), 28. 
Breslau, J., Miller, E., Breslau, N., Bohnert, K., Lucia, V., \& Schweitzer, J. (2009). The impact of early behavior disturbances on academic achievement in high school. Pediatrics, 123(6), 1472-1476. doi:10.1542/peds.2008-1406

Butler, A., \& Monda-Amaya, L. (2016). Preservice teachers' perceptions of challenging behavior. Teacher Education and Special Education, 39(4), 276-292.

Caldarella, P., Larsen, R. A. A., Williams, L., Wills, H., Kamps, D., \& Wehby, J. H. (2018). Effects of CW-FIT on Teachers' Ratings of Elementary School Students at Risk for Emotional and Behavioral Disorders. Journal of Positive Behavior Interventions, 20(2), 78-89. doi:10.1177/1098300717723353

Chen, J. C. (2014). Teaching nontraditional adult students: Adult learning theories in practice. Teaching in Higher Education, 19(4), 406-418. doi:10.1080/13562517.2013.860101

Cook, C. R., Coco, S., Zhang, Y., Fiat, A. E., Duong, M. T., Renshaw, T. L., Long, A. C., Frank, S., \& Curby, T. (2018). Cultivating positive teacher-student relationships: preliminary evaluation of the establish-maintain-restore (EMR) method. School Psychology Review, 47(3), 226-243. doi:10.17105/SPR-2017-0025.V47-3

Cree, R. A., Bitsko, R. H., Robinson, L. R., Holbrook, J. R., Danielson, M. L., Smith, C., Kaminski, J. W., Kenney, M. K., \& Peacock, G. (2018). Health care, family, and community factors associated with mental, behavioral, and developmental disorders and poverty among children aged 2-8 years — United States, 2016. Morbidity and Mortality Weekly Report, 67(50), 1377-1383. doi:10.15585/mmwr.mm6750a1External 
Creswell, J. W. (2014). Research design: Qualitative, quantitative, and mixed methods approaches (4th ed.). Thousand Oaks: Sage.

Crisis Prevention Institute. (2017). PBIS Resources Guide.

Cueva, M. (2010). A living spiral of understanding: Community-based adult education. New Directions for Adult and Continuing Education, 2010 (125), 79-90. doi:10.1002/ace.364

Dodge, K., Pettit, G., McClaskey, C., Brown, M., \& Gottman, J. (1986). Social competence in children. Monographs of the Society for Research in Child Development, 51(2), I-85. doi:10.2307/1165906

Ellis, M. L., Weiss, B., \& Lochman, J. E. (2009). Executive functions in children: Associations with aggressive behavior and appraisal processing. Journal of Abnormal Child Psychology, 37(7), 945-956. doi:10.1007/s10802-009-9321-5

Elswick, S., \& Casey, L. B. (2012). The good behavior game is no longer just an effective intervention for students: An examination of the reciprocal effects on teacher behaviors. Beyond Behavior, (1), 36.

Erikson, E. H. (1950). Childhood and society. New York: W.W. Norton \& Company. Farley, S. E., Adams, J. S., Lutton, M. E., \& Scoville, C. (2005). What are effective treatments for oppositional and defiant behaviors in preadolescents? The Journal of Family Practice, 54(2), 162, 164-5.

Fink, A. (2017). How to conduct surveys: A step-by-step guide (6th ed.). Thousand Oaks, CA: Sage.

Fleming, C., Catalano, R., Oxford, M., \& Harachi, T. (2002). A test of generalizability of the social development model across gender and income groups with longitudinal 
data from the elementary school developmental period. Journal of Quantitative Criminology, 18(4), 423-439.

Green, J. A., Whitney, P. G., \& Potegal, M. (2011). Screaming, yelling, whining, and crying: Categorical and intensity differences in vocal expressions of anger and sadness in children's tantrums. Emotion, 11(5), 1124-1133. doi: $10.1037 / \mathrm{a} 0024173$

Greenberg, M. T., Domitrovich, C. E., Weissberg, R. P., \& Durlak, J. A. (2017). Social and emotional learning as a public health approach to education. Future of Children, 27(1), 13-32.

Harrington, A. (2005). Modern social theory: An introduction. Oxford [England]; New York: Oxford University Press.

Hawken, L. S., MacLeod, K. S., \& Rawlings, L. (2007). Effects of the "behavior education program" (BEP) on office discipline referrals of elementary school students. Journal of Positive Behavior Interventions, 9(2), 94-101.

Henricsson, L., \& Rydell, A. M. (2004). Elementary school children with behavior problems: Teacher-child relations and self-perception. A Prospective Study. Merrill-Palmer Quarterly, 50, 111-138. doi:10.1353/mpq.2004.0012.

Hymel, S., Rubin, K. H., Rowden, L., \& LeMare, L. (1990). Children's peer relationships: Longitudinal prediction of internalizing and externalizing problems from middle to late childhood. Child development, 61(6), 2004. doi:10.2307/1130854

Iannotti, R. J. (2012). Health behavior in school-aged children (HBSC), 2005-2006. Inter-university Consortium for Political and Social Research. Retrieved from 
www.nichd.nih.gov/sites/default/files/publications/pubs/documents/HBSC2005_2006-Final.pdf

Inhelder, B., \& Piaget, J. (1958). The growth of logical thinking from childhood to adolescence : an essay on the construction of formal operational structures. Basic Books.

Jones, S., Brush, K., Bailey, R., Brion-Meisels, G., McIntyre, J., Kahn, J., Nelson, B., \& Stickle, L. (2017). Navigating SEL from the inside out: Looking inside \& across 25 leading SEL programs--A practical resource for schools and OST providers. Cambridge, MA: Harvard Graduate School of Education.

Kaufman, J. S., Jaser, S. S., Vaughan, E. L., Reynolds, J. S., Di Donato, J., Bernard, S. N., \& Hernandez-Brereton, M. (2009). Patterns in office referral data by grade, race/ethnicity and gender. Journal of Positive Behavior Interventions, 12(1), 4454. doi:10.1177/1098300708329710

Klassen, R. M., \& Chiu, M. M. (2010). Effects on teachers' self-efficacy and job satisfaction: Teacher gender, years of experience, and job stress. Journal of Educational Psychology, 102(3), 741-756. doi:10.1037/a0019237

Knowles, M. S. (1980). The modern practice of adult education: From pedagogy to andragogy. Wilton, CN: Association Press.

Kremer, K. P., Huang, J., Vaughn, M. G., \& Flower, A. (2016). Behavior problems and children's academic achievement: A test of growth-curve models with gender and racial differences. Children and Youth Services Review, 67, 95-104. doi:10.1016/j.childyouth.2016.06.003 
Luiselli, J. K., Putnam, R. F., Handler, M. W., \& Feinberg, A. B. (2005). Whole-school positive behaviour support: Effects on student discipline problems and academic performance. Educational Psychology, 25(2-3), 183-198.

Martin, A. J., Burns, E. C., \& Collie, R. J. (2017). ADHD, personal and interpersonal agency, and achievement: Exploring links from a social cognitive theory perspective. Contemporary Educational Psychology, 50 (Understanding Academically At-Risk Students' Learning, Motivation, and Engagement: Focus on ADHD, Executive Functioning, and Learning Disabilities), 13-22. doi:10.1016/j.cedpsych.2016.12.001

Merriam, S., \& Bierema, L. (2014). Adult learning: linking theory and practice. San Francisco: Jossey Bass.

Missouri Department of Elementary and Secondary Education (DESE). (2019). Missouri Comprehensive Data System. Retrieved from https://apps.dese.mo.gov/MCDS/home.aspx

Missouri Department of Elementary and Secondary Education (DESE). (2018). Statistics: October 2018 Free \& Reduced Percentages of Enrollment (includes individual building Community Eligibility Provision (CEP) data). Retrieved from https://dese.mo.gov/sites/default/files/Oct18FreeRedEnrollIndBldgCEPFreeClaim Percent_0.pdf

Missouri School Boards' Association. (2019). Policies - Policy. (2019). Retrieved from https://simbli.eboardsolutions.com/ePolicy/Policy.aspx?S=99\&Sch=99\&PC=GCL $\& Z=P \& r e v N o=1.01 \& \operatorname{srch}=$ professional + development\&ktype $=$ Exact\&encu $=\mathrm{xa} 9 \mathrm{j}$ wu0EeqNJP11MR8zErI2Eu9hM2yurtmPs7R4uWoGuv9F9IpXI4FQNqKypPhJtR 
ceUgSplusUbHEYC3Q5BlzvdHHwvlbz0BhJFRHGHTS0LmmS3KcTB49B26F NzxieskejKDg7zYBXsNQA2lhA6mxF65Km2Pgm0PtbNW14B8IW6iDLwRCsSI AZNiRfgU0D6fC9wQYst8nd6AAV1mjqNGg1HA==

Moore, T. C., Wehby, J. H., Oliver, R. M., Chow, J. C., Gordon, J. R., \& Mahany, L. A. (2017) Teachers' reported knowledge and implementation of research-based classroom and behavior management strategies. Remedial and Special Education, 38 (4), 222-232. doi:10.1177/0741932516683631

National Collaborating Centre for Mental Health (UK); Social Care Institute for Excellence (UK). (2013). Antisocial behaviour and conduct disorders in children and young people: recognition, intervention and management. Leicester (UK): British Psychological Society. (NICE Clinical Guidelines, No. 158.) 2. Retrieved from www.ncbi.nlm.nih.gov/books/NBK327832/

Nelson, M. A., Caldarella, P., Hansen, B. D., Graham, M. A., Williams, L., \& Wills, H. P. (2018). Improving Student Behavior in Art Classrooms: An Exploratory Study of CW-FIT Tier 1. Journal of Positive Behavior Interventions, 20(4), 227-238. doi: $10.1177 / 1098300718762744$

Nightingale, D. S., \& Rossman, S. B. (2015). Collecting data in the field. In K. E. Newcomer, H. P. Hatry, \& J. S. Wholey (Eds.). Handbook of practical program evaluation (pp. 445-473). Hoboken, NJ: John Wiley \& Sons.

Pas, E. T., Bradshaw, C. P., Hershfeldt, P. A., \& Leaf, P. J. (2010). A multilevel exploration of the influence of teacher efficacy and burnout on response to student problem behavior and school-based service use. School Psychology Quarterly, 25(1), 13-27. doi:10.1037/a0018576 
Pearson. (2019). Developmental Reading Assessment Second Edition PLUS. Retrieved from

https://www.pearsonassessments.com/store/usassessments/en/Store/ProfessionalAssessments/Academic-Learning/Reading/Developmental-Reading-Assessment\%7C-Second-Edition-PLUS/p/100001222.html

Pelco, L. E., \& Reed-Victor, E. (2007) Self-regulation and learning-related social skills: Intervention ideas for elementary school students, preventing school failure. Alternative Education for Children and Youth, 51(3), 36-42, doi:10.3200/PSFL.51.3.36-42

Perzigian, A. (2018). Social competence in urban alternative schools. Penn GSE Perspectives on Urban Education, 15(1).

Rose-Krasnor, L. (1997). The Nature of Social Competence: A Theoretical Review. Social Development, 6: 111-135. doi:10.1111/j.1467-9507.1997.tb00097.x

Shook, A. C. (2012). A Study of Preservice Educators' Dispositions to Change Behavior Management Strategies. Preventing School Failure, 56(2), 129-136. doi:10.1080/1045988X.2011.606440

The Collaborative for Academic, Social, and Emotional Learning (CASEL). (2019). History. Retrieved from https:/casel.org/history/

The Collaborative for Academic, Social, and Emotional Learning (CASEL). (2019). What is SEL? Retrieved from https://casel.org/what-is-sel/ University of Kansas. (2019). School-wide Training. Retrieved from https://cwfit.ku.edu/schoolwide-training 
University of Missouri. (2019). Evidence-Based Intervention Network - CW-FIT. Retrieved from http://ebi.missouri.edu/?s=cw + fit

U.S. Department of Education \& National Center for Education Statistics. (2016). School survey on crime and safety 2015-16 school year principal questionnaire. Retrieved from https://nces.ed.gov/surveys/ssocs/pdf/SSOCS_2016_Questionnaire.pdf

Walters, G. D. (2019). Social control versus social learning: Self-efficacy for future academic success and peer delinquency as mediators of the parental supportdelinquency relationship. Criminal Justice Review, 44(2), 101118. doi: $10.1177 / 0734016817753266$

Wills, H., Wehby, J., Caldarella, P., Kamps, D., \& Swinburne Romine, R. (2018). Classroom Management That Works: A Replication Trial of the CW-FIT Program. Exceptional Children, 84(4), 437-456. doi:10.1177/0014402918771321

Wood, R., \& Bandura, A. (1989). Social Cognitive Theory of Organizational Management. The Academy of Management Review, 14(3), 361.

World Health Organization (1992). The ICD-10 classification of mental and behavioural disorders: clinical descriptions and diagnostic guidelines. World Health Organization. Retrieved from https://apps.who.int/iris/handle/10665/37958

Zee, M., de Jong, P. F., \& Koomen, H. M. Y. (2016). Teachers' self-efficacy in relation to individual students with a variety of social-emotional behaviors: A multilevel Investigation. Journal of Educational Psychology, (7), 1013. doi:10.1037/edu0000106 
SECTION TWO: PRACTITIONER SETTING 
This study's setting is in the Ozark Mountains, which includes the states of Missouri, Arkansas, Oklahoma, and a part of Kansas. There are numerous creeks, streams, and caves entangled with hills, valleys, sinkholes, hardwood forests, and wildlife. There are several man-made lakes which, in combination with local tourist attractions, shopping, and family-oriented activities; it is an attractive location to reside.

City A's population has grown over $119 \%$ during the past 10 years due to its attraction and quality of life to residents (City A's website, 2021). Because of that, the area consists of higher and lower-income housing and more affordable residential units than other suburban areas in the Midwest Region (U.S. Census Bureau, 2021). The increased growth in population has directly impacted the enrollment in the local school districts. There are two large districts and several smaller districts within the same county. Resources and quality faculty and staff are increasingly in need. As the district has grown, so has its attention to recruitment and retention of high-quality educators.

This section provides the history and background of a suburban school district. In addition, an organizational analysis of the school building's structural, political, human resource, and symbolic frames and how these influence the building's leadership strategy related to professional development and student behavior are included. In conclusion, a discussion of this research's implications in the building and school district will be presented.

\section{History and Background of the Organization}

\section{City A}

The research study setting was in a southwest Missouri suburban school district located in City A, south of a metropolitan city. In comparison to the state of Missouri's 
2018 population of 6,126,452, City A has a population of around 20,000 (U.S. Census Bureau, 2019). Of this population, the rate of White residents in Missouri was $83 \%$ in 2018, while City A's was near 94\% (U.S. Census Bureau, 2019). The rates of other races were comparable except for Black (11.8\% Missouri to $0.9 \%$ in City A) and Asian $(2.1 \%$ Missouri to $0.4 \%$ in City A).

The educational attainment of a high school diploma average for Missouri was 89.2\% in 2018 and $91 \%$ in City A (U.S. Census Bureau, 2019). The rate of those with bachelor degrees or higher increased from $28.2 \%$ for Missouri to $31 \%$ in City A. The employment rate was also higher in City A (about 70\%) than the state average of $62.8 \%$ (U.S. Census Bureau, 2019). According to the 2018 5-year American Community Survey (ACS) estimate, the median income for residents of Missouri was $\$ 51,542$, with a poverty rate of $13.2 \%$ and above $\$ 52,000$ median income and $11 \%$ poverty rate for the residents of City A (U.S. Census Bureau, 2019).

The occupancy rate in Missouri was $66.9 \%$ and about $63 \%$ in City A. According to the 2018 5-year ACS, the median house value in Missouri was $\$ 145,400$ while near $\$ 143,000$ in City A (U.S. Census Bureau, 2019). According to the 2018 5-year ACS, the median gross rent in Missouri was almost $\$ 800$, and City A's median gross rent was slightly lower. Crime in the area of City A was considerably lower than the state average. According to CityRating.com (2019), the average rate of violent crime in City A in 2016 was $70 \%$ lower than the national average and $77.13 \%$ lower than the state average.

\section{The School District}

The district first opened in 1843 as a one-room schoolhouse. At that time, the population in the area was around 100 residents. In 1892, the first students graduated. 
Within about 100 years, the district grew to approximately 600 students (Organizational website, 2020). After another 50 years, the district grew to house seven buildings and approximately 3,500 students (Organizational website, 2020). Within the past six years, the district had storm shelters added to each of its elementary buildings, and the enrollment has grown to be over 5,800 students (Organizational website, 2020).

As of 2021, the school district has a preschool/childcare facility, four elementary buildings, a middle school, a junior high, a high school, and an alternative high school. The school district employs around 900 people, including approximately 99 teachers (Missouri Department of Elementary and Secondary Education, DESE, 2019). For this study, one elementary school was selected through convenience sampling due to the researcher's access to the building (Fink, 2017). This elementary school has approximately 41 teachers and 650 students from kindergarten to fifth grade. According to DESE (2019), this building has the highest rate of free and reduced lunches for the district (44\%). In each grade level, there are between four and six classrooms. There are also five special education classrooms and five related arts classrooms (e.g., science, art, music, PE, computers).

The district has a record of high achievement than the state average (Organizational website, 2020). In English Language Arts (ELA), 65\% of students scored Proficient or Advanced in 2019 (no state assessments were taken in 2020), while the state average was $48.7 \%$. In Math, $62 \%$ of students in this district scored in the Proficient or Advanced range compared to the state average of $41.9 \%$ (Organizational website, 2020). The student to teacher ratio is approximately 18 to one (Organizational website, 2020). The district has four strategic goals: high-quality instruction, appropriate tiered supports, 
shared leadership (including recruitment, retention, and professional development), and partnering with stakeholders. Regarding behavior, the elementary buildings in the district implement positive behavior interventions and supports (PBIS) (OSEP Technical Assistance Center on Positive Behavioral Interventions and Supports, 2017). PBIS has been practiced since at least 2015 .

\section{Organizational Analysis}

School district organizations are complex systems. Bolman and Deal (2013) identified four frames (structural, human resources, political, symbolic), which have a range of concepts that can help identify an organization's strengths and weaknesses. The researcher examined the school district and building through each lens to make clear connections with the research questions.

\section{Structural Frame}

The Organization's structure is a professional bureaucracy (Bolman \& Deal, 2013) due to its high number of educated professionals performing core activities. The school board; a central office team: superintendent, two assistant superintendents, four executive directors (secondary education, elementary education, special services, and student services); and a chief financial officer perform their duties above a large number of educators and support staff (Bolman \& Deal, 2013). The next level in the Organization is a pooled coupling, as described by Mintzberg (1979). Each building shares common resources within the district but are otherwise independent (Mintzberg, 1979). Mintzberg (1979) describes this sharing as "teachers in a school who share common facilities and budgets but work alone with their pupils" (p. 22). Each elementary building has a principal and an assistant principal, one and a half counselors, and a process coordinator. 
The middle and junior high buildings have a principal and two assistant principals. The high school has a principal and three assistant principals. The elementary buildings share a social worker, and the secondary buildings share another social worker. There is a Math Instructional Coach for every two elementary buildings, and each elementary has an English Language Arts Instructional Coach. The district employs five School Resource Officers (SRO).

The building used for this study has several committees or groups that work alongside or answer to the administration as part of the professional bureaucracy (Bolman \& Deal, 2013). They are experts in their fields and try to do their best for the task given to them. This structure has its challenges, just as Bolman and Deal (2013) describe. There are difficulties with "coordination and quality control" (Bolman \& Deal, 2013, p. 79). The team that assists teachers with intervention ideas does not meet regularly. The teachers do not often know who to contact when they have concerns for a student. Regarding behavior, no one is designated to discuss problem behaviors unless it is an office referral for discipline. With these disruptions of coordination, there is a lack of control of the quality of the teams' work.

\section{Political Frame}

When the school district is viewed through the political lens, it is a typical organization. It has many individuals and interest groups with differences in values, beliefs, and interests (Bolman \& Deal, 2013). Due to its non-profit design and requirements from governmental funding sources, important decisions are made each and every day, including allocating scarce resources. Stakeholders and those within the organization bargain and negotiate to gain resources or positions for their interests. 
According to Bolman and Deal (2013), power in an organization fundamentally can make things happen.

In the elementary building that is the focus of this research study, the same processes and challenges occur on a smaller scale. The principal and assistant principal use their positional power (Bolman \& Deal, 2013) to make critical decisions for students, faculty, and staff every day. They are given a small amount of funding to allocate to each classroom, building expenses, maintenance, and programs. It is here where the focus of this study is impacted the most.

The elementary building has the highest number of students on the Free or Reduced meal plan in the school district. This number is a sign of a high-risk population due to household incomes. Due to this, the building has a Title I program for reading interventions. There are two Title I teachers and an Instructional Coach for reading and writing. Teachers can utilize the informational and expertise power (Bolman \& Deal, 2013) of these individuals to help students struggling in reading and writing. The intervention team is an underbounded system because it is lightly controlled with crucial players, but there are no short-term goals (Bolman \& Deal, 2013). The group includes several members with different backgrounds and skillsets. The associations between the experts and the other members of the team were strained. This conflict was due to the behavior expert working outside of the intervention team, then those in power, either positional or informational, had conflicts about scarce resources. Also, according to Bolman and Deal (2013), goal-setting in the political frame is to "provide opportunity for individuals and groups to express interests" (p. 309). Still, the meetings did not allow the opportunity to express personal interests. 
When teachers note students struggling with negative behaviors, there are no designated teams or individuals to help. There are also no programs for behavior concerns as there are for reading. Title I reading interventions have a specific process and teams that determine which students need the interventions and for how long. The same type of process lacks for behavior concerns. When teachers have difficulties with a student or students, they either take care of the problem themselves, send the student to the office, or call the office for assistance from the administration. During the study, it was found that teachers do not report or send students to the office in fear of retribution (personal communication, 2020).

The district may also allow teachers to access educators within the district with informational and expertise power through Professional Development (PD) opportunities. Professional Development (PD) topics are proposed and presented by individuals with knowledge that can be shared and utilized. Still, they must be approved by those with positional power within the district's central office. Topics presented through PD opportunities may include reading, writing, math, building safety, technology, relationships, trauma, and caregiver fatigue (personal communication, 2021). PD opportunities for classroom behavior strategies have been provided by fellow teachers (personal communication, 2021). Minimal PD opportunities that inform teachers about behavior have been provided by experts such as the school psychologist (personal communication, 2021). PD for crisis interventions has only been offered to special education faculty and staff, and bus drivers (personal communication, 2021). 


\section{Human Resource Frame}

According to Bolman and Deal (2013), the human resource frame's leadership task is to work towards aligning human needs with what the organization needs. The group of professionals within the school district have differing experiences and positions but work together effectively. Even with the Organization's size, over 900 employees (Organizational website, 2020), people's needs are acknowledged and met when possible. In the building of study, faculty and staff rally around others' needs through fundraisers for medical conditions or natural disasters, classroom or work support, or auscultation. Family comes first so that the faculty and staff can then help others and those in the community.

Areas of deficit observed were in safety, communication, and support. Safety was a concern noted by the teachers when students were aggressive. According to Bolman and Deal (2013) and Maslow's Hierarchy of Needs, when our human basic physical and safety needs are satisfied, individual needs move upward toward social and belonging. The teachers need to have a voice about the intervention process. Some teachers noted that they did not feel supported by the administration when they had students misbehaving (personal communication, 2021). Activities to promote participation, feedback, and assistance may help keep the faculty committed to goals. Feedback ideas would also help team members join for a common purpose, recognize that they belong to the group, have roles and norms to govern the interactions and be motivated to work for the students' needs (Levi, 2017). 


\section{Symbolic frame}

According to the Organization's website (2020), the beliefs and values include student preparedness, achievement is attained through independence and collaboration, students learn differently, all can learn in safe and equitable environments, and all serve a vital role in the development and sustainability in the community. According to Bolman and Deal (2013), people want to believe efforts produce intended results. The symbolic meaning of the Organization's beliefs and values in this study lead the staff and faculty on

a journey to produce results. These beliefs and values can be reached through the focus of safety, nutrition, support, relationships, and education. The district's common phrase or statement is "Student Dedicated Every Day, Student Driven in Every Way" (Organizational website, 2020). This statement encompasses the beliefs and values. Each action or decision focuses on students and how each affects them.

\section{Leadership Analysis}

For this study, the leadership analyzed included the principal, assistant principal, and the team members that are a part of the intervention team. The principal has been in the current position for more than ten years. The assistant principal has been in the building of study for less than five years but was an assistant principal in another building in the same district for a few years. Both administrators worked together in the past. The intervention team included two Title I Reading Interventionists, Instructional Coaches (one for reading and one for math), the general education teacher with the student of concern, the school counselor, and sometimes the process coordinator. The focus of these meetings was to discuss academic concerns for specific students. 
In the years before the pandemic, the principal would schedule the intervention team to meet once a month. During these meetings, the teacher would present the concerns he or she had for the student, family history if it was relevant, grades and performance data, attendance, medical information if relevant, and interventions implemented. The team would discuss the information and determine if enough information was available to refer for an evaluation for special education or if other interventions should be attempted. During the pandemic, the meetings were stopped by the principal to minimize interactions of faculty members. Through the fall of 2020 , teachers were unsure of what the process was and what to do when they had a concern (personal communication, 2020). In the building of this study, there was not an organized team for behavior interventions as there was for academic concerns. Professional development for PBIS has not been offered within the district for at least three years, although new teachers are given in-district training (personal communication, 2019).

In Lencioni's (2002) model, "The Five Dysfunctions of a Team," there are five layers demonstrating what teams need to be mindful of and work through to be an effective team. The layers are (a) absence of trust, (b) fear of conflict, (c) lack of commitment, (d) avoidance of accountability, and (e) inattention to results (Lencioni, 2002). On the positive side of this model, Lencioni (2002) describes effective teams as (a) trusting each other, (b) engaging in unfiltered conflict, (c) commitment to decisions, (d) holding each other accountable, and (e) focusing "on the achievement of collective results" (p. 190). When the intervention team met, the members demonstrated trust by asking for help, accepting questions and input, offering feedback and assistance, appreciated and tapped into others' skills, focused time allotted on the topic, and offered 
or accepted apologies without hesitation (Lencioni, 2002). The second layer, engaging in conflict, was apparent during the meetings as each member expressed their thoughts and ideas, solved problems, and discussed critical topics. Commitments were made through priorities determined, alignment of shared objectives, and learning from mistakes. The team was not as effective with accountability. Team members had different standards of performance and expectations. The tip of the model, focusing on results, was also a weak area for the intervention team. There was a general expectation of results for the student of concern but consistent, and data reporting was lacking.

In the building of this study, it was apparent through interviews that the teachers partially had an absence of trust and a fear of conflict (Lencioni, 2002). The absence of trust was found through comments that mentioned concealing problems or hesitation to ask for help from administrators due to a fear of retribution (interview participant \#11). This "vulnerability-based trust" (Lencioni, 2002, p. 197) is challenging to overcome because the team members need to experience many opportunities that demonstrate credibility, understanding, and conclusion. The fear of conflict was apparent with a lack of commitment for intervention meetings, plans, a lack of accountability, and a deficiency of attention to results. These dysfunctions interrupt the success of the team and inevitably the students that are at risk.

To correct these dysfunctions, the team needed to trust each other, have regular follow-up meetings to continue individual development, and most importantly, the leader must demonstrate genuine vulnerability first. By building trust, the team will most likely engage more "knowing that they will not be punished for saying something that might otherwise be interpreted as destructive or critical" (Lencioni, 2002, p. 202). An exercise 
that could improve team effectiveness requires members to identify the sole most influence and one area to improve or remove for the good of the team (Lencioni, 2002). This activity requires some essential trust to be in place to be useful. Having these two dysfunctions diminished leads to the other positive levels of the model: commitment, accountability, and focusing on results (Lencioni, 2002).

\section{Implications for Research in the Practitioner Setting}

This study provided information regarding how professional development for a behavior intervention program aided teachers and students. It also found gaps in the process of interventions of academics versus behavior. The researcher sought to fill the perceived gap in the correlation between externalizing behaviors, and the professional development teachers receive for these behaviors.

The researcher received permission from the Organization to conduct the study. The study's findings will be disseminated to the teachers that participated, the building administration, and the district administration. The researcher gathered with participating teachers to follow-up on how CW-FIT progressed, discussed the study results, and collaborated with the teacher participants. Each participant mentioned in the interview that they would like to collaborate and see what the other teachers were doing, incentives they used, and brainstorm how they can utilize it more effectively. The teachers also suggested that the program be offered through PD for every teacher in the district in the spring and again in the fall, especially for new teachers.

\section{Summary}

This section provides a description of the setting for this study, which should help others make choices regarding the study's findings' transferability. The description of the 
Organization demonstrated that it is in a suburban area with a mid-size enrollment. The Organization is a professional bureaucracy (Bolman \& Deal, 2013). This study will provide the Organization with a better understanding of how professional development for behavior interventions is needed and desired by the teachers. The researcher is an organization employee, which allows the findings to be quickly disseminated to the Organization. 


\section{References}

Bolman, L. G., \& Deal, T. E. (2013). Reframing organizations: Artistry, choice and leadership (5th ed.). San Francisco, CA: Jossey-Bass.

City Rating. (2019). Retrieved from www.CityRating.com

Fink, A. (2017). How to conduct surveys: A step-by-step guide (6th ed.). Thousand Oaks, CA: Sage.

Lencioni, P. (2002). The five dysfunctions of a team. San Francisco, CA: Jossey-Bass.

Levi, D. (2017). Group Dynamics for Teams (5th ed.). Thousand Oaks, CA: Sage.

Mintzberg, H. (1979). The Structuring of Organizations. Englewood Cliffs, N.J.:

Prentice-Hall.

Missouri Department of Elementary and Secondary Education (DESE). (2019). Missouri Comprehensive Data System. Retrieved from https://apps.dese.mo.gov/MCDS/home.aspx

Missouri Department of Elementary and Secondary Education (DESE). (2018). Statistics: October 2018 Free \& Reduced Percentages of Enrollment (includes individual building Community Eligibility Provision (CEP) data). Retrieved from https://dese.mo.gov/sites/default/files/Oct18FreeRedEnrollIndBldgCEPFreeClaim Percent_0.pdf

OSEP Technical Assistance Center on Positive Behavioral Interventions and Supports (2017). Positive behavioral interventions \& supports. Retrieved from www.pbis.org.

U.S. Department Census Bureau. (2021) Retrieved from https://data.census.gov/cedsci/profile?g=0500000US29043 
SECTION THREE: SCHOLARLY REVIEW 


\section{Purpose}

Teachers experience various externalizing student behaviors often, and in a high stakes race for student achievement, they are struggling with educating all students when others are acting out, disrupting class, or lose instructional time due to discipline. Teachers report they are frustrated, do not know what to do with students who externalize behavior, and feel unsupported (Butler \& Monda-Amaya, 2016). Due to these stressors, the purpose of this study is to investigate how a program, within the scope of teacher professional development, can be beneficial in reducing students' externalizing behaviors, improve teacher retention, and ultimately improve academic experiences in a suburban elementary school in Southwest Missouri. The literature reviewed for this study began with an inspection of research on externalizing behavior. Then studies that examined programs for behavior were examined. Finally, the literature reviewed included an examination of relationships between behavior, programs for behavior, or teachers, academics, and/or office referrals.

\section{Research on Behavior}

Through the review of research and discussion of behaviors in childhood, there have been various definitions used. Challenging behavior, conduct problems, tantrums, and externalizing behavior are just a few of the terms found in the literature. However, these terms often have similar definitions. According to Hymel, Rubin, Rowden et al. (1990), externalizing behavior can be defined as hostility and aggression, and Henricsson and Rydell (2004) defined it as "destructive and aggressive behavior, defiance, temper tantrums, impulsive and hyperactive behavior" (p. 112). According to the World Health Organization (WHO) (1992), "conduct disorders are characterized by a repetitive and 
persistent pattern of dissocial, aggressive, or defiant conduct" (p. 266). This behavior could include: "excessive levels of fighting or bullying; cruelty to animals or other people; severe destructiveness to property; fire setting; stealing; repeated lying; truancy from school and running away from home; unusually frequent and severe temper tantrums; defiant provocative behaviour; and persistent severe disobedience" (WHO, 1992, p. 267). Before a behavior is determined to be an unusual problem, the following components: severity, frequency, pattern, setting, duration, impact, disruption and damage to others are considered (WHO, 1992). The various terms used to describe these types of behaviors could be difficult for practitioners that are trying to discern what behavior(s) to observe, track, or treat. The descriptions provided by the WHO (1992) seem to embody the focus of this study. For this study, the term 'externalizing behavior' was used as it encompassed the entirety of challenging behaviors seen in the classroom.

The effects of such behaviors have been researched in the following settings: home, school, or hospitals. How behaviors are different in various settings can be meaningful, but in this literature review, behavior in the school setting was the focus. Student behavior in the school setting is an important factor due to the cascading effects it can have. The WHO (1992) described conduct behavior as when it is severe, it breaks social expectations. Iannotti (2012) reported that the costs of adolescent bullying, fighting, and violence in schools are a significant public health problem. "Physical aggression has been associated with an increase in injuries, violent crime, school adjustment problems, substance use, and mental health problems" (Iannotti, 2012, p. 16). Henricsson and Rydell (2004) found that children with externalizing problems had a significantly less positive relationship with their teacher and had more teacher conflicts. 
These children also had a less favorable self-perception than others in the study (Henricsson \& Rydell, 2004). The relationships students have with peers and teachers can be affected long-term. Ladd and Burgess (1999) studied students over three years from kindergarten through second grade in which they found peers disliked aggressive students, and this continued into the higher grades. Hymel et al. (1990) researched students in second grade and again in fifth grade and found similar results. In their study, Hymel et al. (1990) found that unpopular students, in both grades were regarded as aggressive by peers and were viewed "by teachers as exhibiting externalizing problems (hostility and aggression, grade 2) and acting out behavior (grade 5)” (p. 2018). Aggressive students reported rates of loneliness that increased over time (Ladd \& Burgess, 1999).

\section{Social Emotional Learning Programs}

Evidence-based programs implemented with fidelity could effectively help students deficient in social and emotional learning (SEL). According to Greenberg, Domitrovich, Weissberg, et al. (2017), evidence-based SEL programs can improve children's self-confidence; increase their participation in school, along with their academics; and reduce conduct problems while helping desired behaviors. The Collaborative for Academic, Social, and Emotional Learning (CASEL) is a group that shares "knowledge about high-quality, evidence-based" (CASEL, 2019, About CASEL section, para. 1) SEL that supports teachers and policy leaders and improves the experiences and effects for all PreK-12 students. This collaborative group makes social and emotional competence assessments, develops SEL guidelines, supports districts, 
evaluates SEL programs, works with policymakers, and investigates SEL (CASEL, 2019).

In their research and collaboration efforts, a framework of SEL skills formed. This framework is the core-competencies that children need to integrate skills to manage daily challenges. The competencies include self-awareness, self-management, responsible decision-making, relationship skills, and social awareness (CASEL, 2019, CoreCompetencies section). In the long-term, children with more social-emotional ability are more likely to be prepared for college or career, have positive interactions and improved mental health, and become involved citizens (Greenberg et al., 2017).

Greenberg et al. (2017) reviewed studies focused on selecting correct interventions (Park \& Pinkelman, 2017), classroom management (Bull \& Solity, 2013), parent training (Muratori, Levantini, Manfredi et al., 2018), mindfulness, yoga (Sheinman, Hadar, Gafni et al., 2018), positive behavior interventions and supports (PBIS) (OSEP Technical Assistance Center on Positive Behavioral Interventions and Supports, 2017), and specific programs to implement in classrooms. Greenberg et al. (2017) noted that by applying interventions for the entire population, "many individuals must change their behavior or receive some degree of intervention so that a much smaller number of people will benefit" (p. 21). The benefit to each person may be particularly small even though the collective benefit is substantial (Greenberg et al., 2017). There are many stages of intervention: "universal interventions that focus on all the children and families in a school, selective interventions that focus on at-risk groups, indicated interventions that focus on children already showing early signs of trouble, and treatment for children with formal diagnoses" (Greenberg et al., 2017, p.22). 
Jones et al. (2017) developed and employed a coding system to find whether and how each program targeted "SEL outcomes across five domains (cognitive, social, emotional, character, and mindset) and 12 concrete skills (e.g., inhibitory control, emotion knowledge/expression, conflict resolution, empathy/perspective-taking, and more)" (p. 11) by looking inside programs to detect the specific skills targeted and instructional methods (e.g., books, discussion, drawing, songs, etc.) used within each activity. The group of researchers then standardized a process to collect and summarize the elements of programs and the evidence of success. The Wallace Foundation and six external reviewers reviewed the material of 25 programs (Jones et al., 2017). Each program developer was also invited to review “(a) program description, (b) grade range, (c) duration/timing, (d) areas of focus, and (e) additional/supplementary curricula" (Jones et al., 2017, p. 11). Jones et al. (2017) reported six key features found in effective SEL programs. These features are (a) occur in supportive environments, (b) build adult competencies, (c) partner with family and the community, (d) target specific behaviors and skills, (e) set reasonable goals, and (f) incorporate SAFE (sequenced, active, focused, explicit) elements (Jones et al., 2017).

The ten highest rated programs were reviewed by Jones et al. (2017) for the following domains: cognitive regulation, emotional processes, interpersonal skills, character, and mindset. Cognitive regulation includes the ability to control one's attention, inhibitory control, working memory, planning, and cognitive flexibility. Emotional processes include emotional knowledge, emotional expression, emotional regulation, behavior regulation, empathy, and perspective-taking. Interpersonal skills are understanding social cues, conflict resolution/ social problem-solving, and prosocial 
skills. Character is the ability to respect others, have responsibility, and citizenship. Mindset is a person's thinking, attitude, and beliefs about themselves, others, and conditions.

After noting the most top-performing program overall, K-12 programs were selected. The ability of a program to reach all grade levels is important for possible district-wide implementation. Other considerations included the length of the program, the number of lessons, and the cost of the program was the final detail noted. The overall top-performing program was for grades kindergarten through third. The next highest performing program for K-12th grade had four lessons per week for 35 weeks. The cost of this program was approximately $\$ 400$ per each grade unit (Jones et al., 2017). Jones et al. (2017) reported the next highest performing program available for grades K-12 had between seven and ten lessons of 30-50 minutes in length and costs between $\$ 1,000$ and $\$ 5,000$. The Good Behavior Game (GBG) was in the top ten, for grades K-12, continued yearlong, with three to five lessons per week for 10-40 minutes in length, and is free to use (Jones et al., 2017). Class-Wide Function-related Intervention Teams (CW-FIT) (Caldarella et al., 2018; Nelson et al., 2018; and Wills, Wehby, Caldarella et al., 2018), is a fairly new program that had not yet been evaluated by Jones et al. (2017) but it was noted in a publication of behavior interventions by Grant, Hamilton, Wrabel et al. (2017). The cost of this program was also free, for K-12, and could be continued throughout the school year with minimal time used within the class period.

\section{Analyzing Programs}

Teachers need more support and training for student externalizing behaviors. Zee, de Jong, and Koomen (2016) looked at teacher self-efficiency and challenging behaviors. 
In this research, Zee et al. (2016) found that students who externalize behavior (i.e., aggression, hyperactivity, antisocial) negatively impacted 'teachers' perceived capability in deploying effective methods to prevent and redirect instances of student misbehavior" (p. 1021).

Prather-Jones (2011) examined how administrators were retaining teachers of students with emotional and behavioral disorders (EBD). Through this study, they found that teachers felt support from when administrators: (a) enforced reasonable consequences and included the teacher in decision-making, (b) respected and appreciated them, and (c) helped build relationships between the EBD teacher with other teachers. This study did not specifically examine training as a piece of support nor how the perceived support affected students.

\section{Establish-Maintain-Restore}

Cook et al. (2018) conducted a study in which they evaluated the EstablishMaintain-Restore (EMR) program through a brief professional development for upper elementary teachers and follow-up support. They considered if EMR produced a positive change with student-teacher relationships, with behavior (as measured by academic engagement and disruptive behavior), and with student demographic variables (Cook et al., 2018). In this study, they observed 220 students and ten teachers (Cook et al., 2018). Fifty-three percent of the participants were female; 56\% Caucasian, 21\%

Hispanic/Latino, 20\% Asian/Pacific Islander, 1.8\% African American, and 3\% other; and $47 \%$ of the students qualified for free/reduced-price lunch (FRL) (Cook et al., 2018). Students that qualified for special education totaled $13.8 \%$ and " $8 \%$ were identified as English language learners" (Cook et al., 2018, p. 231). 
Cook et al. (2018) completed pre-treatment observations in all ten classrooms then immediately provided professional development with an active participation approach (Birman, Desimone, Porter et al., 2000). Support also included scripts and a PowerPoint presentation for reference with the five classrooms (Cook et al., 2018). Cook et al. defined academic engagement to include writing, reading audibly, raising a hand and patiently waiting, speaking to the teacher or other students about assignments or content, and investigating content related to an assignment. They defined disruptive behavior to include: "call outs, talking to peers when not permitted, getting out of seat, getting peers off-task, making noise with an object" (Cook et al., 2018, p. 232).

After a week of implementation, the researchers collaborated with the five teachers for further content review, questions, planning, and gave them a quiz to check for understanding (Cook et al., 2018). After two months, the researchers observed all ten classrooms again (Cook et al.). Cook et al. (2018) found that EMR produced positive teacher-student relationships, impacted student learning outcomes through increased engagement, and decreased disruptive behavior. Although this study found a correlation between a program, EMR, professional development, and disruptive behavior, learning outcomes were not investigated thoroughly. Cook et al. (2018) only used observational data to determine whether students were actively engaged and did not measure academic learning outcomes. The study completed by Cook et al. (2018) did not analyze any change to office discipline referrals (ODRs), nor the effect on externalizing behaviors such as described by Henricsson and Rydell (2004) and Pelco and Reed-Victor (2007): destructive and aggressive behavior, defiance, temper tantrums, impulsive and 
hyperactive actions, making inappropriate noises in the classroom, not following directions, yelling, inappropriate language, or lying.

\section{Positive Behavior Support}

Luiselli, Putnam, Handler et al. (2005) conducted a study over three years to examine if the principles of positive behavior support (PBS) implemented in an elementary building for K-5 grades had any effect on the amount of office discipline referrals (ODR) or academic performance. The average ODR per day per 100 students decreased from pre-implementation of 1.3, 0.73 during intervention implementation, to 0.54 after implementation (Luiselli et al., 2005). The number of suspensions also decreased: 0.31 per day per 100 students during pre-intervention, 0.25 during, and 0.20 after (Luiselli et al., 2005). Finally, the students' academic achievement scores on a standardized assessment (MAT-7) for reading and math both improved, 18 points and 25 points, respectively (Luiselli et al., 2005). PBS principles are included in some of the programs reviewed by Jones et al. (2017) but not as a single behavior intervention program.

\section{Good Behavior Game}

The Good Behavior Game (GBG) had positive results and was within the top ten of evaluated SEL programs (Jones et al., 2017). The GBG is distinctive for its only focus is prosocial behavior and working memory/planning skills ( $22 \%$ above the mean) (Jones et al., 2017). "It has a high focus on interpersonal skills (50\% above the cross-program mean) relative to other programs due to its strong focus on prosocial behavior" (Jones et al., 2017, p. 238). The GBG places the uppermost importance on prosocial behavior of all 25 programs (62\% above the mean) (Jones et al., 2017). 
Elswick and Casey (2012) completed a study on the GBG. In this study, Elswick and Casey reported that the GBG was easy to implement as a class-wide intervention. The first-grade classroom met the conditions required for selection: "(a) multiple referrals to the school social worker to assist in creating Behavior Intervention Plans (BIPs) for at least one identified student" (Elswick \& Casey, 2012, p. 38), and (b) student office referrals for exhibiting behavioral disruptions that interrupted the student and other's learning experiences. The teacher was given training for one week and until the teacher had 100\% integrity (Elswick \& Casey, 2012). The professional development comprised of information on GBG's background, "purpose, previous research, and a discussion about the GBG implementation and protocol. The discussion of the implementation of the GBG consisted of didactic training covering all of the steps necessary for a high level of procedural integrity" (Elswick \& Casey, 2012, p. 40). The teacher also received a manual and all materials necessary for implementation. Before and after implementation observational data was recorded over five weeks for talking out, out of seat behavior, and for being disrespectful. Disrespectful behaviors included "peer-to-peer frustration or aggression (verbal or physical)" (Elswick \& Casey, 2012, p. 38). The average talking out behaviors decreased from 21.5 to 6.28 per collection period, out of seat behavior decreased from 14.6 to 1 , and disrespectful behavior decreased from 3.7 to 0.14 (Elswick \& Casey, 2012). The research on the GBG demonstrated a relationship to the professional development of a behavior program and student behavior but not to academic achievement, office referrals, nor teacher retention. 


\section{PATHS}

Bierman et al. (2013) completed a more extensive study which included 55 schools in various demographic areas. In this research, they selected 891 kindergarten students over three years that were aggressive (Bierman et al., 2013). The children were divided up into an intervention and control group (Bierman et al., 2013). The PATHS curriculum was taught to teachers over three days and also included a manual, weekly classroom visits by an educational consultant, and monthly visits with the consultant either individually or in a small group (Bierman et al., 2013). The students also received individual tutoring for 90 minutes per week, peer pairs for 30 minutes weekly, and parents also received training (Bierman et al., 2013). The students were monitored through their high school careers (Bierman et al., 2013). Bierman et al. found that the intervention improved aggressive behavior but not long-term academic success.

\section{Class-Wide Function-Related Intervention Team}

Class-Wide Function-related Intervention Teams (CW-FIT) was developed in 2005 by Howard Wills and Debra Kamps and the Juniper Gardens Children's Project in association with the University of Kansas (2019). This behavior intervention program was "designed to explicitly teach and reinforce appropriate social behaviors through" (University of Missouri, 2019, p. 1) games in the general education setting. CW-FIT incorporates many research-based behavioral strategies such as: direct instruction of skills, self and peer management, extinction by removing reinforcement, differential reinforcement of alternative behaviors through dependent group contingencies, token economy, and teacher praise (University of Missouri, 2019). CW-FIT has been researched over 20 times (H.W., personal communication, November 8, 2019). Recent 
studies investigated the use of the program in differing elementary schools (Caldarella et al., 2018; Nelson et al., 2018; and Wills et al., 2018) and how the program affected student engagement, disruptive behaviors, and teacher praise. The studies did not investigate relationships between CW-FIT and academic performance or office referrals.

Grant et al. (2017) included the CW-FIT program in a report that examined recent peer-reviewed research literature to identify evidence on SEL interventions meeting Every Student Succeeds Act (ESSA) requirements. The report demonstrated the evidence found for 61 evidence-based SEL interventions. The sample size was 2,862+ students at three sites in Grades K-5 (Grant et al., 2017). The study that Grant et al. (2017) cited was completed by Kamps, Wills, Bannister et al. (2015). They observed students in the classroom and their on-task behavior. The sample size was 159 teachers with $18-25$ students per class. Class-wide on-task behavior during CW-FIT increased from 51.95\% in baseline to $82.99 \%$ (Kamps, et al., 2015).

Wills, Wehby, Caldarella et al. (2018) wanted to replicate the first CWFIT randomized controlled trials but this study expanded across three statesMissouri, Utah, and Tennessee with 21 elementary schools, 155 general education teachers, and 324 students. Kindergarten through sixth-grade classrooms, including special education classrooms, were a part of the six-month study (Wills et al., 2018). Teachers were provided two hours of training, opportunities to observe modeling up to two sessions, and weekly to biweekly feedback sessions with the project staff to ensure fidelity of implementation (Wills et al., 2018). Tier 2 interventions were designed for students that demonstrated "more than 10 disruptive behaviors in three of five observations, did not improve engagement to 
$75 \% \ldots$ or received teacher input of a poor response to intervention" (Wills et al., 2018, p. 443). Data was collected through direct observations (Wills et al., 2018). Engagement of students in the CW-FIT group was significant; disruptive behaviors decreased significantly within the CW-FIT group, praise increased for all students, but more so for those targeted in the Tier 2 intervention, and the number of reprimands reduced, but a more significant decrease was found for students receiving Tier 2 interventions (Wills et al., 2018).

Nelson et al. (2018) researched how CW-FIT affected elementary students' ontask behavior in art classrooms. The participants were two third-grade classes and one fifth-grade class which were taught by the same instructor. The teachers were trained to implement CW-FIT with fidelity during a two-hour session in the spring. The research team used seven to 10 direct observations to gather baseline and intervention data points for the classrooms. "On-task behavior immediately improved during implementation of CW-FIT" (Nelson et al., 2018, p. 233) and overall improvement by the end of the study. Nelson et al. (2018) found that the praise to reprimand ratio increased from 0.91:1 to 4.35:1. Classroom 1 (third grade) and Classroom 2 (fifth grade) had a significant decrease in reprimands, and praise increased in Classroom 2.

Caldarella et al. (2018) conducted a randomized control trial with 149 general education teachers and 11 special education elementary school teachers in 19 schools across three states. Teachers identified 350 students at risk for emotional and behavioral disorders. CW-FIT was implemented for about four months and students were directly observed by trained staff. Two-hour training was presented to the teachers after baseline observations were completed. Coaches were available to give feedback for up to two 
weeks after training. Results presented significant improvements in social skills for the students in the treatment classrooms in comparison to those in the control classrooms. There were no significant differences in ratings of problem behaviors; however, the behaviors measured were of blaming others, taking things that belonged to others, and being overly demanding of the teacher's attention, which was different than previous studies (Caldarella et al., 2018).

\section{Framework}

Several theories were considered and reviewed for this study: social science theory (Creswell, 2014), social learning theory (Rotter, 1954), social cognitive theory (SCT) (Bandura, 1986; Martin, Burns, \& Collie, 2017), social development model (SDM) (Fleming, Catalano, Oxford et al., 2002), and social competence (Dodge, Pettit, McClaskey et al., 1986). These theories examine the development of social skills, cognitive capacity of emotional control, and behavioral change (Creswell, 2014; Walters, 2019).

Harrington (2005) stated that "social theory can be defined as the study of scientific ways of thinking about social life... about methods of explaining social behavior... and numerous other concepts and problems in social life” (p. 1). Social science theory can be a thorough framework for mixed methods research (Creswell, 2014). Rotter (1954) proposed that social science theory is the personality as an interaction between the person and the environment. This theory is more of an overall theory. A more direct, smaller focus to determine any relationship between programs and behavior will be used for this study. 
SCT (Bandura, 1986) "identifies such factors and processes that are important for students' academic functioning” (Martin et al., 2017, p. 1). These factors include selfefficacy and perceived control (personal agency) and relational support (interpersonal agency) (Martin et al., 2017). This theory includes some features of SEL but is still too broad for this study. Fleming, Catalano, Oxford et al. (2002) stated that the SDM endeavors to explain the disparity in challenging behavior among youth. The SDM "hypothesizes that during the elementary school developmental period children learn patterns of behavior, whether prosocial or antisocial, primarily from socializing units of family and school, with peers and neighborhood influences playing an increasing role as children" (Fleming et al., 2002, p. 424) complete elementary grades. While SDM includes the developmental period during the elementary years, social competence encompasses the relationship between behavior and information processed, which could shed light on what a program impacts behavior and for other age levels of students. Finally, social competence is the cyclical relationship "between social behavior and social information processing" (Dodge et al., 1986, p. 2).

The theoretical framework selected for this study is social competence (Dodge et al., 1986). According to Perzigian (2018), the definition of social competence is "the myriad of skills with which individuals navigate and fulfill culturally normative social expectations in their interactions with others, such as in schools and communities" (p. 1) or simply put, "as effectiveness in social interaction" (Rose-Krasnor, 1997, p. 1). "Students who demonstrate school-valued prosocial behaviors (e.g., attentive listening or cooperating) are typically regarded as socially competent and are thus more likely to gain peer and teacher approval" (Perzigian, 2018, p. 2). Cyclical components of social 
competence include self-awareness, self-management, social awareness, relationship skills, and responsible decision-making (Greenberg et al., 2017) as well as "judgments by peers about the child's behavior and peers' behavior toward the child" (Dodge et al., 1986, p.3).

The study conducted by Dodge et al. (1986) examined students in second, third, and fourth grades within ten schools. Two percent of that population was deemed aggressive by their teachers and selected for the study, and a group of a similar number of non-aggressive students was selected as a comparison population (Dodge et al., 1986). To determine social competence and social information processing, students rated how much they liked to play with each peer, shown video interactions and asked questions regarding how the victim felt, how they knew, and how he or she would have responded (Dodge et al., 1986). Dodge et al. found that socially "incompetent children were those who displayed incoherent, awkward, and inept behavior" (p. 47).

Perzigian (2018) interviewed teachers of an urban alternative high school which had students placed there due to their behavior. In this study, the teachers defined social competence as an understanding of how to react in all situations, even non-preferred activities, "to put on a happy face" (p. 5), and to be a self-advocate. Rose-Krasnor (1997) also stated that social competence is the "effectiveness in interaction, considered from both self and other perspectives" (p. 123). Rose-Krasnor made an important point to always consider a person's cultural background in regards to social competence. Other cultures regard being quiet and non-interactive as a positive attribute as compared to the general culture in the United States where that mannerism is considered dismissal. 
The rationale for this framework, social competence, is embedded in SEL. The thought is if children have appropriate social and emotional skills, the short-range outcomes include: positive attitudes, positive relationships, less conduct problems, reduced distress, and increased academic performance but in the long-term graduate high school, be ready for college or career, have healthy relationships, minimalize criminal tendencies, and be involved citizens (Greenberg et al., 2017). The theory of social competence includes self-awareness, self-management, social awareness, relationship skills, and responsible decision-making which are included in the characteristics of SEL according to CASEL (2019): self-awareness, self-management, responsible decisionmaking, relationship skills, and social awareness (CASEL, 2019, Core-Competencies section; Greenberg et al., 2017). 


\section{References}

Bandura, A. (1986). Social foundations of thought and action: A social cognitive theory. Englewood Cliffs, N.J.: Prentice-Hall.

Bierman, K. L., Coie, J., Dodge, K., Greenberg, M., Lochman, J., McMohan, R., \& Pinderhughes, E. (2013). School outcomes of aggressive-disruptive children: Prediction from kindergarten risk factors and impact of the fast track prevention program. Aggressive Behavior, 39(2), 114-130. doi:10.1002/ab.21467

Birman, B. F., Desimone, L., Porter, A. C., \& Garet, M. S. (2000). Designing professional development that works. Educational Leadership, 57(8), 28.

Bull, S., \& Solity, J. (2013). Classroom management: Principles to practice. London; New York : Routledge.

Butler, A., \& Monda-Amaya, L. (2016). Preservice teachers' perceptions of challenging behavior. Teacher Education and Special Education, 39(4), 276-292.

Caldarella, P., Larsen, R. A. A., Williams, L., Wills, H., Kamps, D., \& Wehby, J. H. (2018). Effects of CW-FIT on Teachers' Ratings of Elementary School Students at Risk for Emotional and Behavioral Disorders. Journal of Positive Behavior Interventions, 20(2), 78-89. doi:10.1177/1098300717723353

Cook, C. R., Coco, S., Zhang, Y., Fiat, A. E., Duong, M. T., Renshaw, T. L., Long, A. C., Frank, S., \& Curby, T. (2018). Cultivating positive teacher-student relationships: preliminary evaluation of the establish-maintain-restore (EMR) method. School Psychology Review, 47(3), 226-243. doi:10.17105/SPR-2017-0025.V47-3

Creswell, J. W. (2014). Research design: Qualitative, quantitative, and mixed methods approaches (4th Ed.). Thousand Oaks: Sage. 
Dodge, K., Pettit, G., McClaskey, C., Brown, M., \& Gottman, J. (1986). Social competence in children. Monographs of the Society for Research in Child Development, 51(2), I-85. doi:10.2307/1165906

Elswick, S., \& Casey, L. B. (2012). The good behavior game is no longer just an effective intervention for students: An examination of the reciprocal effects on teacher behaviors. Beyond Behavior, (1), 36.

Fleming, C., Catalano, R., Oxford, M., \& Harachi, T. (2002). A test of generalizability of the social development model across gender and income groups with longitudinal data from the elementary school developmental period. Journal of Quantitative Criminology, 18(4), 423-439.

Grant, S., Hamilton, L. S., Wrabel, S. L., Gomez, C. J., \& Whitaker, A. (2017). Social and Emotional Learning Interventions. Santa Monica, California: RAND Corporation.

Greenberg, M. T., Domitrovich, C. E., Weissberg, R. P., \& Durlak, J. A. (2017). Social and emotional learning as a public health approach to education. Future of Children, 27(1), 13-32.

Harrington, A. (2005). Modern social theory: An introduction. Oxford [England]; New York: Oxford University Press.

Henricsson, L., \& Rydell, A. M. (2004). Elementary school children with behavior problems: Teacher-child relations and self-perception. A Prospective Study. Merrill-Palmer Quarterly, 50, 111-138. doi:10.1353/mpq.2004.0012.

Hymel, S., Rubin, K. H., Rowden, L., \& LeMare, L. (1990). Children's peer relationships: Longitudinal prediction of internalizing and externalizing problems 
from middle to late childhood. Child development, 61(6), 2004.

doi: $10.2307 / 1130854$

Iannotti, R. J. (2012). Health behavior in school-aged children (HBSC), 2005-2006.

Inter-university Consortium for Political and Social Research. Retrieved from www.nichd.nih.gov/sites/default/files/publications/pubs/documents/HBSC2005_2006-Final.pdf

Jones, S., Brush, K., Bailey, R., Brion-Meisels, G., McIntyre, J., Kahn, J., Nelson, B., \& Stickle, L. (2017). Navigating SEL from the inside out: Looking inside \& across 25 leading SEL programs--A practical resource for schools and OST providers. Cambridge, MA: Harvard Graduate School of Education.

Kamps, D., Wills, H., Bannister, H. D., Heitzman-Powell, L., Kottwitz, E., Hansen, B., \& Fleming, K. (2015). Class-Wide Function-related Intervention Teams "CW-FIT” Efficacy Trial Outcomes. Journal of Positive Behavior Interventions, 17(3), 134145. https://doi-org.proxy.mul.missouri.edu/10.1177/1098300714565244

Ladd, G. W., \& Burgess, K. B. (1999). Charting the relationship trajectories of aggressive, withdrawn, and aggressive/withdrawn children during early grade school. Child Development, 70(4), 910.

Luiselli, J. K., Putnam, R. F., Handler, M. W., \& Feinberg, A. B. (2005). Whole-school positive behaviour support: Effects on student discipline problems and academic performance. Educational Psychology, 25(2-3), 183-198.

Martin, A. J., Burns, E. C., \& Collie, R. J. (2017). ADHD, personal and interpersonal agency, and achievement: Exploring links from a social cognitive theory perspective. Contemporary Educational Psychology, 50 (Understanding 
Academically At-Risk Students' Learning, Motivation, and Engagement: Focus on ADHD, Executive Functioning, and Learning Disabilities), 13-22. doi:10.1016/j.cedpsych.2016.12.001

Muratori, P., Levantini, V., Manfredi, A., Ruglioni, L., \& Lambruschi, F. (2018). Parent training interventions for children and adolescents with aggressive behavioral problems. doi:10.5772/intechopen.73541

Nelson, M. A., Caldarella, P., Hansen, B. D., Graham, M. A., Williams, L., \& Wills, H. P. (2018). Improving Student Behavior in Art Classrooms: An Exploratory Study of CW-FIT Tier 1. Journal of Positive Behavior Interventions, 20(4), 227-238. doi: $10.1177 / 1098300718762744$

OSEP Technical Assistance Center on Positive Behavioral Interventions and Supports (2017). Positive behavioral interventions \& supports. Retrieved from www.pbis.org.

Park, K., \& Pinkelman, S. (2017). Function-based approach to designing an instructional environment. Beyond Behavior, 26(3), 124-134. doi:10.1177/1074295617729813

Pelco, L. E., \& Reed-Victor, E. (2007) Self-regulation and learning-related social skills: Intervention ideas for elementary school students, preventing school failure. Alternative Education for Children and Youth, 51(3), 36-42, doi:10.3200/PSFL.51.3.36-42

Perzigian, A. (2018). Social competence in urban alternative schools. Penn GSE Perspectives on Urban Education, 15(1). 
Prather-Jones, B. (2011). How school administrators influence the retention of teachers of students with emotional and behavioral disorders. Clearing House, 84(1), 1-8. doi:10.1080/00098655.2010.489387

Rose-Krasnor, L. (1997). The nature of social competence: A theoretical review. Social Development, 6, 111-135. doi:10.1111/j.1467-9507.1997.tb00097.x

Rotter, J. B. (1954). Social learning and clinical psychology. New York: Prentice-Hall. Sheinman, N., Hadar, L. L., Gafni, D., \& Milman, M. (2018). Preliminary investigation of whole-school mindfulness in education programs and children's mindfulnessbased coping strategies. Journal of Child and Family Studies, 27(10), 3316-3328. doi:10.1007/s10826-018-1156-7

The Collaborative for Academic, Social, and Emotional Learning (2019). History. Retrieved from https://casel.org/history/

The Collaborative for Academic, Social, and Emotional Learning (CASEL) (2019). What is SEL? Retrieved from https://casel.org/what-is-sel/

University of Kansas. (2019). School-wide Training. Retrieved from https://cwfit.ku.edu/schoolwide-training

University of Missouri. (2019). Evidence-Based Intervention Network - CW-FIT. Retrieved from http://ebi.missouri.edu/?s=cw+fit

Walters, G. D. (2019). Social control versus social learning: Self-efficacy for future academic success and peer delinquency as mediators of the parental supportdelinquency relationship. Criminal Justice Review, 44(2), 101118. doi:10.1177/0734016817753266 
Wills, H., Wehby, J., Caldarella, P., Kamps, D., \& Swinburne Romine, R. (2018). Classroom Management That Works: A Replication Trial of the CW-FIT Program. Exceptional Children, 84(4), 437-456. doi:10.1177/0014402918771321

World Health Organization (WHO) (1992). The ICD-10 classification of mental and behavioural disorders: clinical descriptions and diagnostic guidelines. World Health Organization. Retrieved from https://apps.who.int/iris/handle/10665/37958

Zee, M., de Jong, P. F., \& Koomen, H. M. Y. (2016). Teachers' self-efficacy in relation to individual students with a variety of social-emotional behaviors: A multilevel investigation. Journal of Educational Psychology, 108(7), 1013-1027. doi:10.1037/edu0000106 
SECTION FOUR: CONTRIBUTION TO PRACTICE 
The plan for dissemination of practitioner contribution would be through professional development within the school district. The program will be offered through professional development for any administrator, educator or paraprofessional in the district during the following school year. I would work with administrators on how to follow up with educators to maintain fidelity while using the program and how to monitor throughout the year. I could offer follow-up professional development sessions for troubleshooting or questions.

The rationale for this contribution type is that it would be the most effective method to give the information to a large number of educators. Having a discussion, role playing, and working through scenarios works best with adult learners. Adults learn "by observing and modeling others" (Merriam \& Bierema, 2014, p. 35). Adults have a profound inner need to be self-directing but may be dependent in momentary circumstances (Knowles, 1980). Educators want to improve and help students, but at times, they may not know what to do and need help from others. Personal experiences help others learn as well as it allow for reflection from the storyteller. "Through listening to participants shar[ing] their story, the power dynamic begins to shift from teachercentered to learner-centered" (Cueva, 2010, p. 84). Adults are ready to learn when there is a need to learn and to assist in coping with real-life problems. New information must be meaningful and useful as to not waste time on something that will not help the learner. Adults wish to apply gained knowledge and or skills today to be more productive tomorrow (Knowles, 1980). Professional development can embody varying modes of delivery to have a more significant impact and pull from the participants' prior experiences. Merriam and Bierema (2014) noted that using several methods of "active 
learning strategies ... create more powerful, effective learning experiences for adults" ( $p$. 125). Knowles (1980) and Merriam and Bierema (2014) suggested strategies such as lecture, group discussion, simulations, role-playing, practicing skills, and demonstrations. These strategies on life experiences as well as increase intrinsic motivation when participants practice or achieve mastery (Merriam \& Bierema, 2014). "Learning occurs when appropriate stimuli are presented and the learner is subsequently rewarded for exhibiting the desired behavior" (Merriam \& Bierema, 2014, p. 150). 


\section{Outline of the Presentation}

Executive Summary: Does Professional Development for Teachers Impact Student Behavior Utilizing Class-Wide Function-related Intervention Teams?

Statement of Problem: Inadequate professional development and students exhibiting externalizing behavior cause of loss of instruction.

Purpose of the Study: To explore how the CW-FIT impacted behaviors of elementary students. It also examined the relationship, if any, between teacher professional development of the CW-FIT and office referrals, teacher retention, and student achievement

\section{Research Questions:}

1. Does the teacher professional development for Class-Wide Function-related Intervention Teams (CW-FIT) impact student behavior in an elementary classroom?

a) in terms of praise versus reprimand ratios

b) in terms of student on-task behavior

c) in terms of student engagement

d) in terms of office discipline referrals (ODR)

2. What is the relationship between CW-FIT and student achievement?

3. Does the teacher professional development for Class-Wide Function-related Intervention Teams (CW-FIT) influence teacher retention?

4. What are the teacher perceptions of the professional development for Class-Wide Function-related Intervention Teams (CW-FIT)?

Review of the Literature/Theoretical Framework:

- Adult Learning: Cueva (2010), Knowles (1980), Merriam and Bierema (2014),

- Social Learning: Bandura (1977), Creswell (2014), Dodge, Pettit, McClaskey, Brown, and Gottman (1986), Fleming, Catalano, Oxford, and Harachi (2002), Harrington (2005), Martin, Burns, and Collie (2017), Perzigian (2018), RoseKrasnor (1997),

- Child Development: Erikson, 1950, Inhelder and Piaget (1958)

Design of Study:

- Methodology: Mixed Methods Approach

- Participants: Elementary and special education teachers

- Data Collections Tools: Survey, Interviews, and Document analysis

\section{Results}

- Survey Data

- Observation Data

○ Praise vs. Reprimand Ratios

- Summary of Engagement

- Average of on-task behavior

- Academic data

- Interviews

\section{Action Items/Discussion}

- Impact on office referrals, student achievement, student engagement, and teacher retention 
Does Professional

Development for Teachers Impact Student Behavior Utilizing the Class-Wide Function-Related Intervention Teams?

By April Phillips, ABD

University of Missouri-Columbia

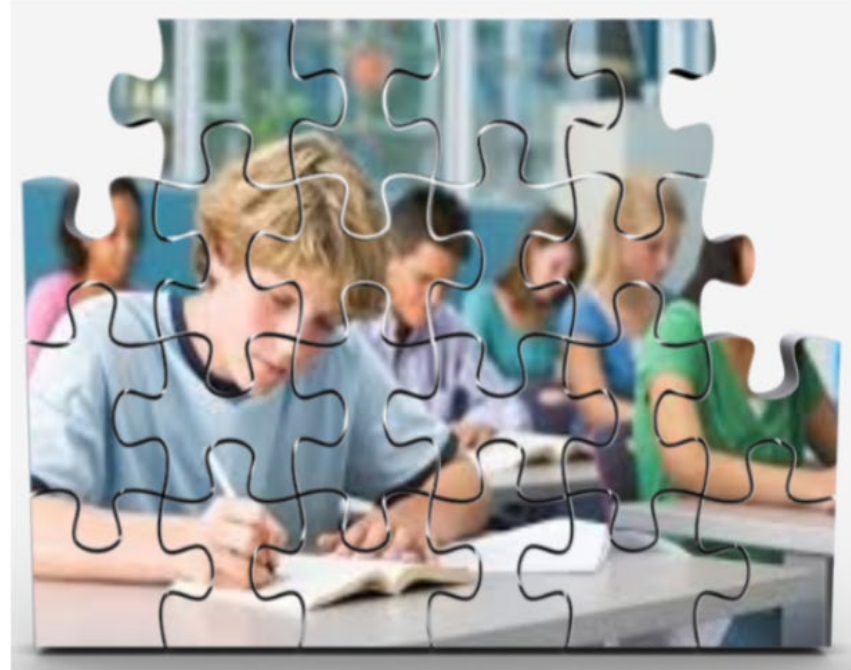

\section{Problem of Practice}

Inadequate professional development or preparedness

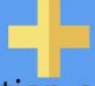

Cost of students disrupting instruction or losing instruction due to discipline

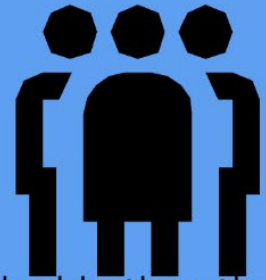

More invaluable than the monetary costs of professional development 


\section{Teachers

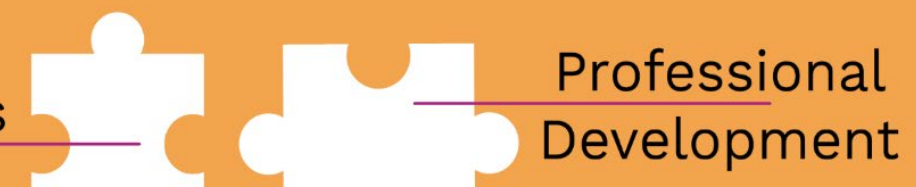

According to Greenberg, Domitrovich, Weissberg, and Durlak (2017), "evidence-based SEL [Social

Teachers experience various externalizing student behaviors often, and in a high stakes race for student achievement, they are struggling with educating all students when others are acting out, disrupting class, or lose instructional time due to discipline (disruptive students and classmates lose instructional time due to the disruption). Teachers report they are frustrated, do not know what to do with students who externalize behavior, and feel unsupported (Butler \& Monda-Amaya, 2016).

Emotional Learning] interventions in all schools-that is, universal interventions-could substantially affect public health" (p.1). These interventions can improve student's confidence in themselves; increase engagement in school, along with improving their test scores and grades; and reduce conduct problems while promoting desirable behaviors (Greenberg et al., 2017).

\section{What is CW-FIT?}

The Class-Wide Function-Related Intervention Team program (CW-FIT) was developed in 2005 by Dr. Howard Wills and Dr. Debra Kamps and the Juniper Gardens Children's Project in association with the University of Kansas

It was designed to explicitly teach and reinforce appropriate social behaviors through games in the general education setting

CW-FIT incorporates many research-based behavioral strategies including direct instruction of skills, self and peer management, extinction by removing reinforcement (i.e., withholding attention when problem behaviors occur) as well as differential reinforcement of alternative behaviors through dependent group contingencies, token economy, and teacher praise

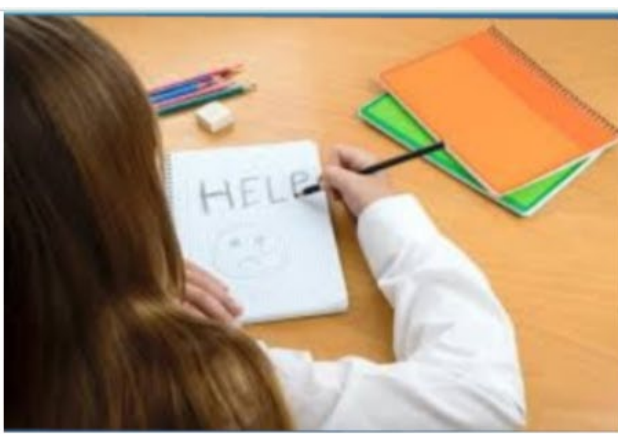

CW-FIT: https://cwfit.ku.edu/

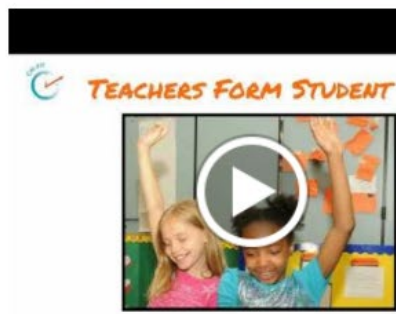




\section{CW-FIT posters/points}

1. Teach behavior expectation

2. Set reward/timer/point goal

3. Teach instructional lesson

4. At the end of lesson count points and present reward
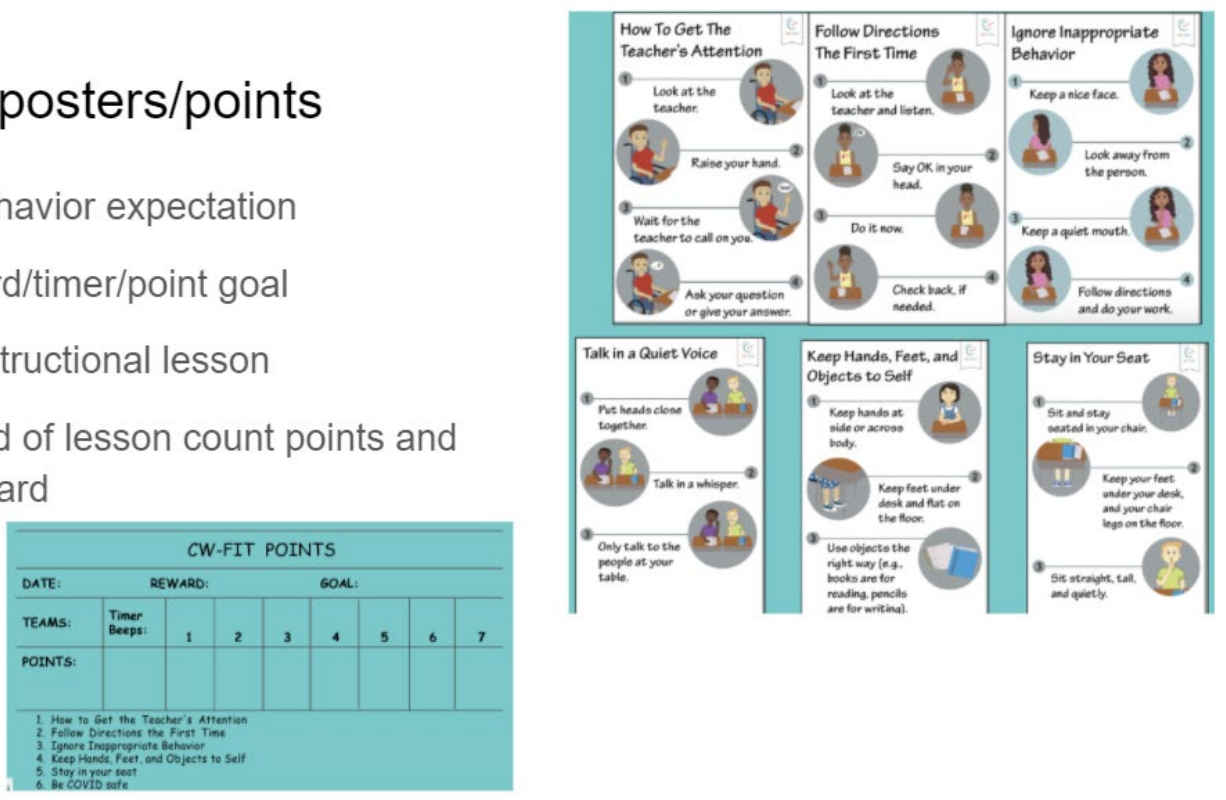

\section{Survey Results (12 teachers)}

Programs to reduce/prevent violence

$21.28 \%$ believed the school district has a formal program for behavioral or behavior modification intervention for students

$22.22 \%$ said either the district did not have or did not know if they had individual attention/mentoring/tutoring/coaching of students by students 
Behaviors seen "very often" Strategies for "noncompliance, noises,

1. Inappropriate noises $(20.69 \%)$

2. Yelling $(17.24 \%)$

3. Arguing (13.79\%)

4. Physical Aggression (13.79\%) blurting, lying"

- Ignore

- Isolate student (remove audience)

- Offer calming strategies

- Give choices

- Conference with student

- Recess consequence

- Blurt cards

- Reminders

- Redirection

- Proximity

- Remove from class

Strategies for "arguing, yelling, throwing small objects, tipping chairs, shoving desk"

Relocation

Give time to de-escalate

Offer calming strategies

Talk about ways to handle anger (after calmed down)

Parent contact

Redirection

Take break

Go to the office / Remove from class 


\section{Strategies for "tantrums, swearing, physical aggression"}

Conference with student at recess

Remove from class

Office intervention

Physical restraint

Make action plan

\section{Professional Development (PD) teachers believe the district to have}

$21.05 \%$ believed training was available in positive behavior intervention strategies (PBIS)

$18.42 \%$ believed training was available in crisis prevention and intervention $(\mathrm{CPI})$

Teachers do not think PD was available on these topics:

$21.05 \%$ - school-wide discipline policies and practices related to violence

$21.05 \%$ - in recognizing early warning signs of students likely to exhibit violent behavior

$21.05 \%$ - in interventions and referral strategies for students displaying signs of mental health disorders 


\section{Witnessing behavior}

$91.67 \%$ of those surveyed have witnessed violent or harmful behavior by students

How prepared did they feel?

$41.67 \%$ felt somewhat prepared

$33.33 \%$ felt not prepared

$16.67 \%$ felt prepared

$8.33 \%$ felt very well prepared

\section{Teachers' perspective}

The percentage of teachers surveyed that had a student that exhibited violent or harmful behavior and considered leaving the field of education... $72.72 \%$

\section{Responses:}

"I do not think it is right that teachers continue to get abused and the safety of other students are in jeopardy because of one student. It is frustrating to put up with that and nothing changes."
"Students with aggressive behaviors need teachers who are willing to find the ways that make them feel comfortable in a learning environment. Being able to adapt to this mentality keeps me in education year after year. Those students with aggressive tendencies need teachers who can adapt to their learning styles and work alongside them for the betterment of their education."
"When I have experienced violent behavior and no consequences were ever given, this frustrated me and I contemplated leaving teaching."

"I feel like these behaviors might not happen if I were better able to handle them.....and if I don't know how to handle them at this point in my career, I might not ever be able to handle them. The behaviors also seem to get worse every year." 


\section{Results}

\section{RQ1: Does the teacher professional development for Class-Wide Function-related Intervention Teams (CW-FIT) impact student behavior in elementary classroom?}

(1a) Praise vs Reprimand

The average amount of praise during the baseline observation was 2.2 . Three classrooms had zero points of praise during the baseline observation. By the final observation, teacher praise increased between 1.25 and 14 times. In some classrooms, the initial reprimand was zero, but the highest amount was six. Compared to the initial observations, praise increased in each classroom, and reprimands decreased except for two classrooms. Classroom 4 maintained the same amount of reprimands, but the praise increased by 13 times. Classroom 11 increased to two reprimands, but praise increased 12 times.

\section{Praise vs. Reprimands}

\section{Praise to Reprimand Ratios}

\begin{tabular}{lcc}
\hline Praise to Reprimand Ratios & Initial & Final \\
\hline Clasaroom 1 & $6: 4$ & $13: 1^{*}$ \\
Classroom 2 & $5: 3$ & $6: 1^{*}$ \\
Clasaroom 3 & $2: 2$ & $9: 0^{*}$ \\
Classroom 4 & $0: 6$ & $13: 6$ \\
Clasaroom 5 & $0: 5$ & $14: 3^{*}$ \\
Classroom 6 & $2: 2$ & $11: 1^{*}$ \\
Clasaroom 8 & $0: 3$ & $7: 2$ \\
Classroom 10 & $4: 0$ & $5: 1^{*}$ \\
Clasaroom 11 & $1: 0$ & $12: 2^{*}$ \\
\hline
\end{tabular}

Note: The asterisk demonstrates a ratio that is equivalent to or greater than the desired $4: 1$ ratio. Most classrooms achieved the 4:1 ratio during the observations between the initial and final data points. 


\section{Average $\%$ on-task behavior}

Percentage of on-tack behavior

\begin{tabular}{lcc}
\hline Average 96 On-Task Behavior & Initial Observation & Final Observation \\
\hline Classroom 1 & $94 \%$ & $100 \%$ \\
Classroom 2 & $78 \%$ & $99 \%$ \\
Classroom 3 & $97 \%$ & $95 \%$ \\
Classroom 4 & $78 \%$ & $99 \%$ \\
Classroom 5 & $85 \%$ & $94 \%$ \\
Classroom 6 & $63 \%$ & $100 \%$ \\
Classroom 8 & $99 \%$ & $100 \%$ \\
Classroom 10 & $91 \%$ & $100 \%$ \\
Classroom 11 & $89 \%$ & $100 \%$ \\
\hline
\end{tabular}

\section{Engagement}

The possible score for the engagement rating was zero to eight. Eight was the highest and most desired score. A score of eight demonstrated a classroom without disruptions, the teacher always reminding students of reinforcement, the teacher addressed inappropriate behavior calmly and positively, and the ratio of praise to reprimand was at least $4: 1$.

The average initial student engagement score was four. By the final observation, all but one classroom obtained a score of eight. All of the classrooms had student engagement scores increase between one and 2.7 times. The increase in student engagement became apparent as early as the second observation after the teachers received the PD. 


\section{Student Engagement}

Student Engagement

\begin{tabular}{lcc}
\hline Engagement Rating Score & Initial & Final \\
\hline Classroom 1 & 4 & 8 \\
Classroom 2 & 3 & 8 \\
Classroom 3 & 4 & 8 \\
Classroom 4 & 4 & 4 \\
Classroom 5 & 3 & 8 \\
Classroom 6 & 4 & 8 \\
Classroom 8 & 4 & 8 \\
Classroom 10 & 4 & 8 \\
Classroom 11 & 7 & 8 \\
\hline
\end{tabular}

Note: Eight was the highest and most desired score. Classroom 4 had obtained that score during two other observations, just not on the final date.

\section{Office Referrals}

Discipline reports for the school year was collected and reviewed for the teachers in the treatment and control groups. There was no direct correlation with office referrals present. Six classrooms had zero office referrals for the entire semester, and three classrooms only had one referral. Classroom 4 had two referrals and Classroom 6 had nine referrals caused by three students. The office referral data did not yield evidence to say CW-FIT had an impact on this measure. 


\section{RQ2: What is the relationship between CW-FIT and student achievement?}

- No significant main effect of the treatment $(F(1,574)=.04, p>0.05)$ with the CW-FIT treatment group for ELA and Math

RQ3. Does the teacher professional development for Class-Wide Function-related Intervention Teams (CW-FIT) influence teacher retention?

The survey occurred before the pandemic and the interviews were conducted during the pandemic. According to the survey results, $27.27 \%$ of the teachers selected "yes" they had considered leaving the field of education due to violent or harmful student behavior and $45.45 \%$ selected "maybe". When interviewed, none of the participants reported that CW-FIT would alter their consideration. 


\section{Teachers' answers}

- "It makes teaching easier but it hasn't changed my outlook. It's researched and I've seen it work" (Teacher 8, p. 6, line 182).

- They appreciated knowing and using the program as another tool.

- All the teachers noted some type of negative feeling when a student exhibited extemalizing behaviors. "[Externalizing behavior] caused instruction to stop... [there was a] loss of leaming time for the other kids" (Teacher 1, p. 4, line 123).

- $\quad$ "Tm trying to take care of [it] myself." (Teacher 11, p. 10, line 275).

- "Other students were scared of them" (Teacher 5, p. 5, line 148).

- "T have geen aggressive students, quite honestly, that scares the hell out of me... that's the one thing that I probably don't handle as well as I should" (Teacher 4, p. 20, line 464)

- "Friendships suffer and the relationships that they have with their peers kind of change" (Teacher 3, p. 3, line 92).

- "It was extremely dangerous. I had a couple of parents angry and upset" (Teacher 11, p. 20, line 572),

- "Other students were scared of them" (Teacher 5, p. 5, line 148).

- Teachers stated unanimous positive comments when asked if CWV-FIT helped with the classroom environment or student attention. They noted that students wanted to play frequently, engaged quickly, and participated more during lessons.

RQ4: What are the teacher perceptions of the professional development for Class-Wide Function-related Intervention Teams (CW-FIT)?

- Prior to CW-FIT

- Teacher 1 noted that using strategies from Kagan, teamwork, or ignoring inappropriate behaviors sometimes worked and sometimes not.

- Many teachers noted nonverbal, verbal, and tangibles (e.g. tickets, rewards) as strategies when students exhibited externalizing behavior.

- Teacher 5 noted calling administrators or special education faculty for help. 


\section{Ease of Implementation}

- Teacher 11 noted that the program was great, easy to implement, and they loved the posters.

- Teacher 5 stated that the program was "fabulous" and didn't have to stress about it.

- Teacher 3 said that it (CW-FIT) was good, detailed, and thought out and the participant felt prepared. The charts helped and it was easy to implement (Teacher 3).

- Teacher 4 reported that CW-FIT was easy to implement and the participant felt comfortable using it.

- Teacher 2 said that the PD was very good, very cut and dry, that the participant loved the visuals.

- Teacher 10 reported that the participant enjoyed it, it was super easy, and that the participant loved the charts.

\section{Impact on Teachers}

- Teacher 8 reported that CW-FIT was a good reminder to do more positive and it was easy.

- It (CW-FIT) was helpful, beneficial, and it changed how the teacher dealt with students' externalizing behaviors (Teacher 6).

- $\quad$ "I'm glad I did it" (Teacher 6, p. 5, line 141).

- Teacher 1 stated, "This would have been awesome to have as a first-year teacher" (p. 14, line 416).

- It makes teaching easier but it hasn't changed my outlook (Teacher 8).

- Teacher 2 stated that it opened up a new avenue, a new strategy that you can use in your classroom to help with students who are exhibiting behaviors that maybe you've never seen before, you don't have a strategy for. If someone is "new to education, and you just don't have a management strategy, period. This would be a great one to start with until you start, you know, figuring out what mix works for you, but then also, for each individual student" (Teacher 2, p. 10, line 318-323). 


\section{Effectiveness}

Attention

- The students had accountability with the charts and it (CW-FIT) helped student attention (Teacher 1).

- "They can get sidetracked so easy and go down a rabbit trail... we start and they get it back together" (Teacher, p. 10, lines 287-291).

- Teacher 2 stated that CW-FIT helped with student focus: students valued and respected peers' worktime, stayed quiet or stayed in their seats, got the teacher's attention correctly, and self-checked. Students' called out team members when they weren't doing the rules on the charts.

- "The CW fit helps them focus faster if they know they're going to that we're going to do CW. They're listening, they're paying attention, they're going to try to earn that point" (Teacher 4, p. 10, line 298-300).

Motivation

- Teacher 10 also stated that the students are motivated by points and tickets; even those students that don't have intrinsic motivation, they work hard for everybody else. This teacher also reported having a student with extreme behavior. He wanted to be part of a team and not as a team of 1 ; it (CW-FIT) motivated the kids.

- "I had a lot more participation in the lessons when they were doing that and.... a lot more to get to share" (Teacher 8, p. 4, line 113).

- "Kids are motivated by like when they can see, like, progress" (Teacher 10, p. 9, line 249).

- Teacher 5 stated the students were so competitive, it (CW-FIT) motivated them and saw "tremendous growth".

Class Climate

- Teacher 11 stated it (CW-FIT) made a difference in the class climate.

- Teacher 3 stated that CW-FIT made a positive difference in the class climate, increased focus, made a positive difference in students attention, "My class really liked it" (p.4, line 113). They enjoy playing the game, they use it more and for longer periods, they asked consistently to play and it keeps them on track.

\section{Teacher Reported Needs}

- The participants asked to have a follow-up session so they could collaborate.

- They wanted to discuss what rewards the other teachers used so they could increase their incentive

library, how other teachers broke up time intervals, and problem-solve tier 2 students.

- The teachers had previously used classroom management skills such as: PBIS, Kagan cooperative learning, blurt chips, loss of recess, conference with the student, behavior charts, active ignoring, clear expectations, student breaks, buddy rooms. However, the PD on CW-FIT increased the praise ratio and made them more aware of their actions.

- Participants noted that CW-FIT made them aware that they tended to use more negative approaches and it reminded them to use positive actions or remarks.

- Participants asked the researcher to provide this PD to all teachers in the district, especially new employees at the beginning of the year. Many participants stated that they wished they had this training when they started teaching. 


\section{Limitations}

- Small sample size of only nine classrooms;

- Self-reporting teachers through a survey and interviews;

- Classrooms and school were not randomly selected;

- A lack of diversity.

- In addition, the COVID-19 pandemic disrupted the study during the spring of 2020. The school district was mandated by the Governor to be closed from mid-March to the end of the academic term. This caused the study to be restarted in the fall of 2020 . Students were not allowed to be in close contact, wore masks, had dividers in-between them, could not participate in group work, or play with anyone outside their cohort.

\section{Implications for Practice}

- The findings from this study provided evidence that CW-FIT made a positive difference in student attention, engagement, and teacher praise.

- The participants noted regret for not having this information when they began teaching and wished it be made available to all new teachers. CW-FIT could be offered as additional PD across the district for consistency of teacher expectations and responses which would help students learn and use appropriate social skills faster.

- CW-FIT began with three charts for 1) how to get the teacher's attention, 2) follow directions the first time, 3) ignore inappropriate behavior. Other charts were offered to the teachers to use if necessary which included 1) staying in our seats, 2) keep hands, feet and objects to self, 3) talk in a quiet voice. In addition, the participants requested a poster to help students remember safety rules during the pandemic. The researcher made an additional chart named COVID Safety to help students remember rules of mask wearing, cleaning their desks, and social distancing.

- It is important to remember not to have too many charts and rules. Practitioners should start with one poster and build up to three main charts for everyday use. It was suggested to add special posters to address current needs, which is why the additional ones were offered.

- Also, observing and documenting troublesome times and subjects is essential before implementing CW-FIT. It is more effective to use during those times and can be played at other times as desired. The program suggests to play several times a day every day but to make sure students vote on the reward each time to continue interest. 


\section{Conclusion}

- Evidence showed the need for student behavior PD, how the CW-FIT increased student achievement through student engagement and teacher praise, and on-task behavior.

- Observation analysis demonstrated significant positive relationship with CW-FIT and teacher praise ratios, student engagement, and on-task behavior.

- CW-FIT made teachers more aware that they needed to increase the amount of praise and how to use praise effectively. During the PD, it was explained that saying "good job" or using other generic terms was not considered effective praise. It was very apparent during the observations post-PD that teachers were actively praising students. They focused on finding positives to comment on and with multiple students, but not the same students.

- It is important to note that there are often no office referrals in these grade levels due to the teachers' fear of negative administrative responses. They stated feelings of being unsupported, and when they have referred a student to the office due to discipline, they were criticized by the administration. One teacher stated that she had feared for her job due to this issue. Many felt that they have to take care of negative behaviors on their own. If they have students with an IEP, they ask for help from the special education teacher if possible. Non-disabled peers may receive support from the building counselor, but this is limited in counselor accessibility, consistency, and availability of assistance in the moment of need.

- Since the teachers did not have organized behavior intervention teams, this area seemed to be an area of need. The participating teachers liked the program so much that they asked that other district teachers, especially new employees, also receive PD on this program. 
References

Cueva, M. (2010). A living spiral of understanding: Community-based adult education. New Directions for Adult and Continuing Education, 2010 (125), 79-90. doi:10.1002/ace.364

Knowles, M. S. (1980). The modern practice of adult education: From pedagogy to andragogy. Wilton, CN: Association Press.

Merriam, S., \& Bierema, L. (2014). Adult learning: linking theory and practice. San Francisco: Jossey Bass.

Srivastava, A. \& Thomson, S. B. (2009). Framework Analysis: A Qualitative Methodology for Applied Policy Research. JOAAG, Vol. 4. No. 2

Wills, H. (n.d.) 5B - Bringing Tier 1 to Your Elementary and Middle School Classrooms$C W$-FIT. Pbismissouri.org. Retrieved from https://pbismissouri.org/wpcontent/uploads/2019/06/5B-MOPBIS-Summer-2019-CW-FIT-HANDOUT.pdf. 
SECTION FIVE: CONTRIBUTION TO SCHOLARSHIP 
Article Title: Does Professional Development for Teachers Impact Student Behavior Utilizing Class-Wide Function-Related Intervention Teams? 
I plan to submit my information to the Journal of Positive Behavior Interventions. At a later time, I plan on producing an additional article which is practitioner focused. The rationale for submitting the research to the Journal of Positive Behavior Interventions is due to several factors: (1) It is a peer-reviewed scholarly journal intended for both researchers and practitioners that work with children within a tiered continuum, (2) It expands on previous publications around the use of CW-FIT, and (3) This journal has a specific focus on expanding the knowledge and practice of effective behavioral support in schools, which is directly aligned to the purpose and outcomes of this study. 
Does Professional Development for Teachers Impact Student Behavior Utilizing Class-

\author{
Wide Function-Related Intervention Teams? \\ April Phillips \\ University of Missouri-Columbia \\ April Phillips \\ 905 W. Ivy Creek Dr. \\ Ozark, MO 65721 \\ Aap6df@gmail.com
}

Reesha Adamson, Missouri State University, radamson@missouristate.edu

James Sottile, Missouri State University, JamesSottile@missouristate.edu

Jon Turner, Missouri State University, JonSTurner@missouristate.edu

Ximena Uribe-Zarain, Missouri State University, XUribeZarain@missouristate.edu 


\begin{abstract}
Student's externalizing behaviors impact and interrupt student learning. The purpose of this study was to explore how a behavior intervention program, Class-Wide Function-related Intervention Teams (CW-FIT), within the scope of teacher professional development, can impact students' externalizing behaviors, improve teacher retention, and ultimately improve student learning. This mixed-methods study used a convergent mixed method design to explore how CW-FIT impacted the behavior of classrooms of elementary students. A correlation approach was used to examine the relationship between teacher professional development of CW-FIT and office referrals, teacher retention, and student achievement. Participants in this research study started with 12 elementary teachers and 10 classrooms. After disruption from the COVID-19 pandemic, the study continued in the fall of 2020 and included 11 teachers and nine classrooms (from third to fifth grade). Analysis of observation results, documents, and interviews, found that CW-FIT positively impacted student behavior in the participating elementary classrooms. Evidence showed the need for PD, how the CW-FIT increased student engagement and teacher praise, and on-task behavior.
\end{abstract}


Does Professional Development for Teachers Impact Student Behavior Utilizing the Class-Wide Function-Related Intervention Teams?

Elementary teachers have many responsibilities, including planning instruction, grading, analyzing student achievement data, and improving student achievement on state assessments. Students who disrupt the classroom due to externalizing behaviors can impact all of these, but more importantly, these behaviors interrupt student learning. This is a multifaceted dilemma in which the student hurts themselves, others, as well as the teacher (Pas, Bradshaw, Hershfeldt et al., 2010). A former elementary teacher in Southwest Missouri stated,

I had this student who would crawl under the table and scream, throw fits, and pretty much disrupt the learning of everyone else. I loved him, because we do. That's what teachers do, we fight for everyone to be successful. We know that there is an underlying cause and that students are not doing this to make our lives harder but are dealing with something much more difficult. But in all honesty, it drains you. It can often suck the life out of you and make you wonder if you are making a difference (S. J., personal communication, February 10, 2019).

Teachers feel ill-prepared when students have externalizing behavior which impacts other teachers and students. The cost of students disrupting instruction or losing instruction due to disciplinary actions could be argued to be more invaluable than the monetary costs of professional development. Research has shown that when teachers implement strategies or programs with fidelity, office referrals decrease (Hawken, 
MacLeod, Rawlings, 2007; Kaufman et al., 2009; Luiselli, Putnam, Handler et al., 2005).

Kaufman et al. (2009) and Luiselli et al. (2005) found when teachers had explicit professional development on preventing or de-escalating externalizing behaviors, there was a marked decrease of externalizing behaviors which would reduce the number of office referrals, increase teacher retention, and improve student achievement.

\section{The Problem}

\section{Student Behavior}

According to Cree et al. (2018), one in six U.S. children aged two-eight years (17.4\%) had a medically diagnosed mental, behavioral, or developmental disorder. These diagnosed conditions are most likely only a small percentage of the students with need within the classroom. All students with diagnosed mental, behavioral, or developmental disorders deserve a free and appropriate public education (FAPE). Externalizing behaviors often involve one or more of the following: destructive and aggressive behavior, defiance, temper tantrums, impulsive and hyperactive actions, making inappropriate noises in the classroom, blurting out, not following directions, being off task, yelling, inappropriate language, or lying (Henricsson \& Rydell, 2004; Pelco \& Reed-Victor, 2007). These behaviors can have a duration from a few minutes to hours, and their frequency can range from once a month to many episodes per day (Green, Whitney, \& Potegal, 2011; National Collaborating Centre for Mental Health, 2013). The length of duration, level of intensity, and frequency all contribute to the disruption of the classroom, learning, and stress of the teacher and students (National Collaborating Centre for Mental Health). Although teacher professional development for behavior interventions has been explored in the area of student behavior (Cook et al., 2018; Moore 
et al., 2017; Pas et al., 2010; Shook, 2012), few studies have explicitly looked at the correlation between the amount of student exhibited externalizing behaviors and the targeted professional development teachers receive for these behaviors.

\section{Teacher Perceptions}

Many times, teachers are on their own to handle the students within their classrooms that demonstrate externalizing behaviors. Zee, de Jong, and Koomen (2016) examined teacher self-efficiency and the behavior management of students with externalizing behaviors. They found that students with externalizing behavior (i.e., aggression, hyperactivity, antisocial) are the core of the daily challenges teachers face (Zee et al., 2016). Other challenges teachers experience include teacher burnout (Pas et al., 2010), loss of teaching efficacy (Klassen \& Chiu, 2010), and, most significantly, an exit from the teaching profession (Algozzine et al., 2008).

Teachers experience various externalizing student behaviors often, and in a high stakes race for student achievement, they are struggling with educating all students when others are acting out, disrupting class, or lose instructional time due to discipline (disruptive students and classmates lose instructional time due to the disruption). Teachers report they are frustrated, do not know what to do with students who demonstrate externalizing behaviors, and feel unsupported (Butler \& Monda-Amaya, 2016). These interventions can improve student's confidence in themselves; increase engagement in school, along with improving their test scores and grades; and reduce conduct problems while promoting desirable behaviors (Greenberg et al., 2017). According to Greenberg et al. (2017), children with greater social-emotional competence 
are have greater chances to be college-ready, successful in their careers, have positive relationships and healthier mental health, and become involved citizens.

\section{Intervention Programs}

Class-Wide Function-related Intervention Teams (CW-FIT) was developed in 2005 by Howard Wills and Debra Kamps and the Juniper Gardens Children's Project in association with the University of Kansas (2019). This behavior intervention program was "designed to explicitly teach and reinforce appropriate social behaviors through" (University of Missouri, 2019, p. 1) games in the general education setting. CW-FIT incorporates many research-based behavioral strategies such as: direct instruction of skills, self and peer management, extinction by removing reinforcement, differential reinforcement of alternative behaviors through dependent group contingencies, token economy, and teacher praise (University of Missouri, 2019). CW-FIT has been researched over 20 times (e.g., Jolstead, Caldarella, Hansen et al., 2017; Kamps, Wills, Dawson-Bannister et al., 2015; Speight, Whitby, \& Kucharczyk, 2020). Recent studies investigated the use of the program in differing elementary schools (Caldarella et al., 2018; Nelson et al., 2018; and Wills et al., 2018) and how the program affected student engagement, disruptive behaviors, and teacher praise. The studies did not investigate relationships between CW-FIT and academic performance or office referrals.

Wills, Wehby, Caldarella et al. (2018) wanted to replicate the first CWFIT randomized controlled trials but this study went across three states-Missouri, Utah, and Tennessee with 21 elementary schools, 155 general education teachers, and 324 students. Kindergarten through sixth-grade classrooms, including special education classrooms, were a part of the six-month study. Teachers were provided 
two hours of training, opportunities to observe modeling up to two sessions, and weekly to biweekly feedback sessions with the project staff to ensure fidelity of implementation. Tier 2 interventions were designed for students that demonstrated "more than 10 disruptive behaviors in three of five observations, did not improve engagement to $75 \% \ldots$ or received teacher input of a poor response to intervention" (Wills et al., 2018, p. 443). Data was collected through direct observations. Engagement of students in the CW-FIT group was significant; disruptive behaviors decreased significantly within the CW-FIT group, praise increased for all students, but more so for those targeted in the Tier 2 intervention, and the number of reprimands reduced, but a more significant decrease was found for students receiving Tier 2 interventions (Wills et al., 2018).

Nelson et al. (2018) researched how CW-FIT affected elementary students' ontask behavior in art classrooms. The participants were two third-grade classes and one fifth-grade class which were taught by the same instructor. The teachers were trained in two hours to implement CW-FIT with fidelity. The research team used seven to 10 direct observations to gather baseline and intervention data points for the classrooms (Nelson et al., 2018). "On-task behavior immediately improved during implementation of CW-FIT" (Nelson et al., 2018, p. 233) and overall improvement by the end of the study. Nelson et al. (2018) found that the praise to reprimand ratio increased to 4.35:1. Classroom 1 (third grade) and Classroom 2 (fifth grade) had a significant decrease in reprimands, and praise increased in Classroom 2 (Nelson et al., 2018).

Caldarella et al. (2018) conducted a randomized control trial with 149 general education teachers and 11 special education elementary school teachers in 19 schools 
across three states. Teachers identified 350 students at risk for emotional and behavioral disorders. CW-FIT was implemented for about four months and students were directly observed by trained staff. A two-hour training was presented to the teachers after baseline observations were completed. Coaches were available to give feedback for up to two weeks after training. Results presented significant improvements in social skills for the students in the treatment classrooms in comparison to those in the control classrooms. There were no significant differences in ratings of problem behaviors; however, the behaviors measured were of blaming others, taking things that belonged to others, and being overly demanding of the teacher's attention, which was different than previous studies (Caldarella et al., 2018).

Due to the stressors teachers have (Butler \& Monda-Amaya, 2016), the purpose of this study was to explore how a behavior intervention program, Class-Wide Functionrelated Intervention Teams (CW-FIT), within the scope of teacher professional development, can impact students' behaviors, improve teacher retention, and ultimately improve academic experiences in a suburban elementary school in Southwest Missouri. The mixed-methods study used a convergent mixed method design (Creswell, 2014) to explore how the CW-FIT impacted behaviors of elementary students. A correlational approach was used to examine the relationship between teacher professional development of the CW-FIT and office referrals, teacher retention, and student achievement. 


\section{Research Questions}

The research questions guiding this study were:

1. Does the teacher professional development for Class-Wide Function-related Intervention Teams (CW-FIT) impact student behavior in an elementary classroom?

a) in terms of praise versus reprimand ratios

b) in terms of student on-task behavior

c) in terms of student engagement

d) in terms of office discipline referrals (ODR)

2. What is the relationship between CW-FIT and student achievement?

3. Does the teacher professional development for Class-Wide Function-related Intervention Teams (CW-FIT) influence teacher retention?

4. What are the teacher perceptions of the professional development for ClassWide Function-related Intervention Teams (CW-FIT)?

\section{Methods}

\section{Design}

This research study was a convergent mixed method design that occurs when "qualitative and quantitative data are collected in parallel, analyzed separately, and then merged" (Creswell, 2014, p. 133). The reason for collecting both quantitative and qualitative data was to investigate the relationship, if any, between teacher professional development of the CW-FIT and office referrals, teacher retention, and student achievement. For this study, the researcher first collected survey data, observed participating classrooms prior to providing PD on CW-FIT, provided PD on CW-FIT 
only to participants, observed each classroom for fidelity in using the program, observed each classroom an additional six times, collected school and student records, and then interviewed each participant to help explain findings from survey responses.

\section{Participants}

Participants in this research study started with 12 elementary teachers and 10 classrooms. Before the Pandemic the study focused on two grade levels for a more manageable amount of data and participants (see Table 1). One of the fourth-grade classrooms was a co-taught setting, which included one general education teacher and one special education teacher. Two of the fifth-grade classes also included a special education teacher to provide co-teaching.

Table 1

Participating Teachers

\begin{tabular}{ccccc}
\hline & Third Grade & Fourth Grade & Fifth Grade & $\begin{array}{c}\text { Special } \\
\text { Education }\end{array}$ \\
\hline $2019-20$ & & 6 & 4 & 2 \\
$2020-21$ & 1 & 5 & 3 & 2 \\
\hline
\end{tabular}

Note: The number of participating teachers in each grade level.

All of the teachers were white females between the ages of late-twenties to midfifties. During the 2018-19 school year, the teachers in the elementary building had an average length of experience of 13.4 years, and 52.3\% have a Master's degree or higher (DESE, Missouri Comprehensive Data System, 2019).

After the pandemic began, the study continued in the fall of 2020 and included 11 teachers and nine classrooms. The third-grade teacher taught a fourth-grade class when the study began, and due to the positive results witnessed, the participant asked to continue in the study. One of the previous fifth-grade teachers went on maternity leave. 
This group was identified through convenience sampling (Fink, 2017) as the researcher was employed in the same building. During the 2018-19 school year, the population of the elementary school was $88 \%$ White, $6 \%$ Hispanic, and $42 \%$ receive the Free/Reduced Lunch program (DESE, Missouri Comprehensive Data System). Teachers were asked to participate by email (Appendix A) which included informed consent (Appendix B).

\section{Data Collection}

Before collecting any data, permission to conduct the study was approved through the International Review Board (IRB) at the school district and researcher's University. This study was conducted over four school quarters in a single calendar year.

\section{Survey}

A survey was completed during the third quarter. The survey was distributed through email and an online survey format using Qualtrics. The email sent to participants included information stating responses were anonymous, an option to opt-out, and a request to have the survey completed within one week.

\section{Observation Tool}

The researcher created the observation tool (Appendix G) by using portions of the Classroom Practices Observation Tool (Midwest PBIS Network and Mid-Atlantic PBIS Network, 2019) and was trained on how to use it for the study. The first portion of the tool collected data on specific behavior and praise how the teacher responded to inappropriate Behaviors. This section was used to collect praise versus reprimand ratios for each collection period. The next section collected the amount of times students were on or off task as well as teacher-given opportunities to respond. Finally, the student engagement rubric was created in combination of the "Classroom Practices Observation 
Tool" (Midwest PBIS Network and Mid-Atlantic PBIS Network, 2019) and the "Quality Rating Definitions for CW-FIT Procedural Fidelity Checklist” (University of Kansas, Elementary School Materials, 2019).

To provide a more rigorous measure of rater agreement, an Interobserver agreement (IOA) was made. This person also worked in the same elementary as the participants and had extensive training on classroom management. The agreement was made to observe the classrooms at the same time. The first observation was used as a practice and not counted in the data. The observation data was scored if a matching number was found with each opportunity (Wills et al., 2018) data collection in the same timeframe using the exact agreement method (Vollmer, Sloman, \& St Peter Pipkin, 2008). Clearly defined examples were included as quality control measures (Berman \& Vasquez, 2015). The researcher then observed each participating classroom for baseline data.

\section{Interviews}

Interviews were conducted after all observations were completed. The approximately hour-long interviews occurred after all classroom observations were complete towards the end of the first semester of the 2020-21 school year. After the researcher was granted permission to documents (discipline records, student demographic information, academic performance, and attendance), information was gathered and analyzed for patterns and trends.

\section{Archival Data}

Data were collected for all of the third through fifth grade classrooms to document the effect of CW-FIT and a control comparison. Data collected included office 
referrals for the first semester of the 2020-21 school year, discipline record details, academic performance on the Evaluate assessment for both English Language Arts (ELA) and Math, and student demographic information to analyze and triangulate the data (Nightingale \& Rossman, 2015).

\section{Instruments}

\section{Survey}

The survey (Appendix C) was designed to be a single point in time (Fink, 2017) through a cross-sectional design. The survey questions were created by the researcher based upon previously used surveys from the U.S. Department of Education \& National Center for Education Statistics (2016). It was designed for the current study and for future use in later studies. Eight quantitative survey items were closed-ended questions about behavior preventive or reduction programs, witnessed behaviors, teachers' feelings about aggressive students, training offered, consideration of leaving the education field, the average number of students in the participant's classroom, and years of experience. For example, one question asked participants "How often do you witness students exhibiting the following behaviors?" with 10 behaviors listed. Four qualitative survey items were open-ended questions about strategies used for students' externalizing behavior and why they thought about leaving the field of education or not.

\section{Pre-PD Observation}

The observation tool (Appendix G) was used to collect data simultaneously during 10-minute periods. Data collected included: teacher reactions to behavior (praise or reprimands), engagement and multiple opportunities to respond, on-task behavior, and a total student engagement rubric. The student engagement rubric had four opportunities 
to score zero, one or two points. One point could be awarded for each of the following: some disruptions but peers were not impacted, the teacher sometimes reminded students of reinforcement, some inappropriate behavior was not addressed appropriately, or praise to reprimand ratio was $3: 1$. Two points were available for: no disruptions during the observation, the teacher always reminded students of reinforcement, inappropriate behavior was addressed appropriately, and the praise to reprimand ratio was $4: 1$ or greater.

\section{School Records}

Archival data access protocols were created to document student performance which could be used in the future for replication. These protocols were used to access classroom demographic summaries, office discipline referrals (ODR), and academic performance on Evaluate. Only ODRs for events that occurred in the classroom were counted. ODRs included the following types of infractions: Disrespectful/Disruptive, Fighting, Assault (3rd-4th degree), Threat/Verbal Assault, Weapon, or Vandalism. Evaluate is a web-based formative reading and math assessment based on "national and state standards-aligned formative assessments that simulate each state's end-of-year proficiency exams" (Catapult Learning, 2021, p. 3) for ELA and Math. "Evaluate assessments employ graphic-rich technology-enhanced question types (TEQs) that challenge students to go beyond typical multiple-choice test items and interact with the question in a variety of engaging ways (Catapult Learning, 2021, p. 4). Respect for the privacy of students and participants was maintained by disassociating names when collecting data from school records, and pseudonyms were used in reporting of the data (Creswell, 2014). 


\section{Interviews}

The semi-structured interview protocol was designed to capture qualitative answers for the research questions: (3) "Does the teacher professional development for Class-Wide Function-related Intervention Teams (CW-FIT) influence teacher retention?" and (4) "What are the teacher perceptions of the professional development for ClassWide Function-related Intervention Teams (CW-FIT)?” The interview had seven questions. Topics explored included: teaching experiences; strategies used when students exhibited externalizing behavior; how teacher's felt in those situations; how behaviors impacted instruction, student achievement, class climate; perceptions regarding the PD on CW-FIT; how CW-FIT impacted their classroom, student attention, behavior, outlook on teaching career; and what support the teachers perceived they needed to continue using CW-FIT. The approximately hour-long interviews occurred after all classroom observations were complete towards the end of the first semester of the 2020-21 school year.

\section{Procedures}

\section{PD}

After initial observations were complete, the participants received professional development on CW-FIT from the trained researcher. The PD took place after school and lasted approximately two hours. Participants were given handouts, CW-FIT student behavior expectation posters, class scoring posters, video demonstrations, and the opportunity to ask questions.

\section{Post-PD Observations}


The researcher observed participating classrooms to check for fidelity of implementation of the intervention. After an initial fidelity check, six more observations were scheduled randomly during teacher-reported troublesome times. At this point the Covid-19 pandemic took place forcing a close in the schools and a halt to the project. When school began again in the Fall of 2020, the participating teachers were observed again for baseline data. Then the teachers were given a refresher course of CW-FIT, fidelity checks were completed, and six more observations were completed by the end of the second quarter during the 2020-21 school year.

\section{Data Analysis}

The quantitative data included observations, academic performance data (Evaluate assessments for ELA and Math), and survey items. These data were used to explore the social competence theory (Dodge et al., 1986; Perzigian, 2018; Rose-Krasnor, 1997) to determine if teacher professional development positively influenced student achievement and student behavior in the classroom. The qualitative data explored the perception teachers have about adequate professional development for behaviors in the classroom and teacher retention through a survey and individual interviews. Participants were encouraged to follow up with the researcher for feedback or questions.

\section{Teacher Measures}

The survey items, achievement data, and observation information were entered into IBM's Statistical Package for the Social Sciences (SPSS) for organizing the data, producing counts and frequency distributions, and statistical analysis when appropriate. Qualitative data were coded to determine common themes related to the teachers' knowledge of what strategies worked best for students externalizing behaviors and if the 
participant has considered leaving the field of education. Quantitative and qualitative questions were to answer the following research question: (3) "Does the teacher professional development for Class-Wide Function-related Intervention Teams (CW-FIT) influence teacher retention?"

The researcher used the Framework Method (Srivastava \& Thomson, 2009) through semi-structured interviews and a contextual category system. In this approach to qualitative data analysis the data are filtered, charted, and arranged under key issues and themes. Then the procedure calls for: familiarization; identifying a thematic framework; indexing; charting; and mapping and interpretation.

\section{Classroom Measures}

Classrooms were observed to answer the research question: (1) "Does the teacher professional development for Class-Wide Function-related Intervention Teams (CW-FIT) impact student behavior in an elementary school?" The researcher analyzed the observational data by looking for frequency, duration, and severity of behaviors pre- and post-intervention. In this case frequency distributions were produced.

In the case of the engagement data, the Wilcoxon test was used. The Wilcoxon signed-rank test is a nonparametric test that is similar to a dependent t-test. Since the Wilcoxon signed-rank test does not assume normality on the distribution of scores, it can be used when the dependent t-test is not suitable. This test is used to compare two groups of scores from the same group of participants. A pre- and post-test is an appropriate situation for the Wilcoxon signed-rank test because the engagement score is a continuous variable and there were two related categorical groups (pre- and post-treatment). 


\section{Student Measures}

To answer the research question, (2) "What is the relationship between CW-FIT and student achievement?", the researcher analyzed student academic performance data (Evaluate for ELA and Math). The data by student were entered in SPSS and were categorized by classroom where the teachers was part of the CW-FIT professional development (treatment group) or where the teacher was not (control group. A couple of two-way ANOVAS were used to investigate the relationship between the ELA and Math scores and whether teachers received the CW-FIT professional development or not.

\section{Results}

\section{RQ1: Does the teacher professional development for Class-Wide Function-related Intervention Teams (CW-FIT) impact student behavior in elementary classroom?}

\section{(1a) Praise vs Reprimand}

To explore the ratio of praise to reprimand, each classroom was observed during 10-minute periods. The researcher created and used an observation tool and interval recording for each time the teacher used one of the following reactions to behavior: General praise for behavior, Specific praise for behavior, Corrections to inappropriate behavior, and Specific correction to inappropriate behavior. The tally marks were added and then a final ratio of praise versus reprimands (corrections) was documented (see Table 2).

The average amount of praise during the baseline observation was 2.2. Three classrooms had zero points of praise during the baseline observation. By the final observation, teacher praise increased between 1.25 and 14 times. In some classrooms, the initial reprimand was zero, but the highest amount was six. Compared to the initial 
observations, praise increased in each classroom, and reprimands decreased except for two classrooms. Classroom 4 maintained the same amount of reprimands, but the praise increased by 13 times. Classroom 11 increased to two reprimands, but praise increased 12 times.

Table 2.

Praise to Reprimand Ratios

\begin{tabular}{lcc}
\hline Praise to Reprimand Ratios & Initial & Final \\
\hline Classroom 1 & $6: 4$ & $13: 1^{*}$ \\
Classroom 2 & $5: 3$ & $6: 1^{*}$ \\
Classroom 3 & $2: 2$ & $9: 0^{*}$ \\
Classroom 4 & $0: 6$ & $13: 6$ \\
Classroom 5 & $0: 5$ & $14: 3^{*}$ \\
Classroom 6 & $2: 2$ & $11: 1^{*}$ \\
Classroom 8 & $0: 3$ & $7: 2$ \\
Classroom 10 & $4: 0$ & $5: 1^{*}$ \\
Classroom 11 & $1: 0$ & $12: 2^{*}$ \\
\hline
\end{tabular}

Note: The asterisk demonstrates a ratio that is equivalent to or greater than the desired $4: 1$ ratio. Most classrooms achieved the 4:1 ratio during the observations between the initial and final data points.

\section{(1b) On-task Behavior}

To examine on-task behavior, each classroom was observed during 10-minute periods using interval recording. The researcher created and used an observation tool during two-minute intervals, tally marks were made if any student in the classroom was off-task at any time during the two-minute interval. The tally marks were added for each interval. This number was subtracted from the total number of students in the classroom during the observation. The five intervals were then averaged for the observation (see Table 3). 
The percentage of on-task behavior for students ranged from $63 \%$ to $99 \%$ during the initial observation. The average initial percentage of on-task behavior was $86 \%$. Compared to the initial and the final observation, the percentage of student on-task behavior increase between 0.98 and 1.59 times. During the final observation, five classrooms had 100\% student on-task behavior. The remaining classrooms all had improvement with percentages of students on-task behavior between $94 \%$ and $99 \%$.

Table 3.

Percentage of on-task behavior

\begin{tabular}{lcc}
\hline Average \% On-Task Behavior & Initial Observation & Final Observation \\
\hline Classroom 1 & $94 \%$ & $100 \%$ \\
Classroom 2 & $78 \%$ & $99 \%$ \\
Classroom 3 & $97 \%$ & $95 \%$ \\
Classroom 4 & $78 \%$ & $99 \%$ \\
Classroom 5 & $85 \%$ & $94 \%$ \\
Classroom 6 & $63 \%$ & $100 \%$ \\
Classroom 8 & $99 \%$ & $100 \%$ \\
Classroom 10 & $91 \%$ & $100 \%$ \\
Classroom 11 & $89 \%$ & $100 \%$ \\
\hline
\end{tabular}

\section{(1c) Student Engagement}

Student engagement was studied by observing classrooms during 10-minute periods. The researcher used an observation tool with an engagement rubric. The classroom received a zero for: Disruptions that impacted peers' ability to learn, teacher never reminding student of reinforcement, most inappropriate behavior not addressed in an appropriate manner, or a praise to reprimand ratio of 2:1 or less.

The highest student engagement score possible for a classroom was an eight. Every participating classroom had an initial score of less than eight. All but one class had 
a score of three or four. The average initial student engagement score was four. By the final observation, all but one classroom obtained a score of eight. All of the classrooms had student engagement scores increase between one and 2.7 times. The increase in student engagement became apparent as early as the second observation after the teachers received the PD (see Table 4).

Table 4.

Student Engagement

\begin{tabular}{lcc}
\hline Engagement Rating Score & Initial & Final \\
\hline Classroom 1 & 4 & 8 \\
Classroom 2 & 3 & 8 \\
Classroom 3 & 4 & 8 \\
Classroom 4 & 4 & 4 \\
Classroom 5 & 3 & 8 \\
Classroom 6 & 4 & 8 \\
Classroom 8 & 4 & 8 \\
Classroom 10 & 7 & 8 \\
Classroom 11 & 4 & 8 \\
\hline
\end{tabular}

Note: Eight was the highest and most desired score. Classroom 4 had obtained that score during two other observations, just not on the final date.

\section{(1d) Office Referrals}

Discipline reports for the school year was collected and reviewed for the teachers in the treatment and control groups. There was no direct correlation with office referrals present. Six classrooms had zero office referrals for the entire semester, and three classrooms only had one referral. Classroom 4 had two referrals and Classroom 6 had nine referrals caused by three students. The office referral data did not yield evidence to say CW-FIT had an impact on this measure.

\section{RQ2: What is the relationship between CW-FIT and student achievement?}


To answer the second research question, the use of a two-way ANOVAS were used to investigate the relationship between the ELA and Math scores and use of CWFIT. The two next tables display the descriptive statistics of the ELA and math Evaluate scores in both groups of classrooms. The control group included eight classrooms (five from grade 3 and three from grade 5) and the treatment group included nine classrooms (one from grade3, five from grade4, and three from grade 5). The scores of all available students were included in the analyses. The initial time was in the first quarter of the 2020-21 school year and the final assessment was in the fourth quarter. All data was collected after the intervention had been completed (see Tables 5 and 6).

Table 5.

Descriptive statistics for the ELA Evaluate scores

\begin{tabular}{ccccc} 
Treatment & Time & Mean & Std. Dev & $\mathrm{N}$ \\
\hline \multirow{3}{*}{ Control group } & Initial & 48.23 & 18.315 & 123 \\
& Final & 63.48 & 19.958 & 137 \\
& Total & 56.27 & 20.625 & 260 \\
\hline \multirow{3}{*}{ Treatment group } & Initial & 49.89 & 18.034 & 145 \\
& Final & 62.48 & 19.818 & 173 \\
& Total & 56.74 & 20.007 & 318 \\
\hline & Initial & 49.13 & 18.148 & 268 \\
Total & Final & 62.92 & 19.854 & 310 \\
& Total & 56.53 & 20.271 & 578 \\
\hline
\end{tabular}

The results of the two-way ANOVA for ELA Evaluate score showed that there was no significant main effect of the treatment $(F(1,574)=.04, p>0.05)$ with the $\mathrm{CW}$ FIT treatment group $(M=56.74 ; S D=20.01)$ and the control group $(M=56.27 ; S D$ $=20.63$ ) producing similar scores. In contrast, there was a significant main effect of Time on scores $(F(1,574)=75.59, p<0.001)$. Students in the initial observation performed significantly worse $(M=49.0613, S D=18.15)$ than in the final observation $(M=62.92$, $S \mathrm{D}=19.85)$. In addition, no significant interaction was found between the two variables 
$(F(1,574)=0.694, p>0.05)$. These findings suggest that scores increased from the initial observation to the final, and that this improvement is similar for classrooms with teachers in the CW-FIT group and those teachers who are not (see Table 7).

The results of the two-way ANOVA for Math Evaluate scores indicated that there was no significant main effect of the treatment $(F(1,573)=1.26, p>0.05)$ with the CWFIT treatment group $(\mathrm{M}=48.42 ; \mathrm{SD}=20.96)$ and the control group $(M=49.837 ; S D$ $=21.08)$ producing similar scores. In contrast, there was a significant main effect of Time on scores $(F(1,573)=192.39, p<0.001)$. Students in the initial observation performed significantly worse $(M=38.12, S D=17.24)$ than in the final observation $(M=59.67, S D$ $=18.79)$. In addition, no significant interaction was found between the two variables $(F(1,573)=2.87, p>0.05)$. These findings suggest that scores increased from the initial observation to the final, and that this improvement is similar for classrooms with teachers in the CW-FIT group and those teachers who are not (see Table 8).

Table 6.

Descriptive statistics for the Math Evaluate scores

\begin{tabular}{lcccc} 
Treatment & Time & Mean & Std. Dev & $\mathrm{N}$ \\
\hline \multirow{3}{*}{ Control group } & Initial & 40.48 & 18.421 & 124 \\
& Final & 59.18 & 19.411 & 125 \\
& Total & 49.87 & 21.081 & 249 \\
\hline \multirow{3}{*}{ Treatment group } & Initial & 36.16 & 15.998 & 150 \\
& Final & 60.06 & 18.340 & 158 \\
& Total & 48.42 & 20.961 & 308 \\
\hline \multirow{3}{*}{ Total } & Initial & 38.12 & 17.240 & 274 \\
& Final & 59.67 & 18.792 & 283 \\
& Total & 49.07 & 21.008 & 557 \\
\hline
\end{tabular}


Table 7.

Two-way ANOVA table for ELA Evaluate scores

\begin{tabular}{lcccc}
\hline \multicolumn{1}{r}{ Source } & $d f$ & MS & $F$ & $p$ \\
\hline Treatment & 1 & 15.500 & .042 & .837 \\
Time & 1 & 27584.639 & 75.585 & .000 \\
Treatment*Time & 1 & 252.502 & .692 & .406 \\
Error & 574 & 364.946 & & \\
\hline
\end{tabular}

Table 8 .

Two-way ANOVA table for Math Evaluate scores

\begin{tabular}{lcccc}
\hline \multicolumn{1}{c}{ Source } & $d f$ & MS & $F$ & $p$ \\
\hline Treatment & 1 & 407.897 & 1.257 & .263 \\
Time & 1 & 62416.110 & 192.393 & $<.001$ \\
Treatment*Time & 1 & 932.210 & 2.873 & .091 \\
Error & 553 & 324.419 & & \\
\hline
\end{tabular}

Attendance

Archival analysis did not demonstrate any correlation between CW-FIT and attendance. The average attendance rate for each classroom was approximately $97 \%$. Each class size was similar, and all but one had students with an IEP or were an ELL. There was a much higher mobility rate in the building used in the study than in the entire district and in Missouri.

\section{RQ3. Does the teacher professional development for Class-Wide Function-related Intervention Teams (CW-FIT) influence teacher retention?}

To answer the third research question, the participants were asked in the survey if they had ever considered leaving the education field and asked during the interview if CW-FIT changed their outlook. The survey occurred before the pandemic and the interviews were conducted during the pandemic. According to the survey results, $27.27 \%$ 
of the teachers selected "yes" they had considered leaving the field of education due to violent or harmful student behavior and $45.45 \%$ selected "maybe". When interviewed, none of the participants reported that CW-FIT would alter their consideration (Appendix I). "It makes teaching easier but it hasn't changed my outlook. It's researched and I've seen it work" (Teacher 8, p. 6, line 182). They appreciated knowing and using the program as another tool. The most significant finding that demonstrated an impact with teachers was found in the interviews. All the teachers noted some type of negative feeling when a student exhibited externalizing behaviors. "[Externalizing behavior] caused instruction to stop...[there was a] loss of learning time for the other kids" (Teacher 1, p. 4, line 123). "I'm trying to take care of [it] myself." (Teacher 11, p. 10, line 275). "Other students were scared of them" (Teacher 5, p. 5, line 148). "I have seen aggressive students, quite honestly, that scares the hell out of me... that's the one thing that I probably don't handle as well as I should" (Teacher 4, p. 20, line 464). The severity level of the behavior impacted both how prepared the teacher felt and how the teacher worked through the situation. The teachers felt as if students lost instruction and it impacted student learning but reported they did not have the data to support that claim. When students exhibited externalizing behavior, the class climate changed. Each teacher noted it either negatively impacted relationships between the students, teacher, or students' parents. "Friendships suffer and the relationships that they have with their peers kind of change" (Teacher 3, p. 3, line 92). "It was extremely dangerous. I had a couple of parents angry and upset" (Teacher 11, p. 20, line 572). "Other students were scared of them" (Teacher 5, p. 5, line 148). Teachers stated unanimous positive comments when asked if CW-FIT helped with the classroom environment or student attention. They noted that 
students wanted to play frequently, engaged quickly, and participated more during lessons.

\section{RQ4: What are the teacher perceptions of the professional development for Class- Wide Function-related Intervention Teams (CW-FIT)?}

To answer the fourth research question, the participants were asked during the interview what their perceptions were of CW-FIT. Teachers expressed frustration that they did not have the knowledge or tools to reach students that misbehaved and caused disruptions in the classroom before the CW-FIT PD (Appendix I). Teacher 1 noted that using strategies from Kagan, teamwork, or ignoring inappropriate behaviors sometimes worked and sometimes not. Many teachers noted nonverbal, verbal, and tangibles (e.g. tickets, rewards) as strategies when students exhibited externalizing behavior. Teacher 5 noted calling administrators or special education faculty for help.

\section{Ease of Implementation}

Teacher 11 noted that the program was great, easy to implement, and they loved the posters. Teacher 5 stated that the program was "fabulous" and didn't have to stress about it. Teacher 3 said that it (CW-FIT) was good, detailed, and thought out and the participant felt prepared. The charts helped and it was easy to implement (Teacher 3). Teacher 4 reported that CW-FIT was easy to implement and the participant felt comfortable using it. Teacher 2 said that the PD was very good, very cut and dry, that the participant loved the visuals. Lastly, Teacher 10 reported that the participant enjoyed it, it was super easy, and that the participant loved the charts. 


\section{Impact on Teachers}

Teacher 8 reported that CW-FIT was a good reminder to do more positive and it was easy. It (CW-FIT) was helpful, beneficial, and it changed how the teacher dealt with students' externalizing behaviors (Teacher 6). "I'm glad I did it" (Teacher 6, p. 5, line 141). Teacher 1 stated, "This would have been awesome to have as a first-year teacher" (p. 14, line 416). It makes teaching easier but it hasn't changed my outlook (Teacher 8). Teacher 2 stated that it opened up a new avenue, a new strategy that you can use in your classroom to help with students who are exhibiting behaviors that maybe you've never seen before, you don't have a strategy for. If someone is "new to education, and you just don't have a management strategy, period. This would be a great one to start with until you start, you know, figuring out what mix works for you, but then also, for each individual student" (Teacher 2, p. 10, line 318-323). Teacher 4 stated CW-FIT was easy to implement and was comfortable using it.

\section{Effectiveness}

Attention. The students had accountability with the charts and it (CW-FIT) helped student attention (Teacher 1). "They can get sidetracked so easy and go down a rabbit trail...we start and they get it back together" (Teacher, p. 10, lines 287-291). Teacher 2 stated that CW-FIT helped with student focus: students valued and respected peers' worktime, stayed quiet or stayed in their seats, got the teacher's attention correctly, and self-checked. Students' called out team members when they weren't doing the rules on the charts (Teacher 2). "The CW fit helps them focus faster if they know they're going to that we're going to do CW. They're listening, they're paying attention, they're going to try to earn that point" (Teacher 4, p. 10, line 298-300). 
Motivation. Teacher 10 also stated that the students are motivated by points and tickets; even those students that don't have intrinsic motivation, they work hard for everybody else. This teacher also reported having a student with extreme behavior. He wanted to be part of a team and not as a team of 1 ; it (CW-FIT) motivated the kids (Teacher 10). "I had a lot more participation in the lessons when they were doing that and.... a lot more to get to share" (Teacher 8, p. 4, line 113). "Kids are motivated by like when they can see, like, progress" (Teacher 10, p. 9, line 249). Teacher 5 stated the students were so competitive, it (CW-FIT) motivated them and saw "tremendous growth".

Class Climate. Teacher 11 stated it (CW-FIT) made a difference in the class climate. Teacher 3 stated that CW-FIT made a positive difference in the class climate, increased focus, made a positive difference in students' attention, "My class really liked it" (p.4, line 113). They enjoy playing the game, they use it more and for longer periods, they asked consistently to play and it keeps them on track (Teacher 3).

\section{Teacher Reported Needs.}

The participants asked to have a follow-up session so they could collaborate. They wanted to discuss what rewards the other teachers used so they could increase their incentive library, how other teachers broke up time intervals, and problem-solve tier 2 students. The teachers had previously used classroom management skills such as: PBIS, Kagan cooperative learning, blurt chips, loss of recess, conference with the student, behavior charts, active ignoring, clear expectations, student breaks, buddy rooms. However, the PD on CW-FIT increased the praise ratio and made them more aware of their actions. Participants noted that CW-FIT made them aware that they tended to use 
more negative approaches and it reminded them to use positive actions or remarks.

Participants asked the researcher to provide this PD to all teachers in the district, especially new employees at the beginning of the year. Many participants stated that they wished they had this training when they started teaching.

\section{Limitations}

Limitations of this study are the small sample size of only nine classrooms; selfreporting teachers through a survey and interviews; the classrooms and school were not randomly selected; and a lack of diversity. In addition, the COVID-19 pandemic disrupted the study during the spring of 2020. The school district was mandated by the Governor to be closed from mid-March to the end of the academic term. This caused the study to be restarted in the fall of 2020. Students were not allowed to be in close contact, wore masks, had dividers in-between them, could not participate in group work, or play with anyone outside their cohort.

\section{Implications for Research}

This study revealed the opportunity for future research to further the evidence of effectiveness of CW-FIT. Due to the small population of participants, similar studies could be conducted at larger buildings, different grade levels, and across buildings in districts. Long-term studies could determine the impact on academic achievement and ODRs. Further research could be used in the effectiveness with self-managers or Tier 2 students. In addition, researching teachers over time could help determine impact on teacher retention if continued use and effective implementation did reduce student externalizing behavior which in turn improves the class climate and teacher efficacy. 


\section{Implications for Practice}

The findings from this study provided evidence that CW-FIT made a positive difference in student attention, engagement, and teacher praise. The participants noted regret for not having this information when they began teaching and wished it be made available to all new teachers. CW-FIT could be offered as additional PD across the district for consistency of teacher expectations and responses which would help students learn and use appropriate social skills faster. CW-FIT began with three charts for 1) how to get the teacher's attention, 2) follow directions the first time, 3) ignore inappropriate behavior. Other charts were offered to the teachers to use if necessary which included 1) staying in our seats, 2) keep hands, feet and objects to self, 3) talk in a quiet voice. In addition, the participants requested a poster to help students remember safety rules during the pandemic. The researcher made an additional chart named COVID Safety to help students remember rules of mask wearing, cleaning their desks, and social distancing. It is important to remember not to have too many charts and rules. Practitioners should start with one poster and build up to three main charts for everyday use. It was suggested to add special posters to address current needs, which is why the additional ones were offered. Also, observing and documenting troublesome times and subjects is essential before implementing CW-FIT. It is more effective to use during those times and can be played at other times as desired. The program suggests to play several times a day every day but to make sure students vote on the reward each time to continue interest.

\section{Conclusion}

Analysis of observation results, documents, and interviews, found that CW-FIT positively impacted student behavior in the participating elementary classrooms. 
Evidence showed the need for student behavior PD, how the CW-FIT increased student achievement through student engagement and teacher praise, and on-task behavior. Observation analysis demonstrated significant positive relationship with CW-FIT and teacher praise ratios, student engagement, and on-task behavior.

CW-FIT made teachers more aware that they needed to increase the amount of praise and how to use praise effectively. During the PD, it was explained that saying "good job" or using other generic terms was not considered effective praise. It was very apparent during the observations post-PD that teachers were actively praising students. They focused on finding positives to comment on and with multiple students, but not the same students. The observer noted that all the participants increased how often they responded to students with explicit notations of expected behavior. The teachers commented on how specific students or groups demonstrated skills depicted on the charts. Students visibly postured to demonstrate similar skills after teachers remarked about other students.

It is important to note that there are often no office referrals in these grade levels due to the teachers' fear of negative administrative responses. They stated feelings of being unsupported, and when they have referred a student to the office due to discipline, they were criticized by the administration. One teacher stated that she had feared for her job due to this issue. Many felt that they have to take care of negative behaviors on their own. If they have students with an IEP, they ask for help from the special education teacher if possible. Non-disabled peers may receive support from the building counselor, but this is limited in counselor accessibility, consistency, and availability of assistance in the moment of need. 
Since the teachers did not have organized behavior intervention teams, this area seemed to be an area of need. The participating teachers liked the program so much that they asked that other district teachers, especially new employees, also receive PD on this program.

\section{Discussion}

The theory of social competence includes self-awareness, self-management, social awareness, relationship skills, and responsible decision-making which are included in the characteristics of SEL according to CASEL (2019): self-awareness, self-management, responsible decision-making, relationship skills, and social awareness (CASEL, 2019, Core-Competencies section; Greenberg et al., 2017). This study sought information on whether CW-FIT would impact these characteristics in students and teachers through investigating teacher praise, perceptions, and student on-task behavior and engagement in class.

As suspected, teachers reported students' relationships were affected when they exhibited externalizing behavior and according to Henricsson and Rydell (2004), these children could have more teacher conflicts and the relationships could be affected longterm. According to Greenberg, Domitrovich, Weissberg, et al. (2017) using evidencebased SEL programs can improve children's self-confidence; increase their participation in school, along with their academics; and reduce conduct problems while helping desired behaviors. "Students who demonstrate school-valued prosocial behaviors (e.g., attentive listening or cooperating) are typically regarded as socially competent and are thus more likely to gain peer and teacher approval” (Perzigian, 2018, p. 2). Cyclical components of social competence include self-awareness, self-management, social 
awareness, relationship skills, and responsible decision-making (Greenberg et al., 2017)

as well as 'judgments by peers about the child's behavior and peers' behavior toward the child" (Dodge et al., 1986, p.3).

CW-FIT explicitly taught and reinforced appropriate social behaviors through games in the general education setting (University of Missouri, 2019). It made a positive difference in the participating classrooms by increasing student engagement, teacher praise, and student attention. There were notable differences in the class climate according to the participants. The program helped increase teacher praise by as much as 14 times. The students even begged the teachers to "play" more often. It was versatile enough to cross over different grade levels without any adaptations. Student academic achievement was observed in multiple areas and through various assessments. The teachers loved the ease, flexibility, and functionality of the program. The greatest increase was in the district-wide assessment, Evaluate. The amount of time students were on-task increased 13 percentage points for all but one classroom. The classroom engagement scores all increased significantly. This program made a difference and the teachers want others to have the same information. Best of all, this program is free and can be used in any grade level.

\section{Challenges}

The beginning of the study started during the second semester of the 2019-20 school year. Teachers noted that CW-FIT was starting to demonstrate positive impacts after only a few weeks before the Pandemic occurred. Nevertheless, starting a new program during this time was difficult as classroom expectations and routines were already established for over five months. The governor mandated the school district to be 
closed from mid-March to the end of the academic term, which resulted in the study being stopped. During the fall of 2020, the teachers had extra challenges from the Pandemic. Students were not allowed to be close, had to wear masks, and had to limit group interactions. Additionally, they had plastic barriers on top of their desks if two students sat at the same table. Teachers had the added stress of having to clean desks and surfaces often. Teaching while wearing a mask or shield complicated communication to students and understanding comments from students. 


\section{References}

Algozzine, K., Christian, C., Marr, M. B., McClanahan, T., \& White, R. (2008).

Demography of problem behavior in elementary

schools. Exceptionality, 16(2), 93-104. doi:10.1080/09362830801981369

Berman, B. J. C., \& Vasquez, V. (2015). Using ratings by trained observers. In K. E. Newcomer, H. P. Hatry, \& J. S. Wholey (Eds.). (2015). Handbook of practical program evaluation, 412-444. Hoboken, NJ: John Wiley \& Sons.

Butler, A., \& Monda-Amaya, L. (2016). Preservice teachers' perceptions of challenging behavior. Teacher Education and Special Education, 39(4), 276-292.

Caldarella, P., Larsen, R. A. A., Williams, L., Wills, H., Kamps, D., \& Wehby, J. H. (2018). Effects of CW-FIT on Teachers' Ratings of Elementary School Students at Risk for Emotional and Behavioral Disorders. Journal of Positive Behavior Interventions, 20(2), 78-89. doi:10.1177/1098300717723353

Catapult Learning. (2020). Assessment for the next generation. Retrieved from http://catapultlearning.com/wp-content/uploads/2018/08/CL15182_EvaluateOverview-Brochure.pdf

Cook, C. R., Coco, S., Zhang, Y., Fiat, A. E., Duong, M. T., Renshaw, T. L., Long, A. C., Frank, S., \& Curby, T. (2018). Cultivating positive teacher-student relationships: preliminary evaluation of the establish-maintain-restore (EMR) method. School Psychology Review, 47(3), 226-243. doi:10.17105/SPR-2017-0025.V47-3

Cree, R. A., Bitsko, R. H., Robinson, L. R., Holbrook, J. R., Danielson, M. L., Smith, C., Kaminski, J. W., Kenney, M. K., \& Peacock, G. (2018). Health care, family, and community factors associated with mental, behavioral, and developmental 
disorders and poverty among children aged 2-8 years — United States, 2016.

Morbidity and Mortality Weekly Report, 67(50), 1377-1383.

doi:10.15585/mmwr.mm6750a1External

Creswell, J. W. (2014). Research design: Qualitative, quantitative, and mixed methods approaches (4th ed.). Thousand Oaks: Sage.

Dodge, K., Pettit, G., McClaskey, C., Brown, M., \& Gottman, J. (1986). Social competence in children. Monographs of the Society for Research in Child Development, 51(2), I-85. doi:10.2307/1165906

Fink, A. (2017). How to conduct surveys: A step-by-step guide (6th ed.). Thousand Oaks, CA: Sage.

Green, J. A., Whitney, P. G., \& Potegal, M. (2011). Screaming, yelling, whining, and crying: Categorical and intensity differences in vocal expressions of anger and sadness in children's tantrums. Emotion, 11(5), 1124-1133. doi: $10.1037 / \mathrm{a} 0024173$

Greenberg, M. T., Domitrovich, C. E., Weissberg, R. P., \& Durlak, J. A. (2017). Social and emotional learning as a public health approach to education. Future of Children, 27(1), 13-32.

Hawken, L. S., MacLeod, K. S., \& Rawlings, L. (2007). Effects of the "behavior education program" (BEP) on office discipline referrals of elementary school students. Journal of Positive Behavior Interventions, 9(2), 94-101.

Henricsson, L., \& Rydell, A. M. (2004). Elementary school children with behavior problems: Teacher-child relations and self-perception. A Prospective Study. Merrill-Palmer Quarterly, 50, 111-138. doi:10.1353/mpq.2004.0012. 
Jolstead, K. A., Caldarella, P., Hansen, B., Korth, B. B., Williams, L., \& Kamps, D. (2017). Implementing Positive Behavior Support in Preschools: An Exploratory Study of CW-FIT Tier 1. Journal of Positive Behavior Interventions, 19(1), 4860. https://doi.org/10.1177/1098300716653226

Kamps, D., Wills, H., Dawson-Bannister, H., Heitzman-Powell, L., Kottwitz, E., Hansen, B., \& Fleming, K. (2015). Class-Wide Function-related Intervention Teams “CWFIT” Efficacy Trial Outcomes. Journal of Positive Behavior Interventions, 17(3), 134-145. https://doi.org/10.1177/1098300714565244

Kaufman, J. S., Jaser, S. S., Vaughan, E. L., Reynolds, J. S., Di Donato, J., Bernard, S. N., \& Hernandez-Brereton, M. (2009). Patterns in office referral data by grade, race/ethnicity and gender. Journal of Positive Behavior Interventions, 12(1), 4454. doi:10.1177/1098300708329710

Klassen, R. M., \& Chiu, M. M. (2010). Effects on teachers' self-efficacy and job satisfaction: Teacher gender, years of experience, and job stress. Journal of Educational Psychology, 102(3), 741-756. doi:10.1037/a0019237

Luiselli, J. K., Putnam, R. F., Handler, M. W., \& Feinberg, A. B. (2005). Whole-school positive behaviour support: Effects on student discipline problems and academic performance. Educational Psychology, 25(2-3), 183-198.

Midwest PBIS Network and Mid-Atlantic PBIS Network (2019). Classroom Practices -. Retrieved from http://www.midwestpbis.org/materials/classroom-practices Missouri Department of Elementary and Secondary Education (DESE). (2019). Missouri Comprehensive Data System. Retrieved from https://apps.dese.mo.gov/MCDS/home.aspx 
Missouri Department of Elementary and Secondary Education (DESE). (2018). Statistics: October 2018 Free \& Reduced Percentages of Enrollment (includes individual building Community Eligibility Provision (CEP) data). Retrieved from https://dese.mo.gov/sites/default/files/Oct18FreeRedEnrollIndBldgCEPFreeClaim Percent_0.pdf

Moore, T. C., Wehby, J. H., Oliver, R. M., Chow, J. C., Gordon, J. R., \& Mahany, L. A. (2017) Teachers' reported knowledge and implementation of research-based classroom and behavior management strategies. Remedial and Special Education, 38 (4), 222-232. doi:10.1177/0741932516683631

National Collaborating Centre for Mental Health (UK); Social Care Institute for Excellence (UK). (2013). Antisocial behaviour and conduct disorders in children and young people: recognition, intervention and management. Leicester (UK): British Psychological Society. (NICE Clinical Guidelines, No. 158.) 2. Retrieved from www.ncbi.nlm.nih.gov/books/NBK327832/

Nelson, M. A., Caldarella, P., Hansen, B. D., Graham, M. A., Williams, L., \& Wills, H. P. (2018). Improving Student Behavior in Art Classrooms: An Exploratory Study of CW-FIT Tier 1. Journal of Positive Behavior Interventions, 20(4), 227-238. doi:10.1177/1098300718762744

Nightingale, D. S., \& Rossman, S. B. (2015). Collecting data in the field. In K. E. Newcomer, H. P. Hatry, \& J. S. Wholey (Eds.). Handbook of practical program evaluation (pp. 445-473). Hoboken, NJ: John Wiley \& Sons.

Pas, E. T., Bradshaw, C. P., Hershfeldt, P. A., \& Leaf, P. J. (2010). A multilevel exploration of the influence of teacher efficacy and burnout on response to student 
problem behavior and school-based service use. School Psychology

Quarterly, 25(1), 13-27. doi:10.1037/a0018576

Pearson. (2019). Developmental Reading Assessment Second Edition PLUS. Retrieved from https://www.pearsonassessments.com/store/usassessments/en/Store/ProfessionalAssessments/Academic-Learning/Reading/Developmental-Reading-Assessment\%7C-Second-Edition-PLUS/p/100001222.html

Pelco, L. E., \& Reed-Victor, E. (2007) Self-regulation and learning-related social skills: Intervention ideas for elementary school students, preventing school failure. Alternative Education for Children and Youth, 51(3), 36-42, doi:10.3200/PSFL.51.3.36-42

Perzigian, A. (2018). Social competence in urban alternative schools. Penn GSE Perspectives on Urban Education, 15(1).

Rose-Krasnor, L. (1997). The Nature of Social Competence: A Theoretical Review. Social Development, 6: 111-135. doi:10.1111/j.1467-9507.1997.tb00097.x

Shook, A. C. (2012). A Study of Preservice Educators' Dispositions to Change Behavior Management Strategies. Preventing School Failure, 56(2), 129-136. doi:10.1080/1045988X.2011.606440

Speight, R., Whitby, P., \& Kucharczyk, S. (2020). Impact of CW-FIT on Student and Teacher Behavior in a Middle School. Journal of Positive Behavior Interventions, 22(4), 195-206. https://doi.org/10.1177/1098300720910133

Srivastava, A. \& Thomson, S. B. (2009). Framework Analysis: A Qualitative Methodology for Applied Policy Research. JOAAG, Vol. 4. No. 2 
University of Kansas. (2019). Elementary School Materials. Retrieved from https://cwfit.ku.edu/wp-content/uploads/2020/11/CW-FIT-Procedural-FidelityQuality-Ratings-Definition-HANDOUT.pdf

University of Kansas. (2019). School-wide Training. Retrieved from https://cwfit.ku.edu/schoolwide-training

University of Missouri. (2019). Evidence-Based Intervention Network - CW-FIT. Retrieved from http://ebi.missouri.edu/?s=cw + fit

U.S. Department of Education \& National Center for Education Statistics. (2016). School survey on crime and safety 2015-16 school year principal questionnaire. Retrieved from https://nces.ed.gov/surveys/ssocs/pdf/SSOCS_2016_Questionnaire.pdf

Vollmer, T. R., Sloman, K. N., \& St Peter Pipkin, C. (2008). Practical implications of data reliability and treatment integrity monitoring. Behavior analysis in practice, 1(2), 4-11. https://doi.org/10.1007/BF03391722

Wills, H., Wehby, J., Caldarella, P., Kamps, D., \& Swinburne Romine, R. (2018). Classroom Management That Works: A Replication Trial of the CW-FIT Program. Exceptional Children, 84(4), 437-456. doi:10.1177/0014402918771321

Zee, M., de Jong, P. F., \& Koomen, H. M. Y. (2016). Teachers' self-efficacy in relation to individual students with a variety of social-emotional behaviors: A multilevel Investigation. Journal of Educational Psychology, (7), 1013. doi:10.1037/edu0000106 
SECTION SIX: REFLECTION 
During the fall of 2016, a colleague spoke to me about the Educational Leadership and Policy Analysis (ELPA) program. She loved it and thought that I would benefit from it. I investigated and eagerly applied. It has been a fantastic journey that I will forever be grateful for. I have gained new friends all over the hemisphere and gained knowledge, but above all, I have accomplished something that will help others. When I applied to the program, I had a specific goal in mind. I wanted more information to help students that were acting out. Teachers I knew were struggling, and I felt that I needed to do something, albeit a call to action. I feel that through this program and the dissertation process, I have succeeded.

The experiences, discourse, and knowledge gained over the past two years are immeasurable for my growth as a leader in education. I have tried to synthesize the knowledge I have learned in my everyday life, both professionally and personally. Reading and having conversations about the program's varying topics have opened my perspective and inspired me to improve how I lead others. This reflection will summarize what I have learned through the Educational Leadership and Policy Analysis (ELPA) program.

\section{Leadership}

My ultimate goal is to be an inspirational leader (Goffee \& Jones, 2011).

Inspirational leaders rely sincerely on intuition to measure appropriate timing and path of action, manage personnel with strong empathy, capitalize on what is distinctive about themselves, and selectively show their weaknesses to reveal openness and humanity (Goffee \& Jones, 2011). I try to be a servant, authentic, situational, and ethical leader (Beck, 2014; George et al., 2011; Hallinger, 2011; Mihelič, Lipičnik, \& Tekavčič, 2010). 
As an educator for children, I automatically fell into the servant leadership role (Beck, 2014). I care for others' well-being and strive to improve their world as best I can. "A leader must understand followers to determine how best to serve their needs" (Beck, 2014, p. 301). Servant leadership fits how I am with others; I am attentive to others' concerns, put my followers first, and empower them (Beck, 2014). I lead from principle; my life experiences help keep me grounded and help those I serve (George et al., 2011). "Authentic leaders demonstrate a passion for their purpose, practice their values consistently, and lead with their hearts as well as their heads. They establish long-term, meaningful relationships and have the self-discipline to get results. They know who they are" (George et al., 2011, p. 8). Distributing my leadership helps my team make sense of situations or needs, have a vision for the future, and work together for the group's good. As an ethical leader, I respect, serve, am honest, build our community, and show justice (Mihelič et al., 2010).

To be an effective leader, one must know how they learn, how others learn, and what needs to be learned (Gill, 2010). I know how I learn: through discourse, activities, and watching others, and this realization has helped me lead others. I have learned to investigate and ask how my team learns. Adults want to learn and wish to be an "active agent in the planning and execution of her/his learning" (Chen, 2014, p. 407). Leaders need to be mindful of adults' self-concept, experience, readiness to learn, problemcentered orientation, and internal motivation (Knowles, 1980). Adults have many responsibilities, differences in learning styles and learning motivations (Ettling, 2012). Adults' situation in life creates a need for knowledge, and adults want to see a connection between the content and their daily lives (Merriam \& Bierema, 2014). My audience may 
include parents, paraprofessionals, beginning teachers, veteran teachers, administrators, therapists, or other graduate students. Considering the level of explanations is necessary for each type of audience for the optimal effect of change. If I want adults to make meaningful change, the information needs to be easily understood and connect with their world (Cueva, 2010). Learning often occurs best through "play," altering the flow of time, and compressing space,' as well as time, so that the learner can see the effects of his or her actions in other parts of a more extensive system (Kofman \& Senge, 1993).

\section{Organizations}

We learned about organizations from Bolman and Deal (2013), which opened my eyes to all the experiences I have had and prepared me for future ones. The knowledge I learned about the frames almost seemed to me as a symbiosis of an organization's parts. I finally could grasp the magnitude of the educational system and that I could make a difference now that I had the tools. Specifically, the human resource frame explained so many situations and how I can now navigate them.

I understand that data needs to be easily understood to connect with stakeholders to help buy-in, make meaningful, transformational change. Theory and data go back and forth continuously (Perry \& Kochhar-Bryant, 2016). By looking at the data, it could help our organization locate where gaps are. Understanding the areas of need can grow into knowledge, which grows into wisdom (Gill). It is equally important to use data to look for marginalized groups (Ma, Dana, Adams et al., 2018). Just because there is an assumption that there is no bias does not mean discrimination is absent.

As I worked through my dissertation, I re-read Lencioni's (2006) Silos, Politics, and Turfwars. I valued the theme of the silo solution, "Why wait for a crisis?" (Lencioni, 
2006, p.142). Even though it was noted that "teams often perform at their best when their backs are up against the wall" (Lencioni, 2006, p.142), why wait? We have students, families, teachers, and colleagues that need inspiring leadership for positive change. Change does not come quickly; patience and perseverance will be my allies.

In conclusion, I will never forget the readings, discourse, challenges, and successes I experienced through the ELPA program. The readings have broadened my perspective and leadership approach. I choose to converse and ask more questions. During my first summer, I found out that my father had cancer, and he passed away in a couple of months. My husband had two surgeries at the end of the next fall semester. During my dissertation phase, my husband became ill with a mysterious illness (that took 16 months to diagnose). We started our own small business, became a grandmother, and the COVID-19 pandemic interrupted my research. Even with all of those challenges, I have not been deterred from my aspiration. I feel successful as I have finished the program and a problem of practice research study. From now on, I will have the confidence when speaking about how professional development is needed for teachers and classroom-wide behavior interventions can benefit students. 


\section{References}

Beck, C. D. (2014). Antecedents of servant leadership: A mixed methods study. Journal of Leadership \& Organizational studies. 21(3), 299-314. doi:10.1177/1548051814529993

Bolman, L. G., \& Deal, T. E. (2013). Reframing organizations: Artistry, choice and leadership (5th ed.). San Francisco, CA: Jossey-Bass.

Chen, J. C. (2014). Teaching nontraditional adult students: Adult learning theories in practice. Teaching in Higher Education, 19(4), 406-418. doi:10.1080/13562517.2013.860101

Cueva, M. (2010). A living spiral of understanding: Community-based adult education. New Directions for Adult and Continuing Education, 2010 (125), 79-90. doi:10.1002/ace.364

Ettling, D. (2012). Educator as change agent: Ethics of transformative learning. In E.W. Taylor, P. Cranton, \& Associates (Eds.), The handbook of transformative learning: Theory, research, and practice (pp. 536-551). San Francisco, CA: Jossey-Bass.

George, B., Sims, P., McClean, A. N., \& Mayer, D. (2011). Discovering Your Authentic Leadership. ASCA Newsletter, 2011 (1), 8-17.

Gill, S. J. (2010). Developing a learning culture in nonprofit organizations. Thousand Oaks, CA: Sage.

Hallinger, P. (2011). Leadership for learning: lessons from 40 years of empirical research. Journal of Educational Administration, 49(2), pp.125-142. 
Knowles, M. S. (1980). The modern practice of adult education : From pedagogy to andragogy. Wilton, CN: Association Press.

Kofman Fred, Senge Peter. 1993. Communities of commitment: the heart of learning organizations. Organizational Dynamics 22(2), p. 5-23. https://doi.org/10.1016/00902616(93)90050-B.

Lencioni, P. (2006). Silos, Politics, and Turfwars. Jossey-Bass, San Fransciso: CA. Ma, V. W., Dana, N., Adams, A., \& Kennedy, B. (2018). Understanding the problem of practice: An analysis of professional practice EdD dissertations. Impacting education: Journal on Transforming Professional Practice. 3. doi:10.5195/IE.2018.50.

Merriam, S., \& Bierema, L. (2014). Adult learning: linking theory and practice. San Francisco: Jossey Bass.

Mihelič, K. K., Lipičnik, B., \& Tekavčič, M. (2010). Ethical leadership. International Journal of Management \& Information Systems, 14(5), 31-41.

Perry, J. A. (2016). Contemporary Approaches to Dissertation Development and Research Methods. V. A. Storey \& K. A. Hesbol (Eds.), The scholarly practitioner as steward of the practice (pp. 300-312). Hershey, PA: IGI Global. 


\section{Appendix A}

\section{Email sent to participants}

Hello friends! As most of you know, I am working on my doctorate degree in Educational Leadership. For my dissertation, I am wanting to focus on aggressive student behavior in the general education setting. For this study, I have the opportunity to provide professional development for the CW-FIT behavior intervention program and send out a survey to you which will help gather data and hopefully help you and the students.

If you could complete the survey I have created, I would appreciate it greatly. It is anonymous. Some of the questions were adapted from surveys created by the U.S. Department of Education (2016). The link will not track any identifying information and you will not be asked to fill in any identifying information. I ask for you not to discuss the survey or your answers with others in the building as it may invalidate the results. You do not have to participate. If you choose to participate, please complete the survey within the next week.

Please contact me if you have any questions! Thank you in advance for helping me so that I can help you all.

Here is the survey: https://missouri.qualtrics.com/jfe/form/SV_e55tUgbniU96Hnn 


\section{Appendix B}

\section{Informed Consent}

Please consider this information carefully before deciding whether to participate in this research.

Description: I am an Ed.D. student at the University of Missouri-Columbia in the Educational Leadership and Policy Analysis program. My research includes a survey, observing classrooms and interviewing teachers.

Purpose of the research: To understand how the professional development on externalizing behaviors of students help teachers, reduce behavior, and/or reduce office referrals.

What you will do in this research: If you decide to volunteer, you will be asked to participate in a survey, up to five observations (pre and post professional development), and an interview. You will be asked several questions, some of which will be about challenges faced by staff and/or administrators. With your permission, I will record the interview in order to focus on the conversation. No student names or identifying information will be recorded or collected.

Time required: The observations could be 20-30 minutes each, the interview could take approximately 45-60 minutes. The survey should take less than 30 minutes.

Risks: No physical or psychological risks are anticipated.

Benefit: To advance the research practices of educational doctoral students, professional development that benefits teachers and students, and to reduce behaviors in elementary buildings.

Confidentiality: No names of students will be recorded during the observations. Your responses in the interview will be kept confidential. At no time will your actual identity be revealed. The survey will be anonymous. With your written permission below, excerpts from the interview may be included in the research paper or other later publications. Any notes, recordings, or names will be kept in a secure cabinet and/or in a password protected electronic file.

Participation and withdrawal: Your participation in this study is voluntary and you may choose to participate or withdraw from the study at any time without penalty. You may withdraw by informing the researcher that you no longer wish to participate (no 
questions will be asked). In addition, you may skip any question during the interview, but continue to participate in the rest of the study.

To contact the researchers: If you have questions or concerns about this research, please contact: April Phillips, 417-546-1508, aap6df@gmail.com. You may also contact the faculty member supervising this work: Dr. James Sottile, JamesSottile@MissouriState.edu 417-836-5326

Agreement: The nature and purpose of this research have been sufficiently explained, and I agree to participate in this study. I understand that I am free to withdraw at any time without incurring any penalty.

Signature:

Date:

Name (print): 


\section{Appendix C}

Survey

앙

University of Missouri

Does your school district have any formal programs intended to prevent or reduce violence that included the following components for students? Select all that apply.

Prevention curriculum, instruction, or training for students (e.g., conflict resolution, anti-bullying, or dating violence prevention)

Behavioral or behavior modification intervention for students (including the use of positive reinforcements)

Counseling, social work, psychological, or therapeutic activity for students

Individual

attention/mentoring/tutoring/coaching of students by students

Individual

attention/mentoring/tutoring/coaching

of students by adults

Recreational, enrichment, or leisure activities for students

Student involvement in restorative circles (e.g., "peace circles", "talking circles", "conflict circles")

Social emotional learning (SEL) training for students (e.g., social skills, anger management, mindfulness)
Yes

No

I don't know

○

O

O

$\bigcirc$

O

$\bigcirc$

O

O
O<smiles>[Co]</smiles>

O

O

O

O

0

0
0

O

O

O

O

O

O

0 
How often do you witness students exhibiting the following behaviors?

Never

Sometimes

Often

Very Often

\begin{tabular}{|c|c|c|}
\hline $\begin{array}{l}\text { Noncompliance (not } \\
\text { following directions, } \\
\text { purposefully not on } \\
\text { task, etc) }\end{array}$ & $\mathrm{O}$ & $\mathrm{O}$ \\
\hline Temper tantrums & $\mathrm{O}$ & $\mathrm{O}$ \\
\hline Arguing & $\mathrm{O}$ & $\bigcirc$ \\
\hline $\begin{array}{l}\text { Mild aggression } \\
\text { (throwing small } \\
\text { objects but not at } \\
\text { people, tip chair, shove } \\
\text { desk, etc) }\end{array}$ & 0 & D \\
\hline $\begin{array}{l}\text { Inappropriate noises in } \\
\text { the classroom }\end{array}$ & 0 & D \\
\hline Blurting out & 0 & $\mathrm{O}$ \\
\hline Yelling & $\mathrm{O}$ & $\mathrm{O}$ \\
\hline Lying & b & $\mathrm{O}$ \\
\hline $\begin{array}{l}\text { Physical aggression } \\
\text { (hitting, kicking, } \\
\text { throwing objects at } \\
\text { people) }\end{array}$ & & $\mathrm{O}$ \\
\hline Swearing & 8 & \\
\hline
\end{tabular}

What strategies work best for non-aggressive behaviors such as noncompliance, inappropriate noises, blurting out, and lying?

What strategies work best for mild-aggressive behaviors such as arguing, yelling, throwing small objects but not at people, tipping chairs, shoving a desk? 
What strategies work best for aggressive behavior such as temper tantrums, swearing, or physical aggression?

Do you have PD available at your school district for the following topics?

Training in classroom
management for teachers
Training in school-wide discipline
policies and practices related to
violence
Training in recognizing early
warning signs of students likely to
exhibit violent behavior
Training in intervention and referral
strategies for students displaying
signs of mental health disorders
(e.g., depression, mood disorders,
ADHD)
Training in recognizing physical,
social, and verbal bullying
behaviors
Training in positive behavioral
intervention strategies
Training in crisis prevention and
intervention
Other

Have you seen a student exhibit violent or harmful behavior?

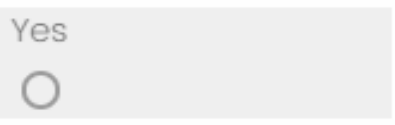

No

0 
How prepared do you feel to deal with students who exhibit aggressive behaviors?

\begin{tabular}{|c|c|c|c|c|}
$\begin{array}{c}\text { Not } \\
\text { Prepared }\end{array}$ & $\begin{array}{c}\text { Somewhat } \\
\text { Prepared }\end{array}$ & Prepared & $\begin{array}{c}\text { Quite a Bit } \\
\text { Prepared }\end{array}$ & $\begin{array}{c}\text { Very Well } \\
\text { Prepared }\end{array}$ \\
\hline & 0 & 0 & 0 & 0 \\
\hline
\end{tabular}

If you have had a student with violent or harmful behavior, did you ever consider leaving the education field?
$\mathrm{O}$ Yes
Maybe
No

Please explain your answer:

How many students do you have on average in your classroom each year?

$\begin{array}{lllllllllll}5 & 8 & 10 & 13 & 15 & 18 & 20 & 23 & 25 & 28 & 30\end{array}$

Number of students

O

How many years have you been teaching?
$0-5$ years
O 6-10 years
O 11-15 years
O $16+$ years 


\section{Appendix D}

\section{Quality Rating Definitions for CW-FIT Procedural Fidelity Checklist}

$1=$ Implemented with partial fidelity, 2=Implemented with good fidelity, 3=Implemented with full fidelity

1. Class expectations clearly posted

$l=$ Posters are up but are visible to less than $50 \%$ of the students

$2=$ Posters are up but are visible to only $50-90 \%$ of the students

$3=$ Posters are up and appear visible to all of the students

2. Team point chart displayed

$\mathrm{l}=$ Point chart is posted but visible to less than $50 \%$ of the students

$2=$ Point chart is posted but visible to $50-90 \%$ of the students

$3=$ Point chart is posted and visible to $90-100 \%$ of the students, $90-100 \%$ of the time

3. Daily point goal posted

$\mathrm{l}=$ Point goal is posted and or announced at the end of the session

$2=$ Point goal is posted but not announced at the beginning of the session

$3=$ Point goal is posted and announced at the beginning of the session

4. Pre-corrects on skills at beginning of session

l= Teacher references skills without stating them explicitly

$2=$ Teacher reviews some, but not all skills

$3=$ Teacher reviews all skills (can be brief)

5. Timer used and set at appropriate intervals

$\mathrm{l}=$ Teacher uses and responds to timer to give points less than half of expected intervals

$2=$ Teacher uses and responds to timer for expected intervals most of the time

$3=$ Teacher uses and responds to intervals every time

6. Points awarded to teams for use of skills

$\mathrm{l}=$ Points are awarded, but skills are not referenced

$2=$ Points are awarded adequately across all groups and skills are referenced some of the time

$3=$ Points are awarded to teams and skills are referenced and reinforced while awarding points

7. Praise/points to reprimand ratio was approximately $4: 1$

$l=$ Teacher praise to reprimand appears to be a $2: 1$ ratio or less

$2=$ Teacher praise to reprimand ratio is $3: 1$

$3=$ Teacher praise to reprimand ratio was $4: 1$ or greater

8. Praise and reprimands were behavior/skill specific

l= Praise is behavior-specific \& Corrections refer to skills less than half the time

$2=$ Praise is behavior-specific \& Corrections refer to skills more than half the time

$3=$ Praise is behavior-specific \& Corrections refer to skills every time it is given

9. Points tallied and reward delivered

$\mathrm{l}=$ Points tallied; Reward not awarded

$2=$ Winners awarded; Points not tallied

$3=$ Points tallied and Reward delivered 


\section{Appendix E}

Interview Protocol

1. What grade/subject do you teach?

a) How long have you taught this grade/subject?

b) Have you taught in another district?

2. What has been your favorite part of teaching this grade/subject?

a) Please tell me why.

3. What has been your least part of teaching this grade/subject?

a) Please tell me why.

4. Before the CW-FIT training, how did you deal when students who exhibited externalizing behavior? Externalizing behaviors would include: destructive and aggressive behavior, defiance, temper tantrums, impulsive and hyperactive actions, making inappropriate noises in the classroom, blurting out, not following directions, being off task, yelling, inappropriate language, or lying.

a) How did you feel when student exhibited these behaviors?

b) How did those behaviors affect your instruction? Student achievement? Class climate?

5. Tell me about the CW-FIT training you have received. Did it change the way you deal with students who exhibit externalizing behavior?

a) What did you think about the training?

b) Was it easy or difficult to implement?

c) Does it make a different on the classroom environment?

d) Does it help students' attention to the teacher?

e) Does it help address peer attention?

f) Does it help address student escape behavior?

6. Do the CW-FIT skills affect your outlook on your teaching career? Do they have a positive impact in the way you see your profession?

7. What support or professional development do you need to continue implementing CW-FIT? 
Name:

Telephone Number:

Email Address:

\section{RESEARCH QUESTION PERTAINING TO DOCUMENT ANALYSIS:}

1. Does the teacher professional development for Class-Wide Function-related Intervention Teams (CW-FIT) impact student behavior in an elementary classroom in terms of office discipline referrals (ODR)?

2. What is the relationship between CW-FIT and student achievement?

\section{SELECTION OF PARTICIPANTS:}

Inclusion Criteria: Current year and up to three years prior.

Exclusion Criteria: Not currently in third, fourth or fifth grade.

Age Range: 9 to 12 years

DATE RANGE OF DATA: $\mathrm{mm} / \mathrm{dd} /$ yyyy to $\mathrm{mm} / \mathrm{dd} /$ yyyy

\section{STUDY METHODS:}

Analysis of student discipline records would be collected for the criteria listed above as well as the frequency of office referrals, office referrals per classroom of the current year, and grade percentage of race, gender, and any special education identification. Only the researcher will identify the data to be reviewed.

\section{CONFIDENTIALITY OF DATA:}

The data (both paper and/or electronic) will be stored to safe-guard confidentiality in a locked cabinet and in a password protected computer. Only the researcher will have access to the harvested data. The data will be stored for five years and it will be destroyed when no longer needed by deleting electronic files and shredding paper documents.

\section{CONSENT AND HIPAA AUTHORIZATION:}

\section{RISKS AND BENEFITS:}

Risks: A confidentiality breach is a risk associated with data review research. 
Benefits: To advance the research practices of educational doctoral students, professional development that benefits teachers and students, and to reduce behaviors in elementary buildings.

STATISTICAL CONSIDERATIONS: Proposed sample size is approximately 12 general education teachers of third, fourth and fifth grade; four special education teachers; and approximately 300 students of third, fourth and fifth grade. 


\section{Appendix G}

\section{Observation Data Sheet}

Observation during a 10-minute period and tally any behaviors below during 2 min intervals. Document date, time, and classroom (including teacher or substitute name) on the following tool:

\section{Responses to Inappropriate Behavior}

Data Point (circle): Baseline $1^{\text {st }}$ Post PD $2^{\text {nd }}$ Post PD 3rd Post PD $4^{\text {th }}$ Post PD $5^{\text {th }}$ Post PD $6^{\text {th }}$ Post PD Final

Teacher:

Date: Time: ___ Grade:

Subject: Researcher or IOA

\begin{tabular}{|l|l|l|}
\hline Teacher Reaction/Behavior & Tally: & Total: \\
\hline General praise for behavior & & \\
\hline $\begin{array}{l}\text { Specific praise for behavior: } \\
\text { Identify student/group, name behavior, name expectation }\end{array}$ & & \\
\hline $\begin{array}{l}\text { Corrections to inappropriate behavior } \\
\text { Verbal, indirect, prompt, gesture, proximity control }\end{array}$ & & \\
\hline $\begin{array}{l}\text { Specific correction to inappropriate behavior } \\
\text { Identify student/group, name behavior, name expectation }\end{array}$ & & \\
\hline Final Ratio of Praise to Reprimand & & \\
\hline Response Strategies Used: & & \\
\hline
\end{tabular}

Data Collection for Engagement \& Multiple Opportunities to Respond

\begin{tabular}{|l|l|}
\hline $\begin{array}{l}\text { Tally of instructional questions, statements or } \\
\text { gestures made by the teacher seeking an academic } \\
\text { response (Group) }\end{array}$ & \\
\hline $\begin{array}{l}\text { Tally of instructional questions, statements or } \\
\text { gestures made by the teacher seeking an academic } \\
\text { response (Individual, single student) }\end{array}$ & \\
\hline $\begin{array}{l}\text { Strategies used to replace single student } \\
\text { responding (e.g. use of response cards, dry erase } \\
\text { boards, white boards, response clickers, choral } \\
\text { response, guided notes, computer assisted } \\
\text { instruction, class-wide peer tutoring and direct } \\
\text { instruction, etc.) }\end{array}$ \\
\hline \multicolumn{2}{|c|}{ Observation of On-Task/Off-Task Behavior for Academic Achievement } \\
\hline
\end{tabular}




\begin{tabular}{|c|c|c|l|l|l|l|l|l|}
\hline $\begin{array}{c}\text { Total \# } \\
\begin{array}{c}\text { Students } \\
\text { in }\end{array}\end{array}$ & $\begin{array}{c}\text { Time of } \\
\text { each scan }\end{array}$ & Time 1: & Time 2: & Time 3: & Time 4: & Time 5: & Total \\
\cline { 2 - 8 } & \#off task & & & & & & \\
\cline { 2 - 9 } & $\begin{array}{c}\text { \%on-task } \\
\text { at each } \\
\text { interval: }\end{array}$ & & & & & & \\
\hline
\end{tabular}

\begin{tabular}{|c|c|c|}
\hline YES $=2$ & SOMEWHAT $=1$ & $\mathbf{N O}=\mathbf{0}$ \\
\hline $\begin{array}{l}\text { Disruptions did not take } \\
\text { place during observation }\end{array}$ & $\begin{array}{l}\text { Some disruptions took } \\
\text { place, peers were not } \\
\text { impacted }\end{array}$ & $\begin{array}{l}\text { Disruptions took } \\
\text { place impacting } \\
\text { peers' ability to } \\
\text { learn }\end{array}$ \\
\hline $\begin{array}{l}\text { Teacher always reminded } \\
\text { student(s) of } \\
\text { reinforcement }\end{array}$ & $\begin{array}{l}\text { Teacher sometimes } \\
\text { reminded student(s) of } \\
\text { reinforcement }\end{array}$ & $\begin{array}{l}\text { Teacher never } \\
\text { reminded student(s) } \\
\text { of reinforcement } \\
\text { (shouting, negative } \\
\text { response) }\end{array}$ \\
\hline $\begin{array}{l}\text { Inappropriate behavior } \\
\text { was addressed in a calm, } \\
\text { consistent, brief, } \\
\text { immediate, and respectful } \\
\text { manner. }\end{array}$ & $\begin{array}{l}\text { Some inappropriate } \\
\text { behavior was not } \\
\text { addressed in a calm, } \\
\text { consistent, brief, } \\
\text { immediate, and/or } \\
\text { respectful manner. }\end{array}$ & $\begin{array}{l}\text { Most inappropriate } \\
\text { behavior was not } \\
\text { addressed in a } \\
\text { calm, consistent, } \\
\text { brief, immediate, } \\
\text { and/or respectful } \\
\text { manner. No } \\
\text { behaviors were } \\
\text { corrected. }\end{array}$ \\
\hline $\begin{array}{l}\text { Praise to reprimand ratio } \\
\text { was } 4: 1\end{array}$ & $\begin{array}{l}\text { Praise to reprimand ratio } \\
\text { was } 3: 1\end{array}$ & $\begin{array}{l}\text { Praise to reprimand } \\
\text { ratio was } 2: 1 \text { or less }\end{array}$ \\
\hline \multicolumn{3}{|c|}{$\begin{array}{l}\text { Brief description of the instructional context } \\
\text { during the observation (individual instruction, } \\
\text { small group, whole class, tech in use, etc.) }\end{array}$} \\
\hline
\end{tabular}




\section{Appendix H}

Table G1

Definitions of behavior

\begin{tabular}{|l|l|l|}
\hline \multicolumn{1}{|c|}{ SAFETY } & \multicolumn{1}{|c|}{ RESPECT } & RESPONSIBILITY \\
\hline Physical Contact & $\begin{array}{l}\text { Minor } \\
\text { Defiance/Disrespectful/Non- } \\
\text { Compliance }\end{array}$ & Schoolwork/Homework \\
\hline $\begin{array}{l}\text { Physical } \\
\text { Aggression/Assault }\end{array}$ & $\begin{array}{l}\text { Minor } \\
\text { Inappropriate Verbal Language }\end{array}$ & Other \\
\hline Bullying/Harassment & Minor Disruption & $\begin{array}{l}\text { Major } \\
\text { Defiance/Disrespectful/Non- } \\
\text { Compliance }\end{array}$ \\
\hline Danger to Self or Others & Major Disruption & \\
\hline $\begin{array}{l}\text { Weapon (possession/use } \\
\text { of) }\end{array}$ & Verbal Assault/Threat & \\
\hline Other & Damage/Destruction of Property & \\
\hline & Major Inappropriate Language & \\
\hline & Other & \\
\hline
\end{tabular}

Note: Externalizing behaviors to document (Adapted from 2017-18 MO SW-PBS Tier 1 Team Workbook).

Table G2

Definitions or Externalizing Behaviors

\begin{tabular}{|l|l|}
\hline Behavior & Definition \\
\hline Physical Contact/Aggression & $\begin{array}{l}\text { Actions involving serious physical contact where } \\
\text { injury may occur (e.g., hitting, punching, hitting } \\
\text { with an object, kicking, hair pulling, scratching, } \\
\text { etc.) }\end{array}$ \\
\hline Assault & $\begin{array}{l}\text { Physical contact such as pushing and hitting with or } \\
\text { without injury to inflict bodily harm to another } \\
\text { student or staff member. }\end{array}$ \\
\hline Bullying/Harassment & $\begin{array}{l}\text { Student delivers disrespectful message (verbal or } \\
\text { gestural) to another person that includes threats and } \\
\text { intimidation, obscene gestures, pictures or written }\end{array}$ \\
\hline
\end{tabular}




\begin{tabular}{|l|l|}
\hline & $\begin{array}{l}\text { notes. May be based on race, religion, gender, age, } \\
\text { and/or national origin, disabilities or other personal } \\
\text { matters. }\end{array}$ \\
\hline $\begin{array}{l}\text { Minor } \\
\text { Defiance/Disrespectful/Non- } \\
\text { Compliance }\end{array}$ & $\begin{array}{l}\text { Student engages in refusal to follow directions, } \\
\text { talks back and/or delivers socially rude } \\
\text { interactions. }\end{array}$ \\
\hline $\begin{array}{l}\text { Minor } \\
\text { Inappropriate Verbal Language }\end{array}$ & Lying, swearing, name-calling \\
\hline Minor Disruption & $\begin{array}{l}\text { Student engages in behavior to cause an } \\
\text { interruption in a class/activity which can include: } \\
\text { loud talk, yelling, screaming, noise with materials, } \\
\text { horseplay, roughhousing, and/or out-of-seat. }\end{array}$ \\
\hline $\begin{array}{l}\text { Major } \\
\text { Defiance/Disrespectful/Non- } \\
\text { Compliance }\end{array}$ & $\begin{array}{l}\text { Sustained refusal to follow directions, accept 'no' } \\
\text { for an answer, or accept a consequence after } \\
\text { reasonable attempts to correct. }\end{array}$ \\
\hline Major Disruption & $\begin{array}{l}\text { Sustained disorderly behavior that prevents } \\
\text { instruction. }\end{array}$ \\
\hline Verbal Assault/Threat & Verbal threats audibly directed at staff or students \\
\hline Damage/Destruction of Property & Destruction or disfigurement of property \\
\hline Major Inappropriate Language & $\begin{array}{l}\text { Sustained swearing audibly directed at staff or } \\
\text { students }\end{array}$ \\
\hline Schoolwork/Homework & Refusal to complete \\
\hline Technology violation & Inappropriate use of cell phone or computer \\
\hline
\end{tabular}

Note: Definitions or Externalizing Behaviors (Adapted from 2017-18 MO SW-PBS Tier 1 Team Workbook). 


\section{Appendix I}

Table I1

Highest Performing Teacher

\begin{tabular}{|l|l|}
\hline Treatment Classroom & Area \\
\hline 1 (highest ratio at final obs) & Praise/reprimand \\
\hline 10 & Engagement \\
\hline 8 & $\%$ on task behavior \\
\hline 10 & Evaluate ELA \\
\hline 6 & Evaluate Math \\
\hline
\end{tabular}

Table I2

Interview statements

\begin{tabular}{|l|l|}
\hline Treatment & \\
\hline 1 & $\begin{array}{l}\text { "[Externalizing behavior] caused instruction to stop...[there was } \\
\text { a] loss of learning time for the other kids" (Teacher 1, p. 4, line } \\
\text { 123). "This would have been awesome to have as a first-year } \\
\text { teacher" (Teacher 1, p. 14, line 416). The students had } \\
\text { accountability with the charts. It (CW-FIT) helped student } \\
\text { attention. I'd like more PD on self-managers. }\end{array}$ \\
\hline 10 & $\begin{array}{l}\text { "Kids are motivated by like when they can see like progress" } \\
\text { (Teacher 10, p. 9, line 249). "I had a student with extreme } \\
\text { behavior. He wanted to be part of a team and not as a team of 1. It } \\
\text { (CW-FIT) motivated the kids. They can see the progress. It has } \\
\text { made a difference in class climate. When they get sidetracked, go } \\
\text { down a rabbit hole, we start and they get it back together. It helps } \\
\text { them come back around. They're motivated by points/tickets. } \\
\text { Even those students that don't have intrinsic motivation, they } \\
\text { work hard for everybody else. }\end{array}$ \\
\hline 8 & $\begin{array}{l}\text { "I had a lot more participation in the lessons when they were } \\
\text { doing that and... a lot more to get to share" (Teacher 8, p. 4, line } \\
113) \text { CW-FIT was a good reminder to do more positive. It was } \\
\text { easy. "I had a lot more participation in the lesson when they were } \\
\text { doing CW-FIT. It helped peer attention too." It makes teaching } \\
\text { easier but it hasn't changed my outlook. It's researched and I've } \\
\text { seen it work. }\end{array}$ \\
\hline 6 & $\begin{array}{l}\text { It changed the perspective slightly, it (CW-FIT) was helpful, } \\
\text { beneficial. "I'm glad I did it". It made a difference in students' } \\
\text { attention. }\end{array}$ \\
\hline
\end{tabular}

Classroom 10 (fifth grade) had the highest levels of student engagement scores and Evaluate ELA scores (67\% mastery by the end of the school year 2020-21). This teacher commented during the interview that when the students get sidetracked, go down a rabbit hole, they start the game and they get it back together. It helps them come back 
around. They are motivated by points and tickets. Even those students that don't have intrinsic motivation, they work hard for everybody else. "Kids are motivated by like when they can see like progress" (Teacher 10, p. 9, line 249). The participant had a student with extreme behavior. He wanted to be part of a team and not as a team of one. The teacher noted that it (CW-FIT) motivated the kids. They can see the progress. It made a difference in class climate.

Classroom 1 (fourth grade) had the highest praise versus reprimands during the last observation. "[Externalizing behavior] caused instruction to stop...[there was a] loss of learning time for the other kids" (Teacher 1, p. 4, line 123). "This would have been awesome to have as a first-year teacher" (Teacher 1, p. 14, line 416). The teacher reported during the interview that students had accountability with the charts. It (CWFIT) helped student attention. The participant noted a request of more PD on selfmanagers.

The teacher that had the highest level of percentage of student on-task behavior was in Classroom 8 (fifth grade). "I had a lot more participation in the lessons when they were doing that and.... a lot more to get to share" (Teacher 8, p. 4, line 113). The teacher had a lot more participation in the lesson when they were doing CW-FIT. It helped peer attention too.

Classroom 6 (third grade) had the highest level of performance for Math $(57 \%$ mastery by the end of the school year 2020-21). The teacher stated that CW-FIT made a difference in students' attention. 
Table I3

Mid-level Performing Teacher

\begin{tabular}{|l|l|}
\hline Treatment Classroom & Area \\
\hline 8 & Praise/reprimand \\
\hline 2 & Engagement \\
\hline 11 & $\%$ on task behavior \\
\hline 11 & Evaluate ELA \\
\hline
\end{tabular}

Table I4

Interview statements

\begin{tabular}{|l|l|}
\hline Treatment & \\
\hline 2 & $\begin{array}{l}\text { "The kids really enjoyed playing it" (Teacher 2, p. 8, line 254). "I } \\
\text { feel like it really is just opened up a new avenue, a new strategy } \\
\text { that you can use in your classroom to help with students who are } \\
\text { exhibiting behaviors that maybe you've never seen before, you } \\
\text { don't have a strategy for. Maybe you are new to education, and } \\
\text { you just don't have a management strategy, period. This would be } \\
\text { a great one to start with until you start, you know, figuring out } \\
\text { what mix works for you, but then also, for each individual } \\
\text { student" (Teacher 2, p. 10, line 318-323). It (CW-FIT) helped } \\
\text { with focus. They valued/respected peers' worktime, stayed quiet } \\
\text { or stayed in their seats, getting the teacher's attention correctly, } \\
\text { and self-checked. Students' called out team members when they } \\
\text { weren't doing it (the rules). Attention and focus did improve. }\end{array}$ \\
\hline 8 & $\begin{array}{l}\text { "I had a lot more participation in the lessons when they were } \\
\text { doing that and.... a lot more to get to share" (Teacher 8, p. 4, line } \\
113) \text { CW-FIT was a good reminder to do more positive. It was } \\
\text { easy. "I had a lot more participation in the lesson when they were } \\
\text { doing CW-FIT. It helped peer attention too." It makes teaching } \\
\text { easier but it hasn't changed my outlook. It's researched and I've } \\
\text { seen it work. }\end{array}$ \\
\hline 11 & $\begin{array}{l}\text { "I'm trying to take care of [it] myself." (Teacher 11, p. 10, line } \\
\text { 275). "It was extremely dangerous. I had a couple of parents } \\
\text { angry and upset" (Teacher 11, p. 20, line 572). The program was } \\
\text { great, easy to implement, and I loved the posters. It (CW-FIT) } \\
\text { made a difference in the class climate. }\end{array}$ \\
\hline
\end{tabular}

The teacher who had a mid-level performance in praise versus reprimand was in Classroom 8 (fifth grade). This classroom also had the mid-level increase of mastery percentage in ELA (5.5 percentage points increase). The teacher stated that CW-FIT was a good reminder to do more positive. It was easy. It made teaching easier, but it had not changed the participant's outlook. The participant stated that it was researched and had seen it work. 
Classroom 2 (fourth grade) had an average score in student engagement. "The kids really enjoyed playing it" (Teacher 2, p. 8, line 254). "I feel like it really is just opened up a new avenue, a new strategy that you can use in your classroom to help with students who are exhibiting behaviors that maybe you have never seen before, you do not have a strategy. Maybe you are new to education, and you just do not have a management strategy period. This would be a great one to start with until you start, you know, figuring out what mix works for you, but then also, for each individual student" (Teacher 2, p. 10, line 318-323). It (CW-FIT) helped with focus. They valued and respected peers' worktime, stayed quiet or stayed in their seats, getting the teacher's attention correctly, and checked themselves. Students' called out team members when they weren't doing it (the rules). Attention and focus did improve.

Classroom 11 (fifth grade) was in the mid-level of the percentage of on-task behavior and mid-level amount of increase in Evaluate Math (15 percentage points increase). "I'm trying to take care of [it] myself." (Teacher 11, p. 10, line 275). "It was extremely dangerous. I had a couple of parents angry and upset" (Teacher 11, p. 20, line 572). The teacher noted that the program was great, easy to implement, and that the participant loved the posters. The teacher also stated that it (CW-FIT) made a difference in the class climate. 
Table I5

Most Improved Performing Teacher

\begin{tabular}{|l|l|}
\hline Treatment Classroom & Area \\
\hline 5 & Praise/reprimand \\
\hline 5 & Engagement \\
\hline 6 & \% on task behavior \\
\hline 11 & Evaluate ELA \\
\hline 5 & Evaluate Math \\
\hline
\end{tabular}

Table I6

Interview statements

\begin{tabular}{|l|l|}
\hline $\begin{array}{l}\text { Treatment } \\
\text { Classroom }\end{array}$ & $\begin{array}{l}\text { "Other students were scared of them" (Teacher 5, p. 5, line 148). } \\
\text { Saw "tremendous growth." The program was "fabulous". Didn't } \\
\text { have to stress about it. The students are so competitive, it (CW- } \\
\text { FIT) motivates them. It helped keep each other accountable. }\end{array}$ \\
\hline 5 & $\begin{array}{l}\text { It changed the perspective slightly, it (CW-FIT) was helpful, } \\
\text { beneficial. "I'm glad I did it". It made a difference in students' } \\
\text { attention. }\end{array}$ \\
\hline 6 & $\begin{array}{l}\text { "I'm trying to take care of [it] myself." (Teacher 11, p. 10, line } \\
\text { 275). "It was extremely dangerous. I had a couple of parents } \\
\text { angry and upset" (Teacher 11, p. 20, line 572). The program was } \\
\text { great, easy to implement, and I loved the posters. It (CW-FIT) } \\
\text { made a difference in the class climate. }\end{array}$ \\
\hline 11 &
\end{tabular}

The classroom with the most improvement was Classroom 5 (fourth grade). This classroom improved the most in praise versus reprimands, student engagement, and Evaluate Math (20 percentage points increase). In the interview, the teacher reported that "tremendous growth" was seen. The program was "fabulous." The teacher did not have to stress about it. The participant also mentioned that the students are so competitive, it (CW-FIT) motivated them. It helped keep each other accountable.

The classroom that had the most improvement in the percentage of on-task behavior was Classroom 6 (third grade). The amount of on-task behavior increased from $63 \%$ to $100 \%$. The teacher reported during the interview that CW-FIT changed the perspective of the class slightly, was helpful, and beneficial. "I'm glad I did it" (Teacher 6, p. 5, line 141). The teacher stated that CW-FIT made a difference in students' attention.

The classroom that had the most improvement in Evaluate ELA was Classroom 11 (fifth grade). The class improved 10 percentage points by the end of the school year 2020-21. The teacher stated in the interview that the CW-FIT program was great and easy to implement. The participant also reported that they loved the posters. It (CW-FIT) made a difference in the class climate. 
Table I7

Lowest Increase Teacher

\begin{tabular}{|l|l|}
\hline Treatment Classroom & Area \\
\hline $\begin{array}{l}10 \text { (least amount of change but still at } \\
\text { least } 4: 1)\end{array}$ & Praise/reprimand \\
\hline 4 & Engagement \\
\hline 5 & $\%$ on task behavior \\
\hline 3 & Evaluate ELA \\
\hline 8 & Evaluate Math \\
\hline
\end{tabular}

Table I8

Interview statements

\begin{tabular}{|c|c|}
\hline $\begin{array}{l}\text { Treatment } \\
\text { Classroom }\end{array}$ & \\
\hline 3 & $\begin{array}{l}\text { "Friendships suffer and the relationships that they have with their } \\
\text { peers kind of change" (Teacher 3, p. 3, line 92). "I thought it } \\
\text { [CW-FIT] was good, detailed, and thought out" I felt prepared. } \\
\text { The charts helped and it was easy to implement. CW-FIT made a } \\
\text { positive difference in the class climate. "I think they are more } \\
\text { focused". It made a positive difference in students' attention. } \\
\text { "My class really liked it" They enjoy playing the game, we use it } \\
\text { more and for longer periods. They asked consistently to play and } \\
\text { it keeps them on track. }\end{array}$ \\
\hline 4 & $\begin{array}{l}\text { I have seen aggressive students, quite honestly, that scares the } \\
\text { hell out of me... that's the one thing that I probably don't handle } \\
\text { as well as I should" (Teacher } 4, \text { p. 20, line 464). "They know } \\
\text { they're working toward a goal, and I think it keeps them focused" } \\
\text { (Teacher } 4, \text { p. } 7 \text {, line 204). "The CW fit helps them focus faster if } \\
\text { they know they're going to that we're going to do CW. They're } \\
\text { listening, they're paying attention, they're going to try to earn that } \\
\text { point" (Teacher } 4 \text {, p. 10, line 298-300). CW-FIT was easy to } \\
\text { implement and I feel comfortable using it. }\end{array}$ \\
\hline 5 & $\begin{array}{l}\text { "Other students were scared of them" (Teacher 5, p. 5, line 148). } \\
\text { Saw "tremendous growth". The program was "fabulous". Didn't } \\
\text { have to stress about it. The students are so competitive, it (CW- } \\
\text { FIT) motivates them. It helped keep each other accountable. }\end{array}$ \\
\hline 8 & $\begin{array}{l}\text { "I had a lot more participation in the lessons when they were } \\
\text { doing that and.... a lot more to get to share" (Teacher } 8, \text { p. } 4 \text {, line } \\
113 \text { ). CW-FIT was a good reminder to do more positive. It was } \\
\text { easy. "I had a lot more participation in the lesson when they were } \\
\text { doing CW-FIT. It helped peer attention too." It makes teaching } \\
\text { easier but it hasn't changed my outlook. It's researched and I've } \\
\text { seen it work. }\end{array}$ \\
\hline
\end{tabular}




\begin{tabular}{|l|l|}
\hline 10 & "Kids are motivated by like when they can see like progress" \\
(Teacher 10, p. 9, line 249). "I had a student with extreme \\
behavior. He wanted to be part of a team and not as a team of 1. It \\
(CW-FIT) motivated the kids. They can see the progress. It has \\
made a difference in class climate. When they get sidetracked, go \\
down a rabbit hole, we start and they get it back together. It helps \\
them come back around. They're motivated by points/tickets. \\
$\begin{array}{l}\text { Even those students that don't have intrinsic motivation, they } \\
\text { work hard for everybody else. }\end{array}$ \\
\hline
\end{tabular}

The classroom with the least amount of change in praise, but the ratio was still at least $4: 1$, was Classroom 10 (fifth grade). The ratio increased from the initial observation of 4:0 to $5: 1$ at the final observation. Other observations were higher; one observation was as high as 26:0.

The class with the lowest engagement score, four, on the last observation was Classroom 4. On other observations, the class had a score of eight. "I have seen aggressive students, quite honestly, that scares the hell out of me... that's the one thing that I probably don't handle as well as I should" (Teacher 4, p. 20, line 464). "They know they're working toward a goal, and I think it keeps them focused" (Teacher 4, p. 7, line 204). "The CW fit helps them focus faster if they know they're going to that we're going to do CW. They're listening, they're paying attention, they're going to try to earn that point" (Teacher 4, p. 10, line 298-300). CW-FIT was easy to implement, and I feel comfortable using it.

The class with the lowest percentage of on-task behavior on the last observation (94\%) was Classroom 5. The initial observation documented $85 \%$ on-task and the classroom improved by the last observation. This class on five other observations had between $99 \%-100 \%$ of on-task behavior. The teacher stated in the interview that "tremendous growth" was seen. The program was "fabulous," and the participant did not have to stress about it. The students are so competitive, it (CW-FIT) motivated them. It helped keep each other accountable.

The class with the lowest evaluate ELA progress was Classroom 3. The mastery level decreased in mastery by two percentage points. The mastery by the end of the school year 2020-21 was 58\%. The participant thought it [CW-FIT] was good, detailed, and thought out. The teacher felt prepared. The charts helped, and it was easy to implement. CW-FIT made a positive difference in the class climate. The participant also stated that the students are more focused. It made a positive difference in students' attention. "My class really liked it" (Teacher 3, p. 4, line 113). They enjoy playing the game, and they use it more and for longer periods. "They asked consistently to play, and it keeps them on track" (Teacher 3, p. 4, lines 115-116).

The lowest evaluate math mastery score was Classroom 8 (fifth grade). This classroom had a $45 \%$ mastery by the end of the school year 2020-21. However, this class did improve by 12 percentage points from the beginning of the year. There was a classroom that only increased by 9.5 percentage points. "I had a lot more participation in the lessons when they were doing that and.... a lot more to get to share" (Teacher 8, p. 4, line 113). The teacher had a lot more participation in the lesson when they were doing CW-FIT. It helped peer attention too. 


\section{Future Needs/extra statements}

The participants asked to have a follow-up session so they could collaborate.

They felt a need to discuss incentive ideas, utilization of the timer, and problem-solve tier 2 students. Since the teachers did not have organized behavior intervention teams, this area seemed to be an area of need. The teachers had engaged classroom management skills, but the PD on CW-FIT increased the praise ratio and made them more aware of their actions. Participants asked the researcher to provide this PD to all teachers in the district, especially new employees at the beginning of the year. Many participants stated that they wished they had this training when they started teaching. Teachers expressed frustration that they did not have the knowledge or tools to reach students that misbehaved and caused disruptions in the classroom. 


\section{Appendix J}

Table J1

Evaluate Comparisons

\begin{tabular}{|c|c|c|}
\hline Classroom 1 ( $4^{\text {th }}$ grade $)$ & ELA & Math \\
\hline Average of Sept/Oct & 57.5 & 35 \\
\hline Avg as of $4 / 10 / 21$ & 64 & 54 \\
\hline$\%$ points change & 6.5 & 19 \\
\hline Classroom 2 & ELA & Math \\
\hline Average of Sept/Oct & 53 & 27 \\
\hline Avg as of $4 / 10 / 21$ & 60 & 44 \\
\hline$\%$ points change & 7 & 17 \\
\hline Classroom 3 & ELA & Math \\
\hline Average of Sept/Oct & 58 & 35 \\
\hline Avg as of $4 / 10 / 21$ & 56 & 48 \\
\hline$\%$ points change & 2 & 13 \\
\hline Classroom 4 & ELA & Math \\
\hline Average of Sept/Oct & 46.5 & 35.5 \\
\hline Avg as of $4 / 10 / 21$ & 55 & 53 \\
\hline$\%$ points change & 8.5 & 17.5 \\
\hline Classroom 5 & ELA & Math \\
\hline Average of Sept/Oct & 51 & 33 \\
\hline Avg as of $4 / 10 / 21$ & 58 & 53 \\
\hline$\%$ points change & 7 & 20 \\
\hline Classroom 6 ( $3^{\text {rd }}$ grade $)$ & ELA & Math \\
\hline Average of Sept/Oct & 46 & 47.5 \\
\hline Avg as of $4 / 10 / 21$ & 54 & 57 \\
\hline$\%$ points change & 8 & 9.5 \\
\hline Classroom 8 ( $5^{\text {th }}$ grade $)$ & ELA & Math \\
\hline Average of Sept/Oct & 57.5 & 33 \\
\hline Avg as of $4 / 10 / 21$ & 63 & 45 \\
\hline$\%$ points change & 5.5 & 12 \\
\hline Classroom 10 & ELA & Math \\
\hline Average of Sept/Oct & 62 & 36.5 \\
\hline Avg as of $4 / 10 / 21$ & 67 & 51 \\
\hline$\%$ points change & 5 & 14.5 \\
\hline Classroom 11 & ELA & Math \\
\hline Average of Sept/Oct & 51 & 29 \\
\hline Avg as of $4 / 10 / 21$ & 61 & 44 \\
\hline$\%$ points change & 10 & 15 \\
\hline Control 1 ( $3^{\text {rd }}$ grade $)$ & ELA & Math \\
\hline Average of Sept/Oct & 51.5 & 54 \\
\hline
\end{tabular}




\begin{tabular}{|c|c|c|}
\hline Avg as of $4 / 10 / 21$ & 61 & 69 \\
\hline$\%$ points change & 9.5 & 15 \\
\hline Control 2 & ELA & Math \\
\hline Average of Sept/Oct & 46.5 & 42 \\
\hline Avg as of $4 / 10 / 21$ & 54 & 56 \\
\hline$\%$ points change & 7.5 & 14 \\
\hline Control 3 & ELA & Math \\
\hline Average of Sept/Oct & 44.5 & 38.5 \\
\hline Avg as of $4 / 10 / 21$ & 49 & 53 \\
\hline$\%$ points change & 4.5 & 14.5 \\
\hline Control 4 & ELA & Math \\
\hline Average of Sept/Oct & 49.5 & 46.5 \\
\hline Avg as of $4 / 10 / 21$ & 55 & 62 \\
\hline$\%$ points change & 5.5 & 15.5 \\
\hline Control 5 & ELA & Math \\
\hline Average of Sept/Oct & 53 & 44.5 \\
\hline Avg as of $4 / 10 / 21$ & 57 & 57 \\
\hline$\%$ points change & 4 & 12.5 \\
\hline Control 6 (5 $5^{\text {th }}$ grade) & ELA & Math \\
\hline Average of Sept/Oct & 54 & 27.5 \\
\hline Avg as of $4 / 10 / 21$ & 60 & 38 \\
\hline$\%$ points change & 6 & 10.5 \\
\hline Control 7 & ELA & Math \\
\hline Average of Sept/Oct & 56.5 & 31 \\
\hline Avg as of $4 / 10 / 21$ & 61 & 44 \\
\hline$\%$ points change & 4.5 & 13 \\
\hline Control 8 & ELA & Math \\
\hline Average of Sept/Oct & 49.5 & 32.5 \\
\hline Avg as of $4 / 10 / 21$ & 59 & 46 \\
\hline$\%$ points change & 9.5 & 13.5 \\
\hline
\end{tabular}

\begin{tabular}{|c|c|c|c|c|c|c|c|c|}
\hline & $\begin{array}{l}\text { Treatment } \\
\text { class }\end{array}$ & ELA & $\begin{array}{l}\text { Treatment } \\
\text { class }\end{array}$ & Mth & Control & ELA & Control & Mth \\
\hline $\begin{array}{l}\text { Biggest } \\
\text { increase }\end{array}$ & 11 & up 10 & 5 & $\begin{array}{l}\text { up } \\
20\end{array}$ & 1 or 8 & $\begin{array}{l}\text { up } \\
9.5\end{array}$ & 1 or 8 & $\begin{array}{l}\text { up } \\
15.5\end{array}$ \\
\hline $\begin{array}{l}\text { Smallest } \\
\text { increase }\end{array}$ & 3 & $\begin{array}{c}\text { down } \\
2\end{array}$ & 8 & $\begin{array}{l}\text { up } \\
12\end{array}$ & 5 & up 4 & 6 & $\begin{array}{l}\text { up } \\
10.5\end{array}$ \\
\hline Middle & 1 or 8 & & 11 & & 6 & & 8 & \\
\hline
\end{tabular}


April has over 25 years working with children. She began as a parent then as a child caregiver in day care centers. She has worked in public schools as a preschool teacher, director, Parents As Teachers educator, special education teacher, special education director, and process coordinator. She has worked in small K-8 districts with less than 100 students and in large districts with almost 6,000 students. Throughout these experiences, she collaborated with general education teachers, special education teachers, therapists, and administrators. She provided training in each district for parents or education faculty.

April's educational background began with a Child Development Associate certificate. She then pursued her Bachelor of Science degree in Early Childhood Education from Missouri State University. Then she obtained a Master of Science degree in Educational Leadership and Policy Analysis from the University of MissouriColumbia. 